Review

\title{
Lifespan age differences in working memory: A two-component framework
}

\author{
Myriam C. Sander*, Ulman Lindenberger, Markus Werkle-Bergner \\ Max Planck Institute for Human Development, Center for Lifespan Psychology, Lentzeallee 94, 14195 Berlin, Germany
}

\section{A R T I C L E I N F O}

\section{Article history:}

Received 22 July 2011

Received in revised form 29 May 2012

Accepted 12 June 2012

\section{Keywords:}

Binding

Change detection

EEG

Lifespan psychology

Top-down control

\begin{abstract}
A B S T R A C T
We suggest that working memory (WM) performance can be conceptualized as the interplay of low-level feature binding processes and top-down control, relating to posterior and frontal brain regions and their interaction in a distributed neural network. We propose that due to age-differential trajectories of posterior and frontal brain regions top-down control processes are not fully mature until young adulthood and show marked decline with advancing age, whereas binding processes are relatively mature in children, but show senescent decline in older adults. A review of the literature spanning from middle childhood to old age shows that binding and top-down control processes undergo profound changes across the lifespan. We illustrate commonalities and dissimilarities between children, younger adults, and older adults reflecting the change in the two components' relative contribution to visual WM performance across the lifespan using results from our own lab. We conclude that an integrated account of visual WM lifespan changes combining research from behavioral neuroscience and cognitive psychology of child development as well as aging research opens avenues to advance our understanding of cognition in general.
\end{abstract}

\section{Contents}

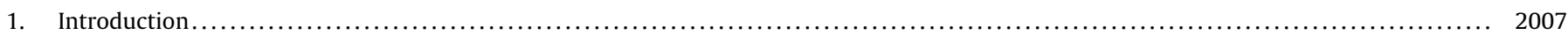

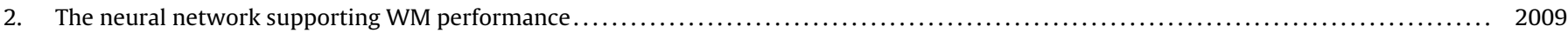

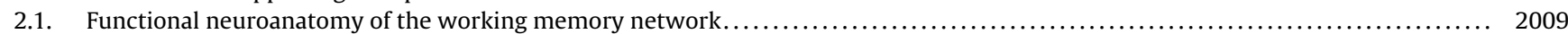

2.1.1. Senescent changes in the structures, functions, and mechanisms of information processing in WM................. 2010

2.1.2. Maturational changes in the structures, functions, and mechanisms of information processing in WM.................. 2011

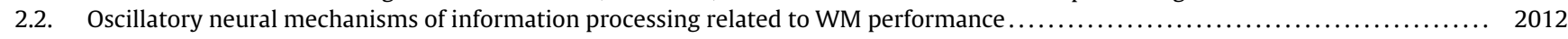

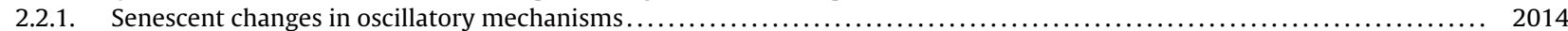

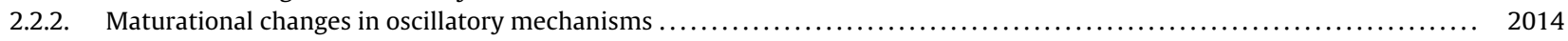

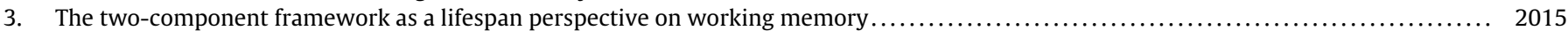

3.1. The interplay of the two components across the lifespan reflected in different markers of WM performance................... 2019

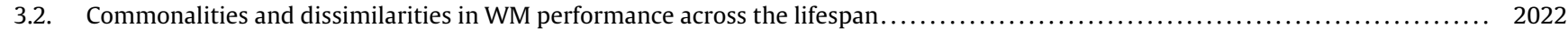

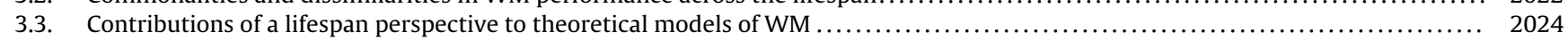

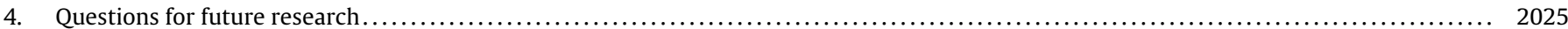

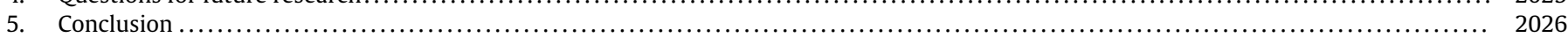

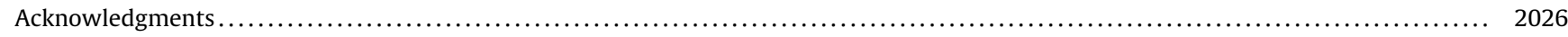

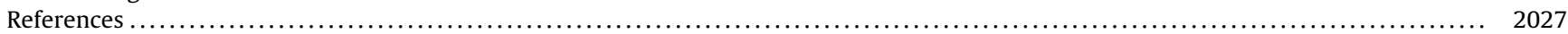

\section{Introduction}

Working memory (WM), our ability to maintain and manipulate information to guide goal-directed behavior, is critically limited and characterized by large differences among individuals of the same age as well as marked age-related trends (Cowan et al., 2005;

\footnotetext{
* Corresponding author.

E-mail address: sander@mpib-berlin.mpg.de (M.C. Sander).
}

Engle, 2002; Gathercole et al., 2004; Luck and Vogel, 1997; Park and Payer, 2006).

Neurally inspired models of visual WM assume that the ability to briefly retain information that was previously experienced, but no longer exists in the environment, emerges from the coordinated interactions of an extended neural network (D'Esposito, 2007; Postle, 2006). This network involves occipital, mediotemporal, parietal and prefrontal brain regions (Linden, 2007; Zimmer, 2008). The internal neural representations are generally 
short-lived but can be actively maintained to guide behavior, possibly via appropriate rehearsal or refreshment mechanisms (D'Esposito, 2007). The main assumption of neural WM models is: "if the brain can represent it, the brain can also demonstrate working memory for it" (Postle, 2006, p. 29). Accordingly, the question of how information is represented in a distributed neural network comes to the fore.

Given that incoming perceptual information in the brain is processed in a distributed network in a highly parallel manner, formation of (mnemonic) representations is closely related to the successful integration of this information at different levels, a function called binding (Hommel and Colzato, 2004; Treisman, 1996; Treisman and Gelade, 1980; Zimmer et al., 2006a). Basic forms of binding processes refer to the integration of features within objects as well as the integration of several objects and their relation in order to build a coherent representation (Treisman, 1996; Treisman and Gelade, 1980). Memory representations can thus be considered as traces of low-level feature and relational binding mechanisms (Zimmer et al., 2006b). Accordingly, the efficiency of binding mechanisms can be a limiting factor for memory performance and may explain individual and age variations in WM performance.

Alongside basic binding mechanisms, at a higher level, the integration of information across different brain regions in extended networks is important for higher order cognition and WM performance. Contributions of the prefrontal cortex (PFC) in the coordination of information processing in distributed networks critically determine WM performance. "Top-down" signals from PFC are thought to bias information processing in posterior brain regions (Desimone and Duncan, 1995), contributing to the encoding, maintenance, and retrieval of representations in WM (Miller and Cohen, 2001).

Neural mechanisms of information processing in distributed networks depend on the precise timing of neuronal firing within and across brain regions (Varela et al., 2001). Synchronized oscillatory activity in the theta ( $\sim 3$ to $7 \mathrm{~Hz})$, alpha $(\sim 7$ to $14 \mathrm{~Hz})$, and gamma band $(>30 \mathrm{~Hz})$, and the interplay of these frequencies has been shown to contribute differentially to WM performance. Theta activity is primarily associated with top-down control processes (Jutras and Buffalo, 2010; Sauseng et al., 2010). Gamma activity and the interaction of gamma and theta activity seem to be closely related to feature-binding processes and the observed capacity limits in WM performance (Axmacher et al., 2010; Sauseng et al., 2009). Alpha activity contributes to WM performance by gating information and inhibitory control of irrelevant information (Jensen and Mazaheri, 2010).

Taken together, WM performance reflects the outcome of processing at multiple hierarchical levels, including the analysis of low-level features and their integration or binding into higher-level representations in interaction with top-down control processes to reconstruct a stable mental representation of previously experienced information (Ranganath, 2006).

In this article we review age-related differences in WM from middle childhood to old age in order to reach a better understanding of the mechanisms through which visual WM performance and its capacity limits emerge. This goal parallels part of the general objective of memory researchers to derive mechanistic and process-oriented explanations for the observed capacity limits WM performance. The focus of this review on maturational and senescent changes in WM is motivated by the empirical observation that WM functions undergo profound and continuous changes across the lifespan. Across all modalities and domains, WM performance increases across childhood (Conklin et al., 2007; Gathercole, 1999; Luciana et al., 2005), and decreases monotonically during adulthood, with accelerated decline in old age (Borella et al., 2008; Cowan et al., 2006; Hasher and Zacks, 1988; Park and Payer, 2006; Park and Reuter-Lorenz, 2009; West, 1999). Despite surface similarities between children's and older adults' performance, lifespan psychology posits that the mechanisms of senescence are not a mere reversal or mirror function of the mechanisms of maturation (Baltes et al., 2006; Craik and Bialystok, 2006). Thus, although age can be seen as a critical source of variation in WM performance, the important task of lifespan research is to unfold this variation by identifying mechanisms, both at the neural and the behavioral level, that influence WM and vary with age. Advances in developmental cognitive neuroscience have revealed widespread neurochemical, neuroanatomical, and functional changes of the human brain across the lifespan (Bäckman et al., 2006; Li et al., 2001; Rodrigue and Kennedy, 2011). However, the way such age-related changes shape and modulate information processing in neural memory networks and relate to cognitive performance is only poorly understood. There is a lack of studies investigating both ends of the lifespan with the same paradigm and trying to relate behavioral performance to models of neural information processing.

As an exception, Shing et al. $(2008,2010)$ recently suggested a two-component framework of episodic memory to inform lifespan research. The integrative framework was derived on the basis of a series of studies examining both children and older adults that provided valuable insights into the age-differential interplay of associative and strategic components in episodic memory.

The present review extends this framework to visual WM functioning by positing that WM performance can be similarly conceptualized as the interplay of two components, namely low-level feature binding processes and top-down control, relating to posterior and frontal brain regions and their interaction in a distributed neural network. This notion is based on the observation that posterior and frontal brain regions undergo nonlinear, heterochronic changes across the lifespan and are differentially affected by effects of maturation, learning and senescence (Gogtay et al., 2004; Raz et al., 2005; Raz and Rodrigue, 2006; Sowell et al., 2003, 2004; Zimmerman et al., 2006). By middle childhood, most posterior brain regions are relatively mature. In medio-temporal regions, maturation is still incomplete at this age (Ghetti et al., 2010), and the same holds true for frontal brain regions, which show continued maturational refinement until young adulthood. In contrast, in old age, most posterior, medio-temporal, and frontal brain regions undergo senescent decline (e.g. Raz et al., 2005). Based on this observation, we suggest that the relative contributions of the binding and the top-down control component to WM performance change with age. Thus, the overarching goal of the present review is to chart the changes in WM-relevant neural networks of children and older adults, and to relate them to behavioral evidence on age-related differences in WM performance, with special attention to top-down control, feature binding processes, and their interaction. Given the large amount of available lifespan evidence from the visual modality as well as a focus of our own research in this domain, we will mainly concentrate our discussions on visual WM.

To achieve this goal, the following review is structured into four sections. First, we briefly outline the neural architecture of the WM network, with an emphasis on interactions between posterior and frontal brain regions ${ }^{1}$. We will then turn to senescent changes and maturational changes in the WM network, and their relation to the interaction of low-level feature binding and top-down control processes. Second, neural mechanisms of information processing in extended neural networks are discussed. Special attention will be given to the interplay of integration processes across different temporal and spatial scales, and their relation to oscillations at specific frequency bands. We will review the available evidence

\footnotetext{
1 We will focus our review on research in humans; for related reviews on the neural basis of WM in non-human primates, the interested reader is referred to Romanski (2004) and Watanabe (2002).
} 
on age-related changes in oscillatory mechanisms and their relation to WM performance, first with regard to changes in older age, then with regard to childhood development. Third, we will piece together the available evidence from child developmental and aging research in order to delineate WM mechanisms that are sensitive to age, and derive hypotheses about age-graded changes in these mechanisms. Primarily drawing on findings from our own laboratory, we will provide preliminary evidence for a lifespan dissociation of top-down control and binding mechanisms in WM, and advocate a two-component of lifespan WM development. We will discuss commonalities and differences in the functional architecture of WM between children, younger adults, and older adults, and highlight the potential contribution of a lifespan perspective to general models of WM. Finally, we note the limitations of the twocomponent framework, and raise questions for future research.

\section{The neural network supporting WM performance}

\subsection{Functional neuroanatomy of the working memory network}

Over the last decades neuroscientific research has greatly advanced our understanding of the neural basis of WM. Neural models of WM suggest that it cannot be mapped to a single brain area but should be considered as an emergent property arising from the interactions of an extended fronto-posterior network (D’Esposito, 2007; Linden, 2007; Postle, 2006; Zimmer, 2008) involving occipital, mediotemporal, parietal, and prefrontal brain regions. Put simply, WM results from prefrontally mediated control directed toward posterior neural systems that serve sensory and perceptual functions. In this sense, neural models of WM refer to a "sensory recruitment" idea (Serences et al., 2009). Along this line of reasoning, information is maintained at multiple levels of analysis by persistent activity in those brain regions in which it is processed in the first place, depending on the level of representation. For instance, Serences et al. (2009) observed stimulus specific activation patterns in sensory areas during the delay period of a memory task (see also Ester et al., 2009). Activation patterns were further modulated by task relevance, providing evidence for the interaction of top-down control and early representational formats of information in WM.

Besides delay activation in sensory and temporal multimodal association areas, several neuroimaging studies point to the importance of the posterior parietal cortex (PPC) as a core region for WM performance. Using a color change detection paradigm, Todd and Marois (2004) found that during the retention interval, the blood oxygenation level dependent (BOLD) signal in PPC tracked the number of items in WM and leveled off as WM capacity limits were reached (see also Sheremata et al., 2010). PPC activity correlates with individual differences in WM capacity (Todd and Marois, 2005; see also Linden et al., 2003). These findings have been supported by similar results from EEG studies (Vogel and Machizawa, 2004; Vogel et al., 2005), in which a sustained negativity over posterior regions related to the individual WM capacity was observed (for more details, see below). The PPC seems to display some important functional segregation, that is, the more inferior intraparietal sulcus (IPS) responds to the number of objects, whereas the superior IPS responds to the total quantity of information in terms of features (Cusack et al., 2010; Sheremata et al., 2010; Xu, 2007, 2009; $\mathrm{Xu}$ and Chun, 2006, 2009). Furthermore, the involvement of the IPS in multiple-object tracking tasks (Culham et al., 2001; Jovicich et al., 2001) and perceptual tasks (Mitchell and Cusack, 2008) suggests that the role of the IPS in WM is likely to be related to spatial processing (Curtis, 2006; Harrison et al., 2010; Sheremata et al., 2010) and attention (Marois and Ivanoff, 2005; Mitchell and Cusack, 2008). This assumption fits to the observation that event-related difference waves elicited in WM and visual search tasks are similar (Emrich et al., 2009) as well as in multiple object tracking (Drew and Vogel, 2008).

Mediotemporal (MTL) brain regions are critical for WM performance when processing and maintaining complex objects (Lee and Rudebeck, 2010; Ranganath et al., 2005; Ranganath and D'Esposito, 2001) or feature conjunctions (Olson et al., 2006a,b), underlining the important role of MTL involvement for intra- and inter-item binding (Piekema et al., 2010).

Furthermore, the PFC is a crucial node in the WM network, given that its role relates to the coordination and control of encoding-, maintenance-, and manipulation-related processes (for a review of general findings and the functional segregation of the PFC, see Curtis and D'Esposito, 2003). Importantly, feedback or topdown signals from prefrontal cortex bias processing in posterior sensory- and multimodal association areas (Bar, 2003; Desimone and Duncan, 1995; Miller and Cohen, 2001; Nobre, 2001). This modulatory effect of the PFC (Murre et al., 2006) and of the frontoparietal network in general plays a critical role not only during encoding of information via the selection of relevant and suppression of irrelevant information (Gazzaley, 2011), but also during maintenance and manipulation of information (D'Esposito, 2007).

The dynamic interaction between the PFC and posterior brain regions, such as occipitotemporal (Gazzaley et al., 2007; Lepsien and Nobre, 2007; Rissman et al., 2008) and parietal cortices (Edin et al., 2009) contribute critically to WM performance. For example, Gazzaley et al. (2007) showed that the strength of functional coupling between PFC and visual association cortices was higher for relevant information than for irrelevant information and correlated with the magnitude of attentional modulation in the visual area. A study by Zanto et al. (2011) corroborated this finding and provided evidence for a causal role of the PFC in top-down modulation of visual processing and working memory. The authors found that the perturbation of PFC function via repetitive transcranial magnetic stimulation (TMS) resulted in diminished top-down modulation of activity in posterior cortex and predicted decrements in WM performance. Enhanced functional coupling between dorsolateral PFC and IPS has also been shown for WM performance at high load indicating that interindividual differences in memory capacity are partly determined by the strength of prefrontal top-down control (Edin et al., 2009).

In the face of abundant or competing information, the mechanism by which top-down control biases processing in posterior brain regions may either refer to selective enhancement of neural activity related to relevant information, to the suppression of neural activity related to irrelevant information, or both.

By comparing electrophysiological activity evoked by targets and distracters relative to a baseline, recent studies found that top-down control results indeed in both an enhancement of relevant information as well as a suppression of irrelevant information, as indicated by early modulations of event-related potentials in posterior brain regions (Gazzaley et al., 2008, 2005a; Rutman et al., 2010). Importantly, the amount of top-down modulation is related to individual WM performance, that is, the individual degree of P1 amplitude modulation predicts WM performance (Zanto and Gazzaley, 2009). Insufficient early top-down modulation thus seems to lead to the excessive processing of irrelevant information and that, in turn, is detrimental for WM performance (Berry et al., 2009; Clapp et al., 2010; for a review see Gazzaley, 2011). This evidence is in line with results obtained with the change detection paradigm. Presenting distracters and targets simultaneously, Vogel et al. (2005) showed that individuals with low WM capacity suffered from reduced "filter efficiency" compared to highcapacity individuals. As reflected in the higher amplitude of the contralateral delay activity (CDA), an event-related difference wave between the posterior sites contra- and ipsilateral to the attended 
hemifield (see below), low performers seemed to maintain distracters along with the targets in WM. High performers, on the other hand, selected only targets for maintenance, displaying CDA amplitude increases for arrays including both targets and distracters as compared to targets only. This finding provides direct evidence that deficient selection of information leads to its subsequent maintenance, impacting performance for relevant information (see Fukuda and Vogel, 2009; Jost et al., 2011, for similar results). In line with this interpretation, recent evidence suggests that insufficient engagement of the dorsal prefrontal cortex as well as the inferior parietal cortex are related to the encoding and maintenance of irrelevant information in WM (Minamoto et al., 2012).

In line with this conjecture, McNab and Klingberg (2008) found that activity in the prefrontal cortex and the basal ganglia preceding the presentation of irrelevant information predicted the degree to which this information was stored. The observation that this "filter activity" was associated with interindividual differences in WM capacity suggests that frontal areas and basal ganglia exert top-down control over WM representations. Evidence from recent clinical studies further underlines the relevance of an intact PFC and basal ganglia for WM performance (Baier et al., 2010; Voytek and Knight, 2010). Thus, top-down control over information selectively encoded and maintained seems to be closely related to a fronto-parietal and fronto-striatal network.

Top-down control is not restricted to perceptual representations, but can also affect memory representations. Several studies have shown that cues indicating targets after stimulus presentation (i.e., retro-cues) bias visual WM like pre-cues, as indicated by performance improvements (Griffin and Nobre, 2003; Nobre et al., 2007; Ruff et al., 2007). Moreover, the mechanisms governing the top-down control of perceptual and memory representations engage overlapping brain areas and show similar temporal dynamics (Kuo et al., 2009; Lepsien et al., 2005; Lepsien and Nobre, 2006). In line with this observation, Eimer and Kiss (2010) reported that using retro-cues to indicate the relevant hemifield for target detection elicited an event-related difference wave that was previously related to WM content. In a similar vein, Kuo et al. (2011) observed top-down modulation of activity in early visual areas related to retro-cues. More importantly, stronger functional connectivity between frontal and posterior occipital regions predicted individual memory performance. Thus, long-range communication between distal brain regions seems to contribute to successful WM performance during later stages of information processing as well.

To summarize, despite a large amount of content- and processspecific selectivity in the recruitment of given brain regions across different WM and attention tasks, many areas in the occipital, mediotemporal, parietal, and frontal lobes are consistently recruited across tasks and task conditions (D'Esposito, 2007). Posterior brain regions seem to play an important role in the formation and maintenance of representations at different levels of processing, whereas prefrontal regions contribute to the selection of relevant information and the stabilization of representations during maintenance. Neural models of WM emphasize the importance of the dynamic interplay between these distributed brain regions to promote a better understanding of WM performance (Postle, 2006). Recent studies have provided a large amount of evidence indicating that individual differences in WM capacity are closely related to top-down control mechanisms that enhance or suppress neural activity related to memory representations in posterior brain regions during early and late processing stages (for a review, see Gazzaley, 2011). In particular, deficient top-down control seems to lead to the abundant processing and maintenance of irrelevant information that in turn impairs WM performance.

In the following, we will review evidence from child development and aging research on maturational and senescent changes in the brain and how they are related to the temporal dynamics in brain circuitries supporting mnemonic functioning. Behavioral and neuroscientific studies show that WM performance increases across childhood (Conklin et al., 2007; Gathercole, 1999; Luciana et al., 2005; Luna et al., 2004), shows a peak in young adulthood, and an accelerated decline with advancing age (Park and Payer, 2006; Park and Reuter-Lorenz, 2009; Reuter-Lorenz and Park, 2010). Findings based on longitudinal studies generally support these cross-sectional results (de Frias et al., 2007; Schneider et al., 2005). At the same time, the human brain circuitries that contribute to WM undergo nonlinear and heterochronic changes during childhood development and aging, such that different brain regions are more or less prone to effects of maturation, learning, and senescence, and differentially affect the dynamic interactions between brain regions in different age groups (Gogtay et al., 2004; Raz et al., 2005; Raz and Rodrigue, 2006; Sowell et al., 2003, 2004; Zimmerman et al., 2006). How changes in neural functioning and observed age-related behavioral changes are associated is only poorly understood (cf. Cabeza et al., 2005; Nelson and Luciana, 2008). The following sections review age-related changes in the WM network and neural mechanisms of information processing.

\subsubsection{Senescent changes in the structures, functions, and mechanisms of information processing in WM}

Neuroanatomical and neurochemical ${ }^{2}$ brain changes are widespread in normal aging. The shrinkage of human brain grey matter volume is especially pronounced in hippocampal (Jernigan et al., 2001; Raz et al., 2005; Zimmerman et al., 2006) and frontal brain regions (Bergfield et al., 2010; Giorgio et al., 2010; Greenwood, 2000, 2007; Jernigan et al., 2001; Raz et al., 2005; Raz and Rodrigue, 2006; Resnick et al., 2000; Sowell et al., 2003; Zimmerman et al., 2006), areas that subserve mnemonic and attentional functions. Some researchers suggest that age-associated decline of the prefrontal lobes plays a major role in cognitive aging (Lindenberger et al., in press; Raz and Rodrigue, 2006; Stuss et al., 1996; West, 1996). Some evidence suggests that even the visual cortex is not completely unaffected by senescent decline (Salat et al., 2004). Changes in the microstructure of white matter integrity as revealed by diffusion tensor imaging (DTI) accompany grey matter losses (Giorgio et al., 2010; Madden et al., 2009; O'Sullivan et al., 2001), also in posterior regions (Wen and Sachdev, 2004). More detailed reviews of structural changes in the brain across the lifespan can be found in Madden et al. (2009), Raz and Rodrigue (2006), Rodrigue and Kennedy (2011), and Sowell et al. (2004).

In addition to structural changes, functional magnetic resonance imaging (fMRI) and positron emission tomography (PET) studies also observed altered task-related activation patterns in perceptual and memory-based tasks in ventral and dorsal prefrontal (e.g., Cabeza et al., 2002, 2004; Grady et al., 1998; Madden et al., 2007; Morcom and Friston, 2012), parietal (e.g., Cabeza et al., 2004; Daselaar et al., 2006; Madden et al., 2007), mediotemporal (e.g., Cabeza et al., 2004; Daselaar et al., 2006), and occipital (e.g., Cabeza et al., 2004; Madden et al., 2002, 1997) regions in older compared to younger study participants.

Age-related changes at the lowest level of information processing, such as decline in visual cortex activation, indicate age-related reduction in the efficiency of bottom-up processing (Cabeza et al., 2004; Madden et al., 2002, 1997; Peiffer et al., 2009). Apart from general reductions, a loss of neural specificity, so-called dedifferentiation, has been observed in ventral visual brain regions (Park

\footnotetext{
2 A review of neurochemical brain changes is beyond the scope of this review but can be found in Stoermer et al. (2011), where the authors give a comprehensive overview on dopaminergic and cholinergic age-related changes and their relation to WM and attention.
} 
et al., 2004; see also Carp et al., 2010, 2011). Evidence derived from the measurement of the fMRI adaptation to repeatedly presented pictures indicates that dedifferentiation processes in older adults may be closely linked to a decline in the (contextual) binding of information (Chee et al., 2006).

With regard to PFC activation patterns in attention and WM tasks, underactivations (e.g., Grady et al., 1998; Jonides et al., 2000; Rypma and D'Esposito, 2000) and overactivations (e.g., Cabeza et al., 2002; Reuter-Lorenz et al., 2000) in older compared to younger adults have been interpreted as a signature of less differentiated representations and processing circuits (Baltes and Lindenberger, 1997; Li et al., 2001), compensatory adaptations to normal aging (Cabeza et al., 2002; Park and Reuter-Lorenz, 2009), or both. Given that complex cognitive functions such as WM do not rely on isolated brain regions, but on the dynamic interplay between brain regions forming a neural network, age-related alterations in posterior and frontal regions are closely related to each other (Park and Reuter-Lorenz, 2009), and overactivation of prefrontal sites is often coupled with underactivation in more posterior regions of the occipital and temporal lobes. For example, decreased neural specialization in ventral visual regions is accompanied by increased frontal activation in older adults (Payer et al., 2006) and the degree of dedifferentiation correlates with measures of fluid intelligence in older adults (Park et al., 2010), indicating the involvement of posterior brain regions in older adults' cognitive functioning.

Recent theorizing (Reuter-Lorenz and Cappell, 2008; ReuterLorenz and Park, 2010) suggests that differences in prefrontal activation patterns result from general differences in performance levels in the sense that older adults need to recruit additional "executive" resources at lower difficulty levels (Cappell et al., 2010; Mattay et al., 2006; Nagel et al., 2009, 2011; Schneider-Garces et al., 2010) and are overtaxed when task demands increase. This resembles the suggestion that aging leads to a shift in the regional recruitment of brain areas along the anterior-posterior axis (Davis et al., 2008). It follows that younger and older adults may reach equal levels of performance through different neural activity patterns. For example, older adults were shown to rely more on frontal regions in an attention task that activated posterior regions in younger adults (Solbakk et al., 2008). Accordingly, frontally mediated processes may contribute differentially to WM performance in older as compared to younger adults (e.g., Reuter-Lorenz and Park, 2010).

As reviewed above, a large body of research from younger adults has provided evidence for prefrontally mediated top-down influences on neural activity in posterior regions during mnemonic functions. Recently, an increasing number of neuroimaging and EEG studies have yielded first insights into age-related changes in neural mechanisms of top-down selection and their effects for WM performance. By comparing neural activity in posterior brain regions related to relevant and irrelevant information, Gazzaley et al. (2005b) revealed selective age-specific impairments in the inhibition of irrelevant information, while the enhancement of relevant information seemed to be preserved. Moreover, impaired suppression during encoding was related to smaller WM performance in older adults. EEG studies have placed this inhibition deficit at early stages of information processing, given that older adults, in contrast to younger adults, show no indication of suppression in early event-related activity, but in later measures such as alpha desynchronization (Gazzaley et al., 2008). This has led the authors to conclude that suppression abilities are not completely abolished in older adults, but delayed to later processing stages (Gazzaley, 2011; Gazzaley et al., 2008). Using a change detection paradigm with simultaneous target and distracter presentation, Jost et al. (2011) obtained similar results. Age differences between younger and older adults were particularly pronounced during early time windows of the contralateral delay activity (350-500 ms after stimulus onset), suggesting that older adults pay more attention to irrelevant information during early visual processing. Age-related impairments in top-down control thus seem to be associated with more processing and greater maintenance of irrelevant information in older adults (see also de Fockert et al., 2009).

In light of the similarities between mechanisms supporting the top-down control of perceptual and memory representations (Lepsien and Nobre, 2006), it seems likely that age-related suppression deficits in early processing stages are accompanied by age-related differences in top-down control of mnemonic representations. There is some evidence suggesting that older adults display reduced activity in the dorsolateral PFC when asked to rethink or "refresh" information encountered just before (Johnson et al., 2004). Effects of this reduced frontal activation may lead to deficits in modulating the activity in posterior brain regions, as shown in a recent fMRI study (Mitchell et al., 2010). Asked to selectively refresh previously seen faces or scenes, older adults did not display suppression effects for the irrelevant category in extrastriate regions. This age deficit in refreshing may be closely related to age-related differences during maintenance of information in WM. To conclude, it appears that age-graded structural and functional changes from early to late adulthood alter the functional architecture of an extended neural network. The resulting changes in frontal and posterior brain regions as well as their interactions contribute to WM deficits in old age.

\subsubsection{Maturational changes in the structures, functions, and mechanisms of information processing in WM}

Increases in WM capacity across childhood and adolescence have been observed in various tasks (e.g., Conklin et al., 2007; Cowan et al., 2006; Gathercole et al., 2004; Luciana and Nelson, 1998; Riggs et al., 2006). It is likely that the development of (visual) WM performance is associated with maturational structural and functional changes in the fronto-parietal network (see Astle and Scerif, 2011, for a recent review of developmental changes related to WM and attentional control). Early post-mortem studies revealed that axons in the frontal cortex undergo myelination well into adolescence (Huttenlocher, 1979, 1990; Yakolev and Lecours, 1967). With the advent of neuroimaging techniques, in vivo examinations contributed evidence for the heterochronicity and regional specificity of brain development. For example, when comparing high-resolution structural MR images of adolescents (12-16 years) and young adults, Sowell et al. (1999) observed only minor maturational changes in the parietal, temporal, and occipital lobes, but large group differences in dorsal, medial, and lateral regions of the frontal lobes. Longitudinal results (Giedd et al., 1999) confirmed the heterochronic development of the cerebral cortex and revealed a peak in gray matter volume in parietal and frontal lobes at around $10-12$ years of age, followed by volume reductions during postadolescence. Increases in white matter as measured with DTI and fractional anisotropy (FA) are commonly observed across childhood (Klingberg et al., 1999; Schmithorst et al., 2002; Snook et al., 2005). Furthermore, FA in regions of the frontal lobe is positively related to the development of WM capacity (Nagy et al., 2004; see also Johansen-Berg, 2010). Accordingly, protracted myelination of prefrontal cortex has been suggested as a major pacemaker for WM capacity development (Klingberg et al., 1999). How regional agerelated changes in cortical thickness and white matter structure relate to each other is only poorly understood. For example, the cortical thickness of parietal and lateral PFC as well as white matter microstructural properties of the superior longitudinal fasciculus (which is connecting these regions) appear to follow different age trajectories, and show unique contributions to verbal WM performance in children aged 8-19 years (Ostby et al., 2011). 
FMRI studies have also related functional changes in frontal and parietal cortex to the development of visuo-spatial WM performance (Klingberg, 2006; Klingberg et al., 2002; Kwon et al., 2002; Nelson et al., 2000; Olesen et al., 2003). Structural and functional changes in the fronto-parietal network are closely related and seem to underlie the development of WM performance, as indicated by positive correlations between the maturation of white matter and the BOLD response in frontal and parietal regions (Olesen et al., 2003).

Besides changes in local brain regions, cognitive maturation may relate strongly to changes in the recruitment and configuration of the brain network, probably by changes in functional connectivity within and across cortical areas (Edin et al., 2007). Age-related differences in top-down control are associated with a strengthening of effective connectivity between frontal and posterior brain regions (Hwang et al., 2010). Recent results from resting state functional connectivity MRI (fcMRI) describe changes in functional networks during development as an increase in segregation (thus a decrease in short-range connections) and an increase in integration (largescale connections; Fair et al., 2009, 2007). Thus, enhanced regional processing and long-distance functional integration increasingly support WM as children grow older.

In summary, the basic neural architecture in terms of brain regions and neural circuitry related to $\mathrm{WM}$ seems to be in place in early childhood, but undergoes subsequent refinement (Brahmbhatt et al., 2010). Hence, children increasingly recruit brain regions that are activated by adults during WM performance, and interactions between these brain regions underlie WM improvements (Bunge and Wright, 2007). In relatively simple WM tasks, children mostly recruit similar fronto-parietal circuitries as adults (Casey et al., 1995; Geier et al., 2009; Nelson et al., 2000; Thomas et al., 1999; Tsujimoto et al., 2004). At the same time, some core regions for WM, such as the PFC, are less consistently recruited in children than in younger adults when working on more complex tasks (Ciesielski et al., 2006; Schweinsburg et al., 2005) or under high load conditions (Thomason et al., 2009). Changes in the recruitment of PFC functions are closely related to general improvements in cognitive control (e.g., Bunge et al., 2002; Bunge and Wright, 2007). Accordingly, recruitment of prefrontal control in WM tasks may fail in children under conditions of high task difficulty. For example, Crone and co-workers (Crone et al., 2006) compared children aged $8-12$ years, adolescents aged $13-17$ years, and younger adults in WM tasks requiring either the maintenance or the manipulation of information. During the delay period, both adolescents and younger adults recruited the DLPFC and the superior parietal cortex for manipulation versus maintenance trials, but younger children failed to do so. The delay-period activation was correlated with behavior, suggesting a link between the activation of prefrontal brain regions and development of WM performance.

Similarly, larger performance decrements caused by distracters in children relative to younger adults may relate to inadequate recruitment of prefrontal brain regions. One study by Olesen et al. (2007) investigated the effect of distraction during the delay in a WM task. Behaviorally, the children, who were 13 years of age, were more distracted than adults. Delay activity was found in the superior frontal sulcus, dorsolateral PFC, and intraparietal cortex. Adults showed higher dorsolateral PFC activation during the delay period than children. Children showed higher activity in the superior frontal sulcus. No age differences were observed for activations in the parietal cortex. The authors suggest that distracter-resistant representations rely on activity in dorsolateral PFC and intraparietal cortex. Immature inhibition of distracters in children may thus be related to weaker representations and maintenance of irrelevant information as reflected by the age-differential recruitment of PFC and superior frontal sulcus, respectively.
It is possible that children not only fail to recruit regions that are involved in WM networks in adults, but also rely on brain regions that are less central to the adult WM brain network. A recent study assessed longitudinal changes in the WM network during early adolescence ( 15 years) and late adolescence ( 18 years; Finn et al., 2010). At both time points, load-dependent lateral PFC activity was observed. Behavioral performance on the criterion task (i.e., delayed matching to sample) did not differ between the first and the second assessment. However, at the first measurement occasion, additional hippocampal activity functionally connected to the PFC was observed. Given that hippocampal activation has been related to intra- and inter-item binding processes in adults (e.g., Piekema et al., 2010), these results suggest that binding mechanisms were differentially involved at the ages of 15 and 18 . These results show that the ways in which WM is implemented in the brain varies within individuals across age. Moreover, WM networks seem to become increasingly specialized with age and show a refinement of the recruitment of prefrontal control structures (Luna, 2009; Luna et al., 2004). Taken together, maturation appears to result in a combination of increasing localization of function in core regions and their integration with prefrontal regions that enhances and stabilizes performance (Scherf et al., 2006).

\subsection{Oscillatory neural mechanisms of information processing related to WM performance}

Evidence from human EEG studies supports the assumption that extended network interactions are the underlying neural mechanisms for complex cognitive functions, such as WM (Bressler and Kelso, 2001). The central postulate of the network view is that complex behavior arises from the dynamic coupling among brain regions. Synchronized oscillatory activity has been suggested as one coordinating mechanism for information processing (Engel et al., 2001; Fries, 2005; Uhlhaas et al., 2009a; Varela et al., 2001) by regulating the timing of neuronal firing and establishing functional networks (Buzsaki and Draguhn, 2004; Klimesch et al., 2007). Accordingly, EEG studies investigating oscillatory mechanisms target the "dual aspect of cognitive functions" (Bressler and Kelso, 2001), that is the large-scale processing by distributed, interconnected areas and the local processing within areas, capturing (short-lived) spatiotemporal relations within and between brain regions.

Synchronous oscillatory activity in a broad range of frequencies, especially in the theta $(3-7 \mathrm{~Hz})$, alpha $(8-12 \mathrm{~Hz})$ and gamma $(>30 \mathrm{~Hz})$ frequency bands have been associated with processes that are important for successful WM performance such as featurebinding, object representation, and attention. In general, it has been suggested that fast frequencies like gamma are related to the local integration of information, whereas global interactions of different brain regions may rely on slower frequencies like theta and alpha (von Stein and Sarnthein, 2000). Synchronization at lower frequencies is particularly well suited for long-range integration because it tolerates longer conduction delays (Kopell et al., 2000).

In line with this reasoning, locally synchronized activity in the gamma frequency band (Engel et al., 1999; Gruber et al., 2006, 2004; Herrmann et al., 1999; Tallon-Baudry and Bertrand, 1999; Tallon-Baudry et al., 1997, 1998, 1999) ${ }^{3}$ has been related to featurebinding and maintenance processes in rather posterior parts of the

\footnotetext{
3 The interpretation of some of these results has been put into question because microsaccades may influence cortically recorded EEG gamma activity (YuvalGreenberg et al., 2008). However, results from intracranial recordings also underline the role of gamma oscillations for binding and memory processes and are usually less influenced by spike-potential related artifacts (Fries et al., 2008). Clearly, the relations among cognitive processes, microsaccades, and oscillations require further scrutiny (Melloni et al., 2009).
} 
WM network (for recent reviews, see Herrmann et al., 2010; Jensen et al., 2007). A recent study using intracranial recordings showed that gamma activity in occipital brain regions can be very specific and can even encode the identity of individual letters (Jacobs and Kahana, 2009). It is important to note that the posterior distribution of these effects does not speak against the operation of top-down control. For example, it has been found that local gamma band activity is enhanced for cued targets (Landau et al., 2007). In addition, several authors have reported increases in gamma band activity over frontal electrodes that appear to be related to cognitive control processes in WM (e.g., Basar-Eroglu et al., 2007; Haenschel et al., 2009; see also Tallon-Baudry et al., 1998).

Top-down processes relevant for WM performance have been mostly related to activity in slower frequencies such as theta and alpha activity. Local increases in (frontal) theta have been observed in various memory and attention tasks during encoding, retention, and retrieval of information (e.g., Brookes et al., 2011; Gevins et al., 1997; Klimesch, 1999; Klimesch et al., 1996; Michels et al., 2008; Raghavachari et al., 2001; Sauseng et al., 2007; Sederberg et al., 2003), pointing to the involvement of frontal control processes in these tasks. WM load has been found to modulate frontal theta activity (Brookes et al., 2011; Jensen and Tesche, 2002). Furthermore, theta activity plays a major role in the integration of distributed neural information, such that interregional theta synchronization co-activates different brain regions (Sauseng et al., 2010). For example, theta synchronization increased between prefrontal and posterior electrodes during the retention interval of a delayed match-to-sample task (Sarnthein et al., 1998; for similar results see Payne and Kounios, 2009; Sauseng et al., 2004, 2005a). Theta synchronization between brain regions may be initiated by the frontal cortex, so that theta activity in posterior regions may be trailing prefrontal sites (Sauseng et al., 2004; for a more exhaustive review on the role of theta oscillations, see Sauseng et al., 2010).

Current theories suggest that WM capacity limits may be explained by the relationship between synchronized activity in the theta and gamma frequency bands (Jensen, 2005; Jensen and Colgin, 2007; Jensen and Lisman, 1996; Lisman and Idiart, 1995). Accordingly, individual memory representations are related to single gamma cycles that are nested in theta cycles. An increasing number of studies provided support for the assumption that thetagamma coupling plays an important role in WM processes (Canolty et al., 2006; Demiralp et al., 2007; Sauseng et al., 2009; Schack et al., 2002). Strong evidence for the proposed theory has recently been provided by Axmacher et al. (2010). Using intracranial recordings, the authors found cross-frequency couplings between theta and higher (gamma/beta) frequencies in the hippocampus. Interestingly, with increasing load, the gamma-modulating theta frequency showed a shift towards lower frequencies. Longer theta cycles may thus allow for the nesting of more gamma cycles within one theta cycle with higher load. Similar results using scalp EEG have been obtained by Sauseng et al. (2009). In this study, subjects performed a cued change detection task. When sorting gamma phase according to theta phase, the authors observed a stronger theta-gamma coupling at posterior sites contralateral to the cued visual field during the retention interval. The lateralized theta-gamma coupling increased up to the average WM capacity limit and was predictive for individual WM performance. Again, the coupling between activity in the gamma and theta frequency can be influenced by top-down control. For example, in a visual attention task, Sauseng et al. (2008) showed that spatial shifts of attention modified phase synchronization between theta and gamma activity in the parietooccipital cortex shortly after stimulus onset (for recent reviews on the functional role of cross-frequency coupling, see Canolty and Knight, 2010; Jensen and Colgin, 2007).

Besides theta and gamma oscillations, oscillations in the alpha band are thought to contribute to WM performance as an inhibition and gating mechanism. Alpha amplitudes show local increases over task-irrelevant brain regions during the retention interval that are modulated with increasing load (Jensen et al., 2002; Tuladhar et al., 2007). It has been suggested that the increase in alpha power reflects inhibition or disengagement of brain regions not necessary for the current task (Jensen et al., 2002; Jokisch and Jensen, 2007; Tuladhar et al., 2007). Amplitudes of ongoing alpha oscillations influence the perception of upcoming stimuli such that low pre-stimulus alpha power is related to better performance (Hanslmayr et al., 2007, 2005; Thut et al., 2006). Investigations of the effects of local stimulation of the visual cortex via TMS showed that periods of spontaneous high alpha activity are related to low cortical excitability (Romei et al., 2008) and that the posterior alpha rhythm is actively involved in shaping forthcoming perception (Romei et al., 2010). These findings add to the hypothesis that alpha oscillations represent an active inhibition mechanism (Klimesch et al., 2007). In line with this assumption, in visuo-spatial attention tasks, alpha power has been found to decrease over sites involved in target processing, and to increase over sites not involved in target processing (Doesburg et al., 2009; Händel et al., 2011; Kelly et al., 2006; Rihs et al., 2007; Sauseng et al., 2005b; Thut et al., 2006; Worden et al., 2000 $)^{4}$. The strength of this alpha lateralization effect predicts target detection in the unattended hemifield (Händel et al., 2011), underlining the inhibitory nature of the alpha increase. The modulation of posterior alpha by covert attentional shifts is so reliable that it can be used for the control of brain-computer interfaces (Bahramisharif et al., 2010; van Gerven and Jensen, 2009).

A similar pattern of lateralized hemispheric alpha power differences was observed in change detection tasks in which participants were cued to maintain information only one from hemifield (Grimault et al., 2009; Sauseng et al., 2009). For example, in the study by Sauseng and colleagues (2009) alpha amplitudes during the retention interval were larger ipsilateral than contralateral to the attended hemifield. This lateralized difference in alpha power increased with load, and the slope of the increase predicted individual WM capacity. This finding suggests that inhibition processes play a critical role in WM, an assumption that is further underlined by recent findings of brain-behavior correlations of increases in alpha activity in task-irrelevant brain areas with task performance (Haegens et al., 2010). An interpretation of the role of oscillatory alpha activity as a mechanism for information routing by inhibition of task-irrelevant pathways has been summarized recently in the "gating by inhibition hypothesis" (see Jensen and Mazaheri, 2010).

Posterior alpha modulations are probably the effect of top-down control processes. A recent study by Capotosto et al. (2009) provided direct evidence for the top-down control of occipito-parietal alpha modulations by fronto-parietal brain regions. Disruption of neural activity in IPS and frontal eye field (FEF) via repetitive TMS disrupted alpha desynchronization in posterior regions and led to impaired performance in subsequent target detection. Freunberger et al. (2009) provided further evidence for the contribution of topdown modulation of alpha activity to WM performance. In a WM task, cues indicated whether participants had to memorize the upcoming picture or not. Non-remember cues elicited pronounced alpha amplitude increase, reflecting top-down modulated preparatory inhibition.

In addition to local alpha power modulations' relations to attention and WM performance, long-range alpha synchronization may also play an important role within neural networks to

\footnotetext{
${ }^{4}$ Note that a recent study (Rihs et al., 2009) suggests that early ( $<700 \mathrm{~ms}$ ) decreases of contralateral alpha power indicate a facilitation effect, whereas later increases of ipsilateral alpha power indicate sustained attention and inhibition. Both effects result in the observed alpha lateralization effect and are not easily distinguished.
} 
establish a large-scale neural ensemble (Palva and Palva, 2007; von Stein and Sarnthein, 2000). In cued visual attention tasks, increased long-range alpha synchronization contralateral to the attended hemifield were observed between occipital and parietal cortex (Doesburg et al., 2009) and between prefrontal and posterior regions (Sauseng et al., 2005b). Long-range synchronization is also increased during WM tasks (Palva et al., 2005) and sustained interareal phase synchrony among visual and frontoparietal regions during the retention interval is strengthened with load (Palva et al., 2010). In a similar vein, Zanto et al. (2010b) observed higher alpha band phase-locking between frontal and posterior regions of interest (ROI) for to-be remembered versus to-be-ignored items, suggesting that alpha phase coherence may serve as a mechanism of anticipatory top-down control. This assumption was corroborated by related evidence showing that perturbing PFC function via repetitive TMS disrupts the attentional modulation of alpha phase coherence (Rihs et al., 2009). Functional coupling between brain areas involved in the WM network may thus also be achieved via synchronization in the alpha frequency band.

To summarize, the available evidence points to the importance of precisely timed neural interactions in the gamma- and thetafrequency for WM performance (for recent reviews see Fell and Axmacher, 2011; Jutras and Buffalo, 2010). Similarly, alpha oscillations contribute critically to dynamic processing in an extended network as local and global inhibition or gating mechanism (Jensen and Mazaheri, 2010; Klimesch et al., 2007). The following sections review the available evidence on age-related differences in oscillatory neural mechanisms that are potentially relevant for agegraded differences in WM performance.

\subsubsection{Senescent changes in oscillatory mechanisms}

Given the role of theta and alpha oscillations in top-down and inhibition processes, and the decline in WM with advancing adult age, one might expect that younger and older adults differ in theta and alpha activity. Indeed, available studies report age-related differences in alpha frequency, alpha and theta power or both (for reviews see Dustman et al., 1993; Klimesch, 1999; Niedermeyer, 1997). The general pattern is a drop in alpha frequency with advancing age (e.g., Dustman et al., 1993), accompanied by power increases in the theta band (Klimesch, 1999; Prinz et al., 1990) and power decreases in the alpha band (e.g., Dustman et al., 1999; Polich, 1997b; Prinz et al., 1990).

However, the functional consequences of spectral changes on WM functioning in old age are only poorly understood. Regarding inhibition processes indexed by alpha oscillations, results are nonconclusive. As reviewed above, some recent studies have reported top-down effects on event-related alpha power in WM tasks but failed to observe age differences therein (Gazzaley et al., 2008; Zanto et al., 2010c). In contrast, a recent study by Deiber et al. (2010) has reported age-related changes in alpha synchronization for face and letter stimuli in a delayed recognition task. Compared to younger adults, older adults showed delayed alpha synchronization that was reduced for to-be-ignored letters, in line with an age-related alteration of inhibition processes.

Phase synchronization across trials has only rarely been investigated in older adults. As an exception, Müller et al. (2009) observed significantly stronger phase locking in the alpha frequency band in older adults than in younger adults and children in an auditory perception task. Further research is needed to examine whether stronger phase synchronization is a general characteristic of older adults' neural responses.

Hogan et al. (2003) suggested that older adults show loaddependent theta decreases in a Sternberg WM task. However, their study compared healthy older adults to patients with early Alzheimer disease but did not include a group of younger adults, so that conclusions about general age-related changes are not warranted. In a modified Sternberg paradigm, Cummins and Finnigan (2007) observed reduced theta power during the retention and recognition interval in older adults compared to younger adults. However, age groups also differed in resting state theta power. Given that the modulation of theta power by WM load was not investigated, the functional relevance of the observed age differences is unclear.

As a notable exception, McEvoy et al. (2001) investigated agerelated changes in alpha and theta power as a function of task load in a visuo-spatial WM task. Younger adults showed an increase in frontal midline theta with increasing load, whereas older adults did not. Additionally, older adults showed widespread reductions in alpha power in both frontal and parietal regions for larger WM load, whereas younger adults only showed parietal decreases. The widespread alpha reduction may mean that older adults needed to recruit more cortical resources for successful task performance. At the same time, reduced frontal theta may indicate that older adults are less able to recruit resources related to top-down control with increasing demands. The authors suggest that these effects reflect a posterior-to-frontal shift in processing with advancing age (but see Babiloni et al., 2004, for a contrary proposition).

Low-level feature binding processes as indexed by gamma oscillations have been investigated in a recent lifespan study (Werkle-Bergner et al., 2009). In comparison to younger adults, older adults' evoked gamma power was less reliably modulated by increases in stimulus sizes, possibly reflecting reduced sensitivity to perceptual input due to aging. However, the impact of impaired binding processes on memory performance was not investigated.

The role of synchronized oscillations for WM performance has received increasing attention in recent years. However, with a few notable exceptions, the well-known decline of WM functioning in normal aging has not yet been investigated from this perspective. The available evidence is scarce and far from being conclusive. Adequate comparison groups are often absent, and age-related confounding factors are often not considered or controlled. In particular, given the decrease in alpha power with adult age (Klimesch, 1999; Polich, 1997a), parametric designs are needed to assess the functionality of synchronized activity in older adults (Gazzaley and D'Esposito, 2005). Accordingly, it remains an open question how senescent changes alter WM-related neural mechanisms and circuitries.

\subsubsection{Maturational changes in oscillatory mechanisms}

Electrophysiological research focusing on oscillatory mechanisms of information transmission in the normally developing brain is scarce and has rarely been linked to WM performance. In an auditory oddball task, Yordanova and Kolev (1997) investigated developmental changes in the early stimulus-related alpha activity and phase-locking in children and young adults. Relative to young adults, children aged 6-11 years showed differences in topography and higher amplitudes, and phase-locking. However, by the age of 10-11 years, the strength of phase-locking was comparable to that of young adults. Müller et al. (2009) reported complementary results. In a lifespan sample, they observed lower local phase synchronization in children than in younger and older adults, but higher EEG power in delta and theta frequencies. Additionally, children aged 9-11 years did not differ from children aged 11-13 years in local phase-locking, but showed lower long-range synchronization. These childhood transitions support the conjecture of continued development of functional networks.

The development of WM-relevant functional networks was recently investigated with measures of neural synchrony during a Gestalt perception task in an age-heterogeneous sample ranging from 6 to 21 years (Uhlhaas et al., 2009b). Amplitudes of theta- and gamma-band oscillations showed selective increases with age, whereas alpha power remained stable. Developmental 
improvements in cognitive performance were accompanied by an enhancement of long-range synchronization in the theta, beta, and gamma frequency ranges. Age-related increases in theta synchrony patterns were found in particular between frontal and occipitalparietal electrodes. These results point to a close relation between structural brain development, neural synchrony, and cognitive development that needs to be ascertained by longitudinal assessments. They also highlight the prolonged maturation of functional networks and their importance for cognition. Uhlhaas et al. (2010) provide a detailed review of the available evidence about neural synchrony in developing networks.

Recently, developmental changes in alpha activity have also been investigated in relation to WM functioning. One of these studies focused on changes in long-range synchronization and local desynchronization of alpha oscillations during visual WM retention in children 6-10 years of age (Doesburg et al., 2010). In accordance with previous observations in adult samples (Doesburg et al., 2009), an increase in long-range synchronization within the frontoposterior network was found, together with a decrease in alpha amplitudes over posterior sensors. The study did not include an adult sample, so that direct comparisons between age groups were not possible.

Effects of top-down control on visual WM were also investigated in a recent magnetoencephalographic (MEG) study (Ciesielski et al., 2010). Event-related desynchronization (ERD) in the alpha band was compared between 10-year-old children and younger adults. Target anticipation effects yielded a significant modulation of ERD by target proximity in younger adults, whereas children displayed a smaller degree of anticipatory ERD modulation. Given that the age groups did not differ in accuracy and speed, the authors concluded that children may use different strategies and rely on different neural networks to accomplish top-down control than younger adults.

Overall, the evidence for maturational changes in oscillatory mechanisms of information processing and their relation to WM performance is similarly scarce in research on child development as it is in research on normal aging. The available data suggest that child development is indeed associated with changes in neural information processing that refer mostly to the integration of information across different brain regions and less to local changes. Nevertheless, even local oscillatory phenomena, such as posterior alpha power, possibly reflect the interplay between frontal and posterior brain regions and thus may operate differently in children than in older individuals. Given their potential significance for understanding child development, the interactions among alpha, theta, and gamma oscillations in relation to top-down control and binding processes in WM definitely deserve closer attention.

\section{The two-component framework as a lifespan perspective on working memory}

The reviewed literature suggests that WM relies on an extended neural network (D’Esposito, 2007; Postle, 2006; Ranganath, 2006; Zimmer, 2008). Information is processed in parallel at different levels of the cortical hierarchy and can be described as the interaction of (low-level feature) binding and control processes (see Shing et al., 2010,2008 , for a similar formulation of a two-component model in the domain of episodic memory functioning).

Low-level feature binding mechanisms integrate perceptual inputs into a coherent representation (Craik, 2006; Zimmer et al., 2006b), possibly through synchronization of neural activity in and across posterior brain regions (Murre et al., 2006; Von der Malsburg, 1981). Being the basis of memory representations, the co-occurrence of features and objects is thought to lead to spontaneous and fast binding (Hommel and Colzato, 2004). Low-level feature binding processes can be broadly mapped onto more posterior brain regions such as occipital, temporal, and mediotemporal cortices, and are assumed to be critically involved in the formation and maintenance of memory representations (Piekema et al., 2010; Zimmer et al., 2006b).

Top-down control can be understood in terms of feedback processes from higher cortical regions that bias processing in posterior regions under conditions of competing information and stabilize representations over time (Desimone and Duncan, 1995; Miller and Cohen, 2001). The source of top-down control is broadly mapped to prefrontal regions, but effects of control manifest themselves primarily in posterior regions that bind and maintain representations. On a neural level, local binding processes are reflected in gamma activity in posterior brain regions (Herrmann et al., 2010), whereas control processes in WM are closely related to theta oscillations (Sauseng et al., 2010). Interactions among activities in the gamma and theta frequency bands contribute to the observed capacity limit in WM performance (Freunberger et al., 2011). In addition, alpha oscillations related to inhibition and gating processes also support WM performance (Jensen and Mazaheri, 2010). In particular, top-down modulations of posterior alpha oscillations reflect the effects of successful implementation of prefrontal top-down control (Capotosto et al., 2009).

Clearly, low-level feature binding and top-down control are functionally intertwined (Miller and Cohen, 2001; Werkle-Bergner et al., 2006). On the one hand, maintenance of the representations as a result of binding mechanisms may depend on stabilization by top-down control, and thus representations may be more durable and precise when optimal cognitive control is called into service. On the other hand, the necessity to rely on top-down control may depend on the stability of the binding that has been achieved. In addition, the relative contribution of top-down control and binding mechanisms may not be invariant across task conditions. For example, binding processes may contribute critically to performance under stringent time constraints, whereas performance may rely more strongly on top-down control when enough processing time is provided. This intrinsic interdependence needs to be kept in mind when attempting to describe and understand age-related changes in visual WM performance in terms of a two-component model that contrasts the influences of bottom-up binding and topdown control on WM. Based on this model, we assume that the relative contributions of low-level feature binding and top-down control processes are not invariant across the human lifespan but evolve across the life course, reflecting differences in the relative efficiency and integrity of the corresponding brain areas and their interconnections. Furthermore, the interaction between the two components may be more or less successful in different age groups, reflecting age-graded differences in the functionality of top-down control and low-level feature binding processes.

The available evidence suggests that aging is characterized by a widespread decline of various regions of the WM network. Posterior regions are characterized by less efficient processing of visual information, probably related to dedifferentiation processes in early visual regions (Carp et al., 2010; Park et al., 2004). Mediotemporal regions related to the integration of information show large senescence-related changes (Raz et al., 2005; Raz and Rodrigue, 2006). Frontal regions contributing to the top-down control of information processing are especially affected by age (Rodrigue and Kennedy, 2011; West, 1996), as reflected by a loss of early and late inhibition processes with advancing age (Gazzaley, 2011; Hasher et al., 2007; Hasher and Zacks, 1988; Mitchell et al., 2010; Werkle-Bergner et al., 2012).

By late childhood, temporal and occipital lobes have matured to a considerable extent, whereas dorsal, medial, and lateral regions of the frontal lobes continue to show major maturational changes that extend into early adulthood (Giedd et al., 1999; Gogtay et al., 2004; Sowell et al., 2003). The maturation of prefrontal regions is closely 
Top-down control Local binding

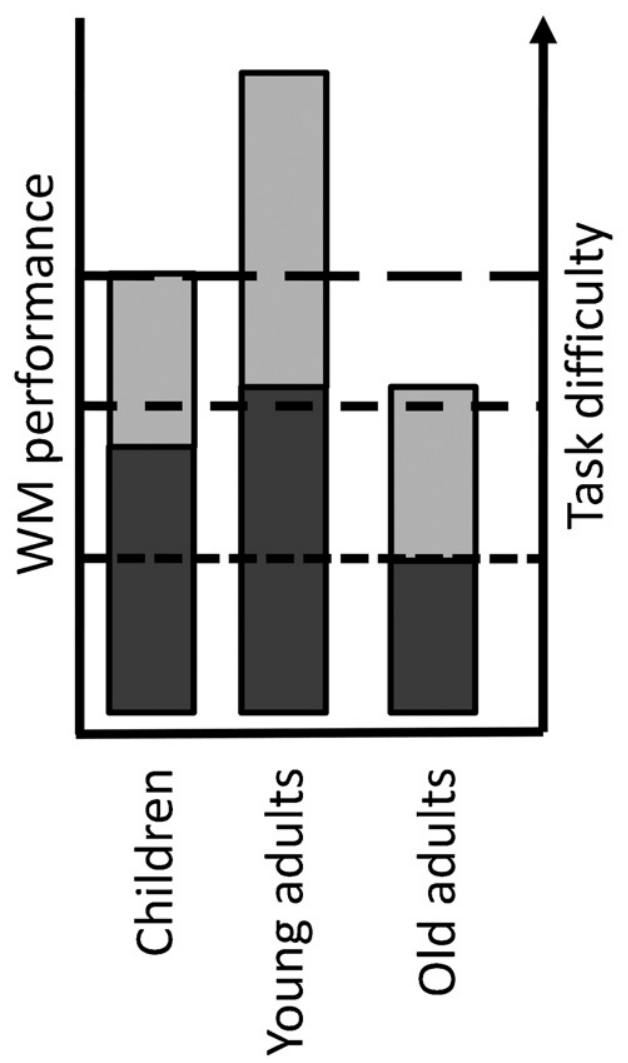

Fig. 1. Schematic illustration of the two-component framework with the expected age differences (on the $x$-axis) in binding (in dark) and top-down control processes (in light) and their effects on WM performance (on the left $y$-axis) depending on task difficulty (on the right $y$-axis). The interaction of binding component and top-down control component underlies WM performance and gives rise to typical age differences on the behavioral level as indicated by the total height of the bars. (Binding and top-down control components are presented as additive factors for illustration purposes only.) Both components show age-differential trajectories across the lifespan. The functionality of the binding component almost reaches the young adults' level in children, but is reduced in older adults. Both children and older adults differ from young adults with regard to the functionality of the top-down control component. The reliance on the binding component and on top-down control differs between age groups and between task conditions. For example, with low task difficulty, WM performance may rely primarily on the binding component whereas with high task difficulty, the successful interaction of the two components is necessary for a given WM performance. A given level of task difficulty may tax the two components to a different degree in the different age groups, giving rise to age-differential patterns of neuronal measures of WM performance.

related to the development of WM capacity (Nagy et al., 2004). Cognitive development in middle and later childhood appears to depend on changes in the configuration of the brain network, in general, and the increasingly reliable recruitment of prefrontal regions under conditions of high load and distracting information, in particular (Bunge and Wright, 2007; Fair et al., 2009; Luna, 2009). In terms of the two-component framework, the preceding observations lead to the central proposition that low-level feature binding and cognitive control processes contribute differentially to WM at different periods of the lifespan. Based on this proposition, we would expect both commonalities and discrepancies in WM performance and its neural implementation as a function of age across the lifespan (see Fig. 1, illustrating the rationale of the two-component framework with regard to WM performance):
First, less efficient prefrontal functioning in both children and older adults can be expected to lead to lower WM performance relative to younger adults. This finding would be consistent with theories that emphasize the critical role of the frontal lobes in cognitive child development (Dempster, 1992; Diamond, 2002) and aging (Hasher et al., 2007; West, 1996). The evidence reviewed above suggests that the involvement of prefrontal brain regions depends on task difficulty and performance level (Luna, 2009; Reuter-Lorenz and Park, 2010; Schneider-Garces et al., 2010). In line with this conjecture, children and older adults may show especially large behavioral deficits relative to younger adults when confronted with high WM load, distracting or irrelevant information, or both (see Gazzaley et al., 2008; Olesen et al., 2007).

Second, dissimilarities between children and older adults can be expected in the binding component and its interaction with topdown control. The binding component is supposed to be relatively mature in children, but compromised in older adults. Accordingly, when performance mainly relies on posterior regions, that is, under easy conditions, children's performance might be more similar to younger adults' than to older adults'. In contrast, older adults' performance may suffer from impaired binding mechanisms even under conditions that impose relatively low demands on top-down control. Older adults may tend to counteract this hypothesized binding impairment by recruiting frontal regions, resulting in an altered interaction between low-level binding processes and topdown control relative to younger adults (Table 1 ).

Preliminary empirical support for these hypotheses has been obtained in our lab by comparing lifespan samples of children, younger, and older adults in the change detection task (Luck and Vogel, 1997; Vogel and Machizawa, 2004). In this paradigm, observers are briefly presented with a memory array containing a variable amount of information. After a retention interval typically one second - the observer compares the representation maintained in WM to a probe array in which one item has or has not been changed ${ }^{5}$. Based on the correct and incorrect answers to a varying number of presented items, the change detection paradigm yields an estimate of the individual WM capacity, the so-called $k$-score (Cowan, 2001; see Pashler, 1988, for the first introduction of the formula). The $k$-score is computed as follows: $k=$ (hit rate - false alarm rate) $\times$ set size. Accordingly, the $k$-score reaches an asymptote for large set sizes and is therefore considered as a stable behavioral marker of visual WM capacity. Based on the $k$-score, the capacity limit of WM has been estimated to be about 3-4 items in younger adults.

Alone and in combination with neuroimaging techniques, the change detection paradigm yields several markers of WM performance that provide valuable insights into the mechanisms and capacity limits of visual WM (e.g., Grimault et al., 2009; Luck and Vogel, 1997; Sauseng et al., 2009; Todd and Marois, 2004, 2005; Vogel and Machizawa, 2004; Vogel et al., 2005; Wheeler and Treisman, 2002).

So far, the change detection tasks have only rarely been used in age-comparative settings. This observation applies to behavioral studies (but see Cowan et al., 2005, 2010, 2006; Riggs et al., 2006), and especially to electrophysiological studies (see Jost et al.,

\footnotetext{
5 Note that according to the traditional view of WM referring to "storage plus manipulation" (Baddeley, 2003), the change detection task would qualify as a "pure storage" task, and performance accordingly as visual short-term memory (VSTM) performance, not as WM performance. Neural models of WM challenge this theoretical distinction and argue for rather relative changes in the contribution of control processes to different tasks (D’Esposito et al., 1999; Postle, 2006; Ranganath, 2006 Zimmer, 2008) and in different age groups (Reuter-Lorenz and Park, 2010). These differences in opinion and terminology are reflected in the literature, which refers to the change detection task as a paradigm for assessing either VSTM or WM. In the present review, we refer to the change detection paradigm as a WM task.
} 
Table 1

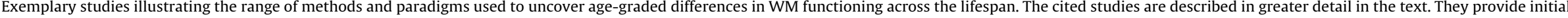
empirical evidence for the two-component framework of lifespan WM development proposed in this article.

\begin{tabular}{|c|c|c|c|c|c|c|}
\hline Component & Study & Participants' age & Paradigm & Method & Focus on & Major finding \\
\hline \multicolumn{7}{|c|}{ Evidence from lifespan research } \\
\hline 1,2 & Cowan et al. (2006) & CH 8-12 yrs;YA; OA 65-85 yrs & $\begin{array}{l}\text { Visual change detection task } \\
\text { with colored squares }\end{array}$ & $\begin{array}{l}\text { Behavioral performance } \\
\text { measures }\end{array}$ & $\begin{array}{l}\text { Age-graded differences in the } \\
\text { ability to keep item } \\
\text { information and item-location } \\
\text { binding information in WM }\end{array}$ & $\begin{array}{l}\text { CH and OA showed lower WM } \\
\text { performance than YA. } \\
\text { OA had an additional binding deficit } \\
\text { when item- and binding-change trials } \\
\text { were mixed together. }\end{array}$ \\
\hline 2 & Müller et al. (2009) & $\begin{array}{l}\text { CH 9-11 yrs, } 11-13 \text { yrs; YA; OA } \\
64-75 \text { yrs }\end{array}$ & Auditory oddball task & $\begin{array}{l}\text { EEG: Whole and evoked power } \\
\text { as well as phase } \\
\text { synchronization within and } \\
\text { between electrodes }\end{array}$ & $\begin{array}{l}\text { Age-graded differences in } \\
\text { neural coding }\end{array}$ & $\begin{array}{l}\text { Lower local phase synchronization, } \\
\text { higher delta and theta power, and } \\
\text { lower long range synchronization in } \\
\text { younger CH relative to YA. } \\
\text { OA show higher phase synchronization } \\
\text { across trials in alpha frequency as well } \\
\text { as lower evoked and whole power } \\
\text { relative to YA. }\end{array}$ \\
\hline 2 & Werkle-Bergner et al. (2009) & $\begin{array}{l}\mathrm{CH} 10-12 \text { yrs, YA; OA 70-76 } \\
\text { yrs }\end{array}$ & $\begin{array}{l}\text { Visual choice-reaction task } \\
\text { with geometric figures of } \\
\text { varying size }\end{array}$ & $\begin{array}{l}\text { EEG: Evoked gamma power, } \\
\text { gamma band inter-trial phase } \\
\text { stability }\end{array}$ & $\begin{array}{l}\text { Age-graded differences in } \\
\text { low-level feature binding } \\
\text { processes }\end{array}$ & $\begin{array}{l}\text { CH show lower levels of evoked } \\
\text { gamma power and phase-stability than } \\
\text { YA. } \\
\text { In OA, gamma power is less modulated } \\
\text { by varying stimulus size than in YA. }\end{array}$ \\
\hline \multicolumn{7}{|c|}{ Evidence from aging research } \\
\hline 1 & Gazzaley et al. (2005b) & OA 60-77 yrs; YA & $\begin{array}{l}\text { Delayed match-to-sample task } \\
\text { with faces and scenes; items } \\
\text { have to be attended, ignored or } \\
\text { passively viewed }\end{array}$ & MRI: BOLD & $\begin{array}{l}\text { Enhancement or suppression } \\
\text { of activity relative to passive } \\
\text { viewing condition in } \\
\text { stimulus-specific (posterior) } \\
\text { regions of interest }\end{array}$ & $\begin{array}{l}\text { Relative to YA, OA show selective } \\
\text { impairments in suppressing irrelevant } \\
\text { information, while the enhancement of } \\
\text { relevant information is preserved. } \\
\text { Suppression impairments among OA } \\
\text { are related to memory performance. }\end{array}$ \\
\hline 1 & Gazzaley et al. (2008) & OA 60-72 yrs; YA & see Gazzaley et al., 2005b & $\begin{array}{l}\text { EEG: ERPs and oscillatory } \\
\text { activity }\end{array}$ & $\begin{array}{l}\text { Enhancement or suppression } \\
\text { of amplitudes relative to } \\
\text { passive viewing condition in } \\
\text { posterior regions }\end{array}$ & $\begin{array}{l}\text { Relative to YA, OA show selective } \\
\text { impairments in suppressing irrelevant } \\
\text { information, in particular during early } \\
\text { time-windows (P1, N1), but not later } \\
\text { time-windows (alpha } \\
\text { oscillations).Suppression impairments } \\
\text { among OA are related to memory } \\
\text { performance. }\end{array}$ \\
\hline 1 & Jost et al. (2011) & OA 64-92 yrs, YA & $\begin{array}{l}\text { Visual change detection } \\
\text { paradigm with orientation bars } \\
\text { which were marked as relevant } \\
\text { or irrelevant items }\end{array}$ & $\begin{array}{l}\text { EEG: ERPs (contralateral delay } \\
\text { activity) }\end{array}$ & $\begin{array}{l}\text { Contralateral delay activity } \\
\text { over posterior regions during } \\
\text { the retention interval: } \\
\text { Comparison of amplitudes } \\
\text { between conditions with } \\
\text { relevant versus } \\
\text { relevant + irrelevant items }\end{array}$ & $\begin{array}{l}\text { Adult age differences are particularly } \\
\text { pronounced during early time } \\
\text { windows of contralateral delay } \\
\text { activity, suggesting that older adults } \\
\text { pay more attention to irrelevant } \\
\text { information during early visual } \\
\text { processing. }\end{array}$ \\
\hline 1 & Mitchell et al. (2010) & OA 64-85 yrs; YA & $\begin{array}{l}\text { Participants attended (precue) } \\
\text { versus refreshed (postcue) } \\
\text { faces or scenes presented } \\
\text { simultaneously on each trial }\end{array}$ & fMRI: BOLD & $\begin{array}{l}\text { Enhancement or suppression } \\
\text { of activity relative to baseline } \\
\text { condition in stimulus-specific } \\
\text { regions of interest for attend } \\
\text { versus refresh conditions }\end{array}$ & $\begin{array}{l}\text { Age-related deficit in suppressing } \\
\text { activity in extra-striate cortex, in } \\
\text { particular in the "refresh" condition, } \\
\text { but not in the perceptual attention } \\
\text { condition. }\end{array}$ \\
\hline
\end{tabular}


Table 1 (Continued)

\begin{tabular}{|c|c|c|c|c|c|c|}
\hline Component & Study & Participants' age & Paradigm & Method & Focus on & Major finding \\
\hline 2 & Carp et al. (2010) & OA 61-82 yrs; YA & $\begin{array}{l}\text { Delayed verbal and } \\
\text { visuo-spatial item-recognition } \\
\text { working memory tasks }\end{array}$ & $\begin{array}{l}\text { fMRI: Multi-voxel pattern } \\
\text { analysis }\end{array}$ & $\begin{array}{l}\text { Multi-voxel pattern analyses to } \\
\text { measure age differences in the } \\
\text { distinctiveness of neural } \\
\text { representations }\end{array}$ & $\begin{array}{l}\text { Relative to YA, distinctiveness of } \\
\text { neural representations is reduced in } \\
\text { OA in early visual areas during } \\
\text { encoding and retrieval. During } \\
\text { maintenance, adult age and load } \\
\text { interactively predict distinctiveness in } \\
\text { prefrontal and parietal regions. }\end{array}$ \\
\hline 1 & Zanto et al. (2010c) & OA 60-83 yrs; YA & $\begin{array}{l}\text { Delayed-recognition WM } \\
\text { tasks. Lower-level visual } \\
\text { features (color hue and motion } \\
\text { direction) have to be attended, } \\
\text { ignored or passively viewed. }\end{array}$ & $\begin{array}{l}\text { EEG: P1, N1, selection } \\
\text { negativity, event-related alpha } \\
\text { power }\end{array}$ & $\begin{array}{l}\text { Enhancement or suppression } \\
\text { of activity relative to passive } \\
\text { viewing }\end{array}$ & $\begin{array}{l}\text { Relative to YA, OA show a latency delay } \\
\text { of the selection negativity (SN) and } \\
\text { alpha band activity during WM } \\
\text { encoding. SN predicts subsequent } \\
\text { recognition performance. Shows age } \\
\text { differences in attentional modulation } \\
\text { of low-level visual features. }\end{array}$ \\
\hline \multicolumn{7}{|c|}{ Evidence from child developmental research } \\
\hline 1 & Crone et al. (2006) & $\mathrm{CH}$ and $\mathrm{YA} 8-25$ years & $\begin{array}{l}\text { Object-working memory task } \\
\text { (maintenance/manipulation } \\
\text { condition) }\end{array}$ & fMRI: BOLD & $\begin{array}{l}\text { Age-related differences in } \\
\text { delay related activation } \\
\text { patterns during manipulation } \\
\text { of information relative to pure } \\
\text { maintenance. }\end{array}$ & $\begin{array}{l}\text { Age-graded improvements in } \\
\text { performance are associated with } \\
\text { increased recruitment of DLPFC and } \\
\text { superior parietal cortex during the } \\
\text { delay period for manipulation relative } \\
\text { to maintenance. }\end{array}$ \\
\hline 1 & Olesen et al. (2007) & CH 13 yrs; YA & $\begin{array}{l}\text { Visuo-spatial WM task with } \\
\text { and without distracters }\end{array}$ & fMRI: BOLD & $\begin{array}{l}\text { Age-related differences in } \\
\text { delay and distraction related } \\
\text { activation patterns }\end{array}$ & $\begin{array}{l}\text { Stronger delay activity in YA in middle } \\
\text { frontal gyrus and intraparietal cortex. } \\
\text { Distraction evoked activation in } \\
\text { parietal and occipital cortices in both } \\
\text { YA and } \mathrm{CH} \text {, and additionally in frontal } \\
\text { cortex in CH. }\end{array}$ \\
\hline 1,2 & Uhlhaas et al. (2009b) & $\mathrm{CH}$ and $\mathrm{YA}$ 6-21 yrs & Gestalt perception task & $\begin{array}{l}\text { EEG: changes in spectral power } \\
\text { and long-range } \\
\text { phase-synchronization }\end{array}$ & $\begin{array}{l}\text { Age-related differences in } \\
\text { neural coding, development of } \\
\text { functional networks }\end{array}$ & $\begin{array}{l}\text { Age-graded cognitive improvements } \\
\text { are associated to increases in neural } \\
\text { synchrony until adolescence, followed } \\
\text { by a decrease and a period of } \\
\text { reorganization of neural patterns. }\end{array}$ \\
\hline 1,2 & Doesburg et al. (2010) & CH 6-10 yrs & $\begin{array}{l}\text { Visual short-term memory task } \\
\text { (delayed match-to-sample) }\end{array}$ & $\begin{array}{l}\text { MEG: Long range } \\
\text { synchronization and local } \\
\text { desynchronization of alpha } \\
\text { oscillations }\end{array}$ & $\begin{array}{l}\text { Oscillatory mechanisms of } \\
\text { information processing during } \\
\text { WM retention interval in } \\
\text { children }\end{array}$ & $\begin{array}{l}\text { Increase in long-range synchronization } \\
\text { within a fronto-posterior network } \\
\text { during the retention interval. Decrease } \\
\text { in alpha amplitudes over posterior } \\
\text { sensors }\end{array}$ \\
\hline 2 & Yordanova and Kolev (1997) & CH 6-11 yrs, YA & Auditory oddball task & $\begin{array}{l}\text { EEG: Event-related alpha } \\
\text { amplitude and inter-trial } \\
\text { phase-stability }\end{array}$ & $\begin{array}{l}\text { Age-related differences in } \\
\text { neural coding }\end{array}$ & $\begin{array}{l}\text { Age-related differences in the } \\
\text { topography of alpha responses. } \\
\text { Increase in alpha phase-stability with } \\
\text { age. Decrease of alpha power with age. }\end{array}$ \\
\hline 1 & Ciesielski et al. (2010) & CH 10 yrs; YA & $\begin{array}{l}\text { Visual WM task (categorical } \\
\text { n-back) }\end{array}$ & $\begin{array}{l}\text { MEG: Event-related alpha } \\
\text { synchronization and } \\
\text { desynchronization }\end{array}$ & $\begin{array}{l}\text { Age-related differences in } \\
\text { anticipation of target detection }\end{array}$ & $\begin{array}{l}\text { Smaller modulation of alpha } \\
\text { desynchronization by target } \\
\text { anticipation in } \mathrm{CH} \text {. CH may use } \\
\text { different top-down strategies than YA. }\end{array}$ \\
\hline
\end{tabular}


2011, for the only study investigating older adults). Hence, our studies served two purposes: (a) to describe differences in visual WM between children, younger adults, and older adults in terms of established behavioral and electrophysiological markers of visual $\mathrm{WM}$; (b) to interpret these differences from the lifespan perspective of the two-component model. Below, we summarize and integrate the main results.

\subsection{The interplay of the two components across the lifespan reflected in different markers of WM performance}

In the first study (Sander et al., 2011a), we investigated the lifespan trajectories of low-level feature binding and top-down control processes by exploring their relative contributions under conditions of shorter and longer presentation times in a behavioral change detection paradigm with a distracter-free (Experiment 1 ) and distracter (Experiment 2) version (see Fig. 2a and b, respectively). In Experiment 1, memory arrays with a varying number of colored squares (2-10 items) were presented for 100,500 , or $1000 \mathrm{~ms}$ to the participants. Following a $1000 \mathrm{~ms}$ blank retention interval, participants had to indicate whether all of the colors of the presented squares were identical to the memory array or whether one of the squares had changed in color. In Experiment 2, participants saw displays of colored squares and circles and were instructed to remember only the colors of the squares. Target set size varied from one to five, including an always equal number of distracters. The sample of participants included children aged 9-12 years, younger adults aged 20-26 years, and older adults aged 69-76 years. WM performance was estimated at the individual level across a large range of load conditions using a procedure suggested by Rouder et al. (2008).

Based on the proposition that low-level feature binding is relatively mature in children but compromised in older adults, we expected older adults to generally show lower WM performance than children and younger adults when presentation times are fast. We further assumed that WM performance would improve with longer presentation times due to increasing reliance on (more time-consuming) control processes, necessary to stabilize early representations. Since prefrontal brain regions related to control processes undergo profound changes until young adulthood and are especially prone to senescent changes, we further hypothesized that both children and older adults would show deficits in WM performance compared to younger adults, even with longer presentation times. These hypotheses were examined in Experiment 1 . In Experiment 2 of the same study, we tested explicitly for the relation between presentation time and reliance on control processes. We assumed that simultaneously presented distracters increase the need for control and impair performance in all age groups, especially under the condition of short presentation times when control over stimulus perception is less efficient. We further hypothesized that distracter effects should decrease with increasing presentation times due to the growing influence of control processes. We predicted that children and older adults would not be able to fully inhibit irrelevant information even with longer presentation times, reflecting less efficient control operations compared to younger adults. In line with the expected inverted U-shaped function of memory performance across the lifespan, visual WM performance was lower in older adults and children than in younger adults, with older adults showing the lowest performance of all three age groups.

In accordance with the hypothesized deficits in low-level feature binding, performance of older adults was lower relative to children and younger adults when presentation times were short. Longer presentation times were associated with better performance in all age groups, presumably reflecting increasing effects of strategic selection mechanisms on WM performance (see Fig. 3a).
This finding suggests that top-down control over visual input contributes to WM performance, and needs time to be established. The finding of improved behavioral performance in the change detection paradigm related to longer encoding is at odds with several studies, reporting that WM capacity is generally independent of encoding duration (e.g., Gold et al., 2003; Sperling, 1960; Vogel et al., 2001). Nevertheless, some studies also point to the close relation between perceptual complexity of items as measured by visual search rate and WM capacity (Alvarez and Cavanagh, 2004; Eng et al., 2005). The theory of visual attention even provides an explicit treatment of the relation between encoding time and WM (Bundesen, 1990; Bundesen et al., 2005; Shibuya and Bundesen, 1988). In this theory, both visual processing speed and visual span are considered capacity-limiting parameters. Empirically, the two factors covary (Habekost and Starrfelt, 2009), pointing to their close interdependence. Recent studies also suggest that encoding strategies in terms of attentional selectivity contribute to individual differences in change detection performance (Cusack et al., 2009; Linke et al., 2011).

We interpret improved performance with longer presentation time as a reflection of the need to gain control over visual input to perform successfully (Gazzaley et al., 2005a; Todd et al., 2011; Vogel et al., 2005). This interpretation is in line with the timebased resource sharing hypothesis of WM (Barrouillet and Camos, 2007), suggesting that time plays a major role in determining the effect of control processes on performance. In agreement with this interpretation, the influence of distracters on performance was less detrimental with longer than with shorter presentation time, regardless of age. In the presence of distracters, top-down control may be necessary to bias incoming information (Desimone and Duncan, 1995; Miller and Cohen, 2001), allowing for the enhancement of relevant information and the suppression of irrelevant information (Gazzaley et al., 2005b). Accumulating evidence suggests that individual differences in WM maintenance may be mainly determined by differences in information selection prior to WM maintenance (e.g., Gazzaley, 2011; Gazzaley et al., 2007; Vogel et al., 2005). From a process-oriented view of WM, capacity measures are a complex function of various cognitive processes that have to be accomplished successfully. Therefore, variations in WM capacity measures such as the $k$-score as a function of encoding time may not necessarily reflect differences in terms of "stored items." Instead, they may indicate more efficient encoding mechanisms, both in terms of more efficiently bound information and more stabilized representations that facilitate WM maintenance. In line with the assumption of less efficient control processes at both ends of the lifespan, distracter effects were larger in children and older adults than in younger adults and even persisted at with long presentation times (see Fig. 3b).

In summary, this study provided initial support for the age-differential contribution of low-level feature binding and control processes to WM performance, extending the former two-component framework suggested by Shing et al. (2008). We followed up on these results by examining two electrophysiological measures of WM performance, namely the contralateral delay activity (CDA) and (lateralized) alpha oscillations in a lifespan setting. We will first turn to the CDA.

Some of the prior studies with the change detection paradigm have taken EEG measurements to obtain a better understanding of the neural mechanisms underlying WM performance. By using a cued version of the change detection paradigm, researchers discovered a new neural marker of WM capacity, the CDA (McCollough et al., 2007; Vogel and Machizawa, 2004), also called sustained posterior contralateral negativity (SPCN; Jolicoeur et al., 2008). In this variant of the paradigm, observers are cued to one hemifield prior to the presentation of the memory array, and are instructed to only memorize the items of the relevant hemifield. Vogel and 
2a. Change-detection task used in Sander et al., 2011a, Experiment 1:

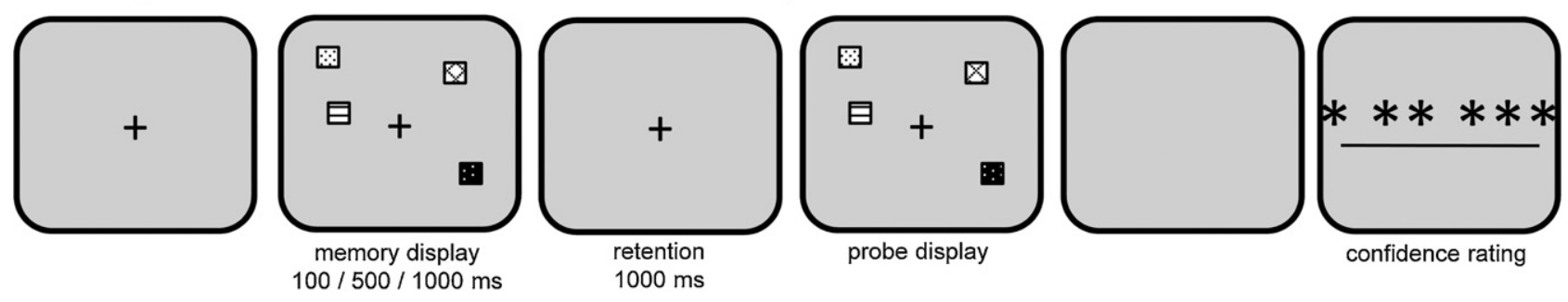

2b. Change-detection task used in Sander et al., 2011a, Experiment 2:

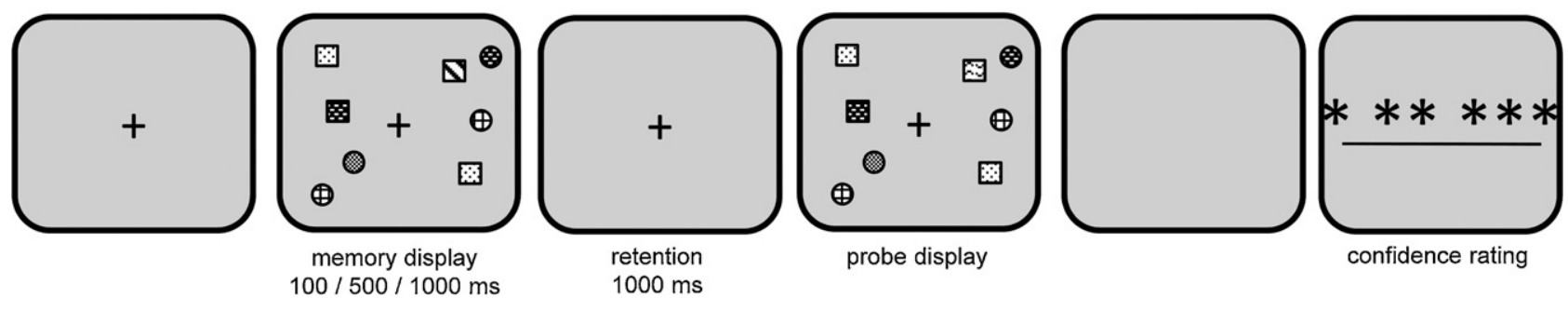

2c. Cued version of the change-detection task used in Sander et al., 2011b, 2012 :

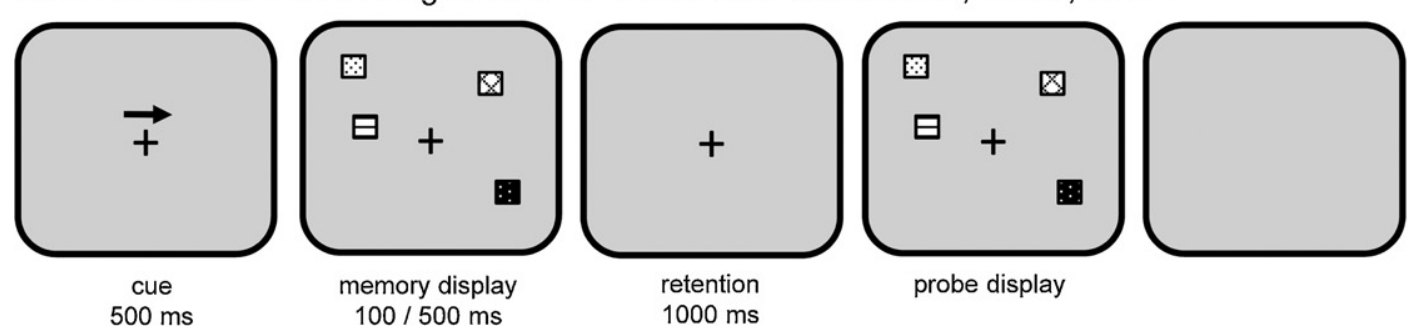

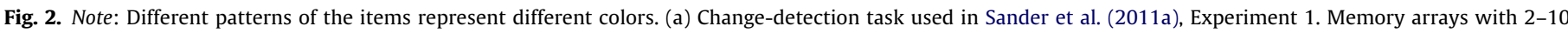

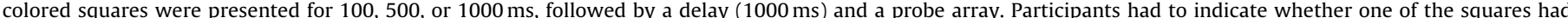

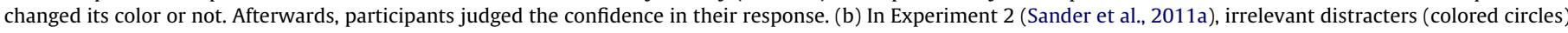

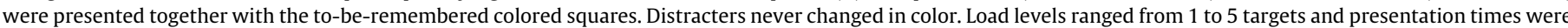

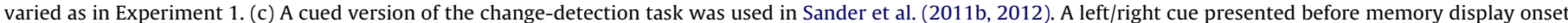
indicated which hemifield should be attended, i.e. the hemifield containing the relevant items.

colleagues (McCollough et al., 2007; Vogel and Machizawa, 2004) observed that during the delay period of the task, the event-related potential (ERP) over posterior electrodes became more negative contralateral than ipsilateral to the attended hemifield. Furthermore, they found that the difference wave between contralateral and ipsilateral activity (i.e., the CDA) has an interesting property:
Its amplitude increases with increasing load, but only up to the capacity limit of WM. Thus, in correspondence to the $k$-score, the amplitude of the CDA plateaus around 3-4 items. Furthermore, Vogel and Machizawa (2004) observed strong correlations between the CDA and the $k$-score. Therefore, the CDA has been proposed to be an online marker of memory content (Ikkai et al., 2010;
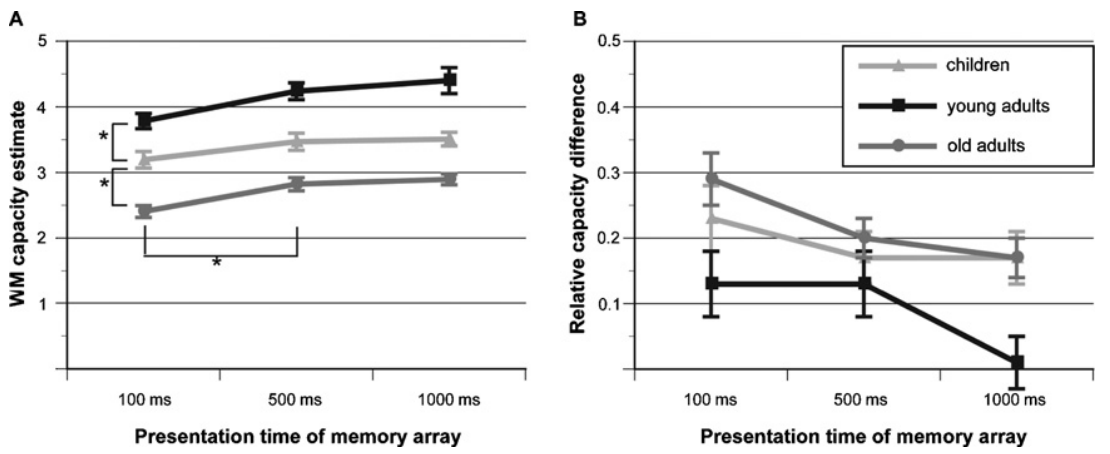

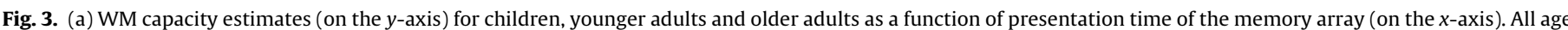

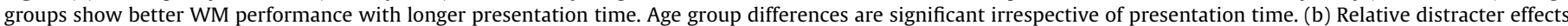

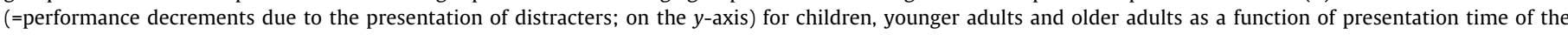

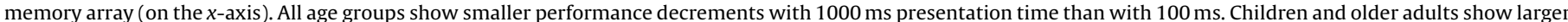
distracter effects than younger adults.

Source: Adapted from Sander et al. (2011a). 
McCollough et al., 2007). A related component has been observed in MEG recordings, called sustained posterior contralateral magnetic response (SPCM; Robitaille et al., 2009; see Mitchell and Cusack, 2011, for a detailed account of similarities and differences between contralateral and bilateral EEG and MEG markers). Several studies point to parietal sources for the CDA (Mitchell and Cusack, 2011; Robitaille et al., 2009, 2010) with a primary candidate neural source being the IPS (Drew and Vogel, 2008).

Despite its posterior distribution, and in line with the dynamic and distributed view of WM summarized above, it is likely that CDA amplitudes are influenced by both feed-forward and feedback processes from more sensory and frontal regions (Corbetta et al., 2008; McCollough et al., 2007). For example, CDA amplitudes have been shown to vary across conditions despite identical stimulation, depending on the instruction to memorize the color of bars, the orientation, or both (Woodman and Vogel, 2008). This observation strongly suggests that the amount of top-down control required by the task modulates CDA amplitudes. Investigating the effect of reward on visual search, Kiss et al. (2009) found enhanced CDA amplitudes for high-reward targets compared to low-reward targets. Furthermore, a difference wave very similar to the CDA observed in visual search tasks (Emrich et al., 2009) predicts WM performance, pointing to the close relation between processes regulating attention and WM. In a similar vein, Drew and Vogel (2008) observed a load-dependent modulation of the CDA during multiple objects tracking, where slope of the modulation predicted individual tracking capacity.

In particular, the load-dependent scaling of the CDA appears to reflect differences in the relative contribution of top-down control. In a recent study investigating patients with unilateral PFC lesions, load modulations of the CDA were only observed ipsilesional, but not contralesional (Voytek and Knight, 2010). The authors suggested that PFC lesions lead to a loss in top-down facilitation contributing to WM performance. The degree of top-down control over WM content, as reflected in CDA amplitudes when confronted by distracting information, has also been found to predict individual differences in WM performance (Fukuda and Vogel, 2009; Vogel et al., 2005). A recent study by Eimer and Kiss (2010) found that a sustained posterior negativity could also be elicited when postcues after the presentation of bilateral memory arrays indicated the hemifield of the target, again pointing to the involvement of top-down control.

At the same time, the CDA not only varies as a function of top-down control, but also by stimulus attributes. For example, orientation bars (McCollough et al., 2007) or polygons (Luria and Vogel, 2011) elicit larger amplitudes than colored squares. Furthermore, these results are in line with the assumption that binding processes occur briefly after stimulus presentation (Hommel and Colzato, 2004). Hence, based on the available evidence, we propose that mechanisms related to top-down control as well as processes related to binding influence the CDA.

Based on the assumption that lifespan age differences in visual WM may be brought about by age-differential recruitment of lowlevel binding and top-down control processes, we investigated whether CDA modulations by WM load in three different age groups would vary depending on the possibility to control WM content, that is, under conditions of shorter versus longer presentation times (Sander et al., 2011b). EEG was recorded from a sample of 22 children (aged 10-13 years), 12 younger adults (aged 20-26 years), and 22 older adults (aged 70-76 years). A hemifield version of the change detection task was used (see Fig. 2c). Load levels (2 and 4 items) and presentation times (100 and $500 \mathrm{~ms}$ ) of the memory array were varied within subjects. To allow agefair comparisons, a data-driven approach was chosen to determine time windows (TOI) and ROI for each age group and presentation time condition. This statistical procedure yielded reliable negative-going contralateral activity during the retention interval within a cluster of electrodes at posterior-parietal locations. Additional frontal effects were observed in children and older adults under the condition of longer presentation time. Behavioral markers of WM capacity showed the expected lifespan pattern, with younger adults reaching higher $k$-scores than older adults, and children performing in-between the two adult age groups. Furthermore, performance increased with longer presentation times in all age groups. Hemispheric differences were present in all age groups, suggesting that participants of all age groups were able to shift their attention to the cued hemifield as instructed. With short presentation times, the CDA showed (a) the expected load-dependent modulation in younger adults, (b) smaller, but still reliable load modulation in older adults, but (c) no load modulation in children. With long presentation time, the load effect (a) disappeared in younger adults, (b) remained reliable in older adults, (c) and appeared in children. This pattern of findings confirms that the CDA is strongly modulated by load. As a qualification to this observation, we propose that the load modulation of the CDA is seen only if successful WM performance depends on the interaction between binding and control processes. Hence, CDA amplitude does not vary with load when top-down control is impossible (i.e., in children with fast presentation time) or not needed (i.e., in younger adults with slow presentation time). Based on this proposition, we suggest that the CDA may serve as a useful indicator for studying age differences in the top-down control of WM performance.

WM performance depends not only on successful retention of relevant information but also on efficient suppression of irrelevant information. In the time domain, Vogel et al. (2005) provided neurophysiological evidence for a close relation between "filter efficiency" and visual WM performance. Further recent evidence from the time-frequency domain (Sauseng et al., 2009) underlines this hypothesis. Using a cued version, Sauseng et al. (2009) observed larger ipsilateral than contralateral alpha oscillations ( $\sim 8$ to $12 \mathrm{~Hz}$ ) during the delay period. The lateralized alpha power difference showed an increase with load and predicted individual WM capacity. In contrast to interpretations of the CDA, the lateralized alpha power difference has been interpreted in terms of inhibition processes related to visual WM maintenance, instead of a reflection of the amount of WM content ${ }^{6}$.

Theories in child development (e.g., Diamond, 2002) and cognitive aging (e.g., Hasher and Zacks, 1988) postulate that inhibition processes are impaired in both children and older adults relative to younger adults. However, it has not yet been investigated whether effects of maturation and senescence can be observed in alpha-band oscillations reflecting WM-related inhibition processes. Recent evidence suggests that older adults may be affected by an early inhibition deficit (e.g., Gazzaley et al., 2008), leading to unnecessary encoding of irrelevant information. Accordingly, we examined the effect of varying WM load on lateralized alpha power in a cued change detection paradigm in children, younger adults and older adults (Sander et al., 2012). The lateralized presentation of relevant items implied the need to suppress irrelevant items from the other hemifield. Therefore, alpha power was expected to be higher

\footnotetext{
${ }^{6}$ A recent study by van Dijk et al. (2010; see also Mazaheri and Jensen, 2008) suggests a close relationship between the CDA and the lateralized alpha power difference. According to these authors, alpha amplitude modulations may occur asymmetrically around baseline. Oscillatory peaks would then be more strongly modulated than troughs, resulting in slow potential drifts such as the CDA. This reasoning suggests that the $\mathrm{CDA}$ does not reflect retention per se, but rather the contribution of inhibition processes to WM performance. The finding of a close relation between CDA and alpha amplitude modulation further strengthens the view that the CDA is an indicator of top-down control over WM content. This perspective, which runs counter to the standard interpretation as a direct reflection of WM content, needs to be tested in future work.
} 
ipsilateral to the relevant hemifield. If maturational or senescentrelated changes in inhibition processes affect WM performance, the load-dependent modulation of EEG alpha-band measures of power should differ across age. In addition, we also examined age differences in early information processing as indexed by phasestability measures. Based on earlier findings (Müller et al., 2009), we expected greater stimulus-locked phase stability at encoding in older adults relative to children and younger adults. EEG was recorded from 20 children (aged 10-13 years), 12 younger adults (aged $20-26$ years), and 20 older adults (aged $70-76$ years). Participants performed a cued change detection task (see Fig. 2c) requiring the selective maintenance of a varying number of items from the cued hemifield. To control for group differences in performance level, we used age-adapted load levels with low, medium, and high load referring to 2-4 items for children and older adults, and 2, 4 and 5 items for younger adults. Age differences in the effect of WM load on alpha power differences between the ipsi- and contralateral hemisphere were of main interest. For each participant, we determined the individual alpha frequency (IAF) and examined alpha power during the retention interval. In addition, we used the phase-locking factor (PLF), an index of inter-trial phase stability, to examine age differences in stimulus encoding.

At the behavioral level, group differences in overall accuracy were absent, suggesting that the use of age-differential load levels compensated age-differences in performance. Given that similar levels of performance were achieved under different load levels, the estimation of k-scores resulted in the typically observed pattern of age differences, with higher scores for younger adults than children and older adults. On the neural level, reliable age differences were found for both lateralized alpha-band power and phase stability. Replicating previous results (Sauseng et al., 2009), we found larger alpha power ipsilateral to the attended hemifield in younger adults. Furthermore, the difference between ipsilateral and contralateral power showed a load-dependent increase, possibly reflecting increasing inhibition processes due to the growing number of irrelevant items. Like younger adults, children and older adults showed differences in lateralized alpha power for small versus medium load conditions. This finding shows that indicators of attentional selection or inhibition processes can be observed in children and older adults. However, under conditions of high load, hemispheric differences in alpha power were absent in these two age groups (see Fig. 4). We suggest that deficits in exhibiting stable inhibitory control under highly challenging conditions as indexed by alpha oscillations may contribute to age differences in performance.

In addition to age differences in alpha power during the retention interval, we also observed age differences in alpha inter-trial phase stability just after stimulus presentation. All three age groups showed increased inter-trial phase stability around $180-240 \mathrm{~ms}$ after stimulus onset. Children and younger adults did not differ in inter-trial phase stability, but older adults showed higher phase stability than the two groups (see also Müller et al., 2009). We suggest that higher phase stability in older adults relative to other age groups indicates a greater degree of entrainment by external stimuli, possibly reflecting a loss of complexity of the neurophysiological response with advancing age. The loss of complexity may also be at the origin of the early inhibition deficit postulated by Gazzaley and colleagues (e.g., Gazzaley et al., 2008).

Overall, the results point to age differences in oscillatory mechanisms underlying inhibition processes and WM performance during both early and later stages of information processing. The observed differences in inter-trial phase stability between children and older adults are consistent with the theoretical notion that similar levels of cognitive performance may reflect different mechanisms at different ages (Baltes et al., 2006; Craik and Bialystok, 2006).

\subsection{Commonalities and dissimilarities in WM performance} across the lifespan

The two-component framework of memory across the lifespan suggests that WM performance can be seen as the result of the successful interplay between low-level feature binding and top-down control. This interplay relates posterior to frontal brain regions and regulates their interaction in a distributed neural network. We postulated that the relative contribution of top-down control and binding mechanisms is not invariant across task conditions. Specifically, binding processes may contribute critically to performance when processing time is limited, whereas performance may rely more strongly on top-down control when time constraints are less stringent. In addition, we assumed that the relative contributions of top-down control and binding mechanisms to WM performance change from childhood to early adulthood, and from early adulthood to old age. Given the heterochronic nature of maturational brain changes, most of the mechanisms supporting low-level feature binding are relatively functional in children, whereas those supporting top-down control show a maturational lag, reflecting the late maturation of the prefrontal lobes. In contrast, both mechanisms of low-level feature binding and top-down control processes would be impaired in older relative to younger adults because normal aging is marked by widespread cortical decline (e.g. Raz et al., 2005).

In line with cognitive WM theories (e.g. Baddeley, 2003; Cowan, 2001; Engle, 2002; Kane et al., 2001), our studies support the contribution of top-down control to WM performance. Signatures of top-down control can be found in all three age groups, in terms of (a) improved performance and smaller distracter effects with longer presentation time, and (b) attentional modulation of posterior event-related potentials and alpha power. These findings suggest that top-down control influences WM performance from middle childhood to old age, and provide additional support for the claim that the basic neural architecture of top-down control is present early in child development (Luna, 2009) and continues to be operational in old age (Gazzaley et al., 2008).

Besides commonalities across age groups, we also observed important differences between age groups that are consistent with the available evidence on age-graded changes in the brain areas supporting WM. Maturational and senescence-related changes are especially pronounced in the PFC (Klingberg, 2006; Klingberg et al., 2002; Raz et al., 2005; Raz and Rodrigue, 2006), a brain region critically related to the top-down control of WM (Desimone and Duncan, 1995). Accordingly, prominent theories of child development (Diamond, 2002) and aging (Hasher and Zacks, 1988; West, 1996) posit an age-related impairment in the inhibition of irrelevant information (Dempster, 1992; Fuster, 2002). In line with these assumptions, our studies provided evidence for immature topdown control in children and age-related decline in older adults.

First, both older adults and children showed larger distracter effects than younger adults. Furthermore, distracter effects in older adults and children persisted with long presentation time, whereas younger adults were able to efficiently suppress distracters under this condition. Available neural evidence relates larger distracter effects in children and older adults to prefrontal dysfunctions. For example, in a study by Olesen and colleagues (2007), larger behavioral distraction effects in children compared to younger adults were paralleled by stronger frontal sulcus activity in children, presumably reflecting their tendency to process distracting information. Within the group of younger adults, more distracterresistant representations were related to stronger activity in frontal and parietal cortices.

With respect to normal aging, several studies indicate that older adults are more impaired by distracters than younger adults, especially when WM load is high (Gazzaley et al., 2008, 2005b). 

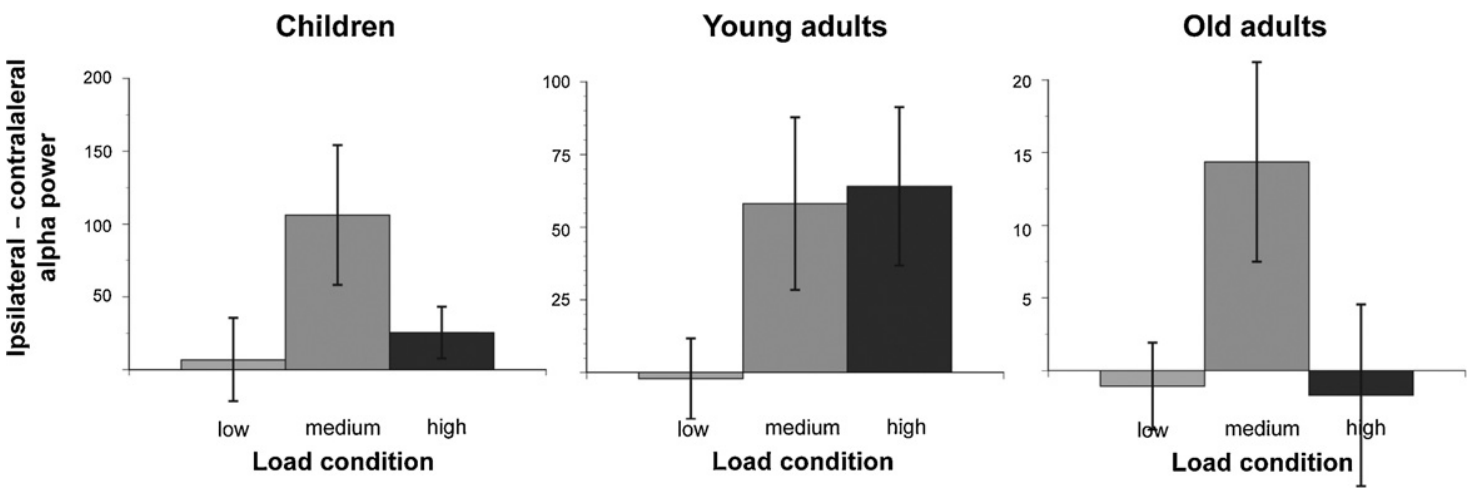

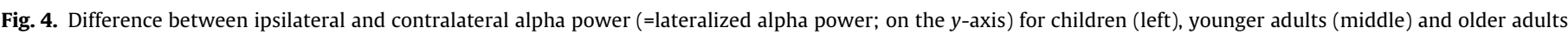

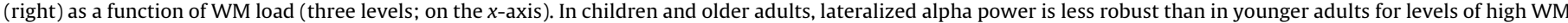
load. Note that due to general age differences in alpha power, scales differ between the plots for the different age groups.

Source: Adapted from Sander et al. (2012).

EEG studies show that older adults suppress information less efficiently during early stages of WM processing than younger adults, with cascading detrimental effects on later WM processing (Gazzaley et al., 2008; Jost et al., 2011; Stoermer et al., submitted for publication; Zanto et al., 2010a,c). Our behavioral results (Sander et al., 2011a) add to these findings by suggesting that adult age differences in distracter suppression are particularly pronounced when demands on controlled processing are high, that is, under conditions of high WM load or short presentation time. In sum, it is likely that: (a) older adults and children profited from increasing presentation time by recruiting top-down control processes that stabilize relevant representations and filter out irrelevant ones, (b) greater distracter effects in children and older adults relative to younger adults persisted with long presentation times because of deficiencies in early top-down control.

Additional insights into lifespan differences in top-down control were gained by investigating the load-dependent modulation of lateralized alpha oscillations. Top-down control and related inhibition processes may contribute to WM performance not only during early selection, but also during maintenance processes to stabilize representations. As shown in a study with younger adults by Sauseng et al. (2009), successful WM performance depends on inhibition processes during the maintenance phase of WM. In our study we observed that high load conditions that exceeded the age-group specific capacity estimates resulted in hemispheric differences in lateralized alpha power that were not reliably different from zero. Apparently, then, inhibitory control of WM broke down in both children and older adults under challenging task conditions.

Recently, Rissman et al. (2009) reported that younger adults failed to inhibit irrelevant distracters and did not show reliable signatures of neural suppression when WM load was high, whereas neural markers of enhancement were not reliably modulated by WM load. Rissman et al. (2009) concluded that cognitive control necessary for distracter suppression cannot be exerted when WM capacity is overly taxed. Due to the age-specific adaptation of WM load, children and older adults did not differ from younger adults in mean performance level under high load conditions. Nevertheless, younger adults showed reliable alpha power lateralization under this condition. Thus, our results suggest that inhibition processes in WM are less robust in children and older adults than in younger adults, even at equivalent levels of difficulty. This finding speaks to a current debate in child development and aging. According to one view, neural correlates are largely invariant across age groups when accounting for task difficulty and performance level (Schneider-Garces et al., 2010). The alternative view suggests that older adults and children are likely to recruit different or additional brain regions even when behavioral performance is equal (Luna,
2009). Our results suggest that age groups may recruit the same neural mechanisms when equating for performance. However, in the case of WM overload, the processing systems of younger adults continue to exert inhibitory control over WM contents, whereas inhibitory control seems to wane in children and older adults. In summary, our results suggest that inhibitory top-down control over WM content is less efficient in children and older adults than in younger adults.

In addition to studying inhibition processes during retention, our results also followed up on early selection deficits in older adults by investigating the inter-trial phase stability of ongoing alpha oscillations soon (i.e., around $180-240 \mathrm{~ms}$ ) after stimulus presentation. Children and younger adults did not differ in intertrial phase stability, whereas older adults showed greater inter-trial phase stability than children and younger adults. At first sight, this finding seems to defy aging theories that posit a nosier neurophysiological system with advancing age (Li et al., 2006; MacDonald et al., 2006; Welford, 1981; but see Garrett et al., 2010; McIntosh et al., 2010). However, our finding is not without precedent. For example, Müller et al. (2009) observed stronger phase locking in older than in younger adults in an auditory oddball task. Within the sample of older adults, stronger phase locking was negatively correlated with measures of perceptual speed. Recent findings from our own lab also suggest that individual WM performance differences may relate differentially to early phase stability in younger and older adults (Werkle-Bergner et al., 2012). Thus, it appears like some amount of variability may be necessary for optimal neural functioning and does not simply represent noise in the neural system (Garrett et al., 2010). Accordingly, the increased inter-trial phase stability in older adults may indicate a loss of complexity in the neurophysiological response (Cantero et al., 2009; cf. Müller et al., 2009). One possible consequence may be that the response becomes more easily entrained by external stimulation. In agreement with this line of reasoning, the early inhibition deficit of older adults reported in several recent studies could reflect an inability of older adults to resist neural entrainment by the visual stimulus.

In sum, our studies revealed both similarities and differences between children and older adults. In line with the two-component framework of WM, older adults and children showed less functional top-down control processes than younger adults. In addition, older adults showed a unique effect, namely, a larger inter-trial phasestability that may be closely related to less differentiated processing in posterior regions of the brain, perhaps due to deficiencies in the binding component of working memory (for a similar argumentation see Werkle-Bergner et al., 2012).

So far, the binding component has been empirically underidentified in all three of our studies (Sander et al., 2011a,b, 2012); 
clearly, further research is needed. Therefore, the present experiments provide only indirect evidence for the claim that low-level binding processes are relatively mature in children but impaired in older adults. Nevertheless, several findings in this context are worth emphasizing: Despite similarities between children and older adults in the control component of WM, children usually outperformed older adults. This was especially true for conditions with short presentation times, where the relative demands on the binding component are arguably larger. Given that binding processes establish memory traces, these group differences may be interpreted in terms of more functional binding processes in children relative to older adults. Similarly, the stronger phasestability observed in older adults (Sander et al., 2012) may point to less distinct representations brought about by aging-related binding impairments in older adults (cf. Craik, 2006). In addition, the age-differential contribution of the two components and their interaction may be inferred from the age-differential patterns observed for the CDA (Sander et al., 2011b). Previous studies suggest that the CDA can be considered as an online marker of WM content in terms of number of items currently maintained (Ikkai et al., 2010; McCollough et al., 2007). Interestingly, recent evidence nevertheless points to the influence of binding processes and topdown control on the CDA. For example, CDA amplitudes reach their asymptote for complex stimuli earlier than for simple stimuli (Gao et al., 2009; see also Luria et al., 2009). The observation that the CDA varies as a function of stimulus characteristics suggests that its amplitude may be related to the efficiency of binding features into compound objects. Furthermore, the CDA is closely related to attentional processes (Drew and Vogel, 2008; Emrich et al., 2009) and intact prefrontal control (Voytek and Knight, 2010).

In light of these considerations and the observed age-differential patterns in relation to behavioral measures, we proposed that the CDA reflects the successful interplay between binding and control processes, and not just the content of WM per se. By relating the observed age differences in load- and time-dependent CDA modulations to previous evidence, the results can be interpreted as signatures of lifespan changes in the interaction between binding and control processes.

\subsection{Contributions of a lifespan perspective to theoretical models of WM}

How does a lifespan perspective on working memory contribute to the ongoing debate about the nature of WM capacity limits? Currently, two contrasting positions dominate the discussion: The slot model of WM assumes that the maximum number of objects that can be held in memory defines the WM capacity limit (Anderson et al., 2011; Barton et al., 2009; Cowan, 2001; Luck and Vogel, 1997; Rouder et al., 2008; Zhang and Luck, 2008). This view competes with the flexible resource model (Bays et al., 2009, 2011; Bays and Husain, 2008; Fougnie et al., 2010; Huang, 2010; Wilken and Ma, 2004), according to which capacity limits derive from a fixed amount of a common resource that can be flexibly distributed among items maintained in WM. This model assumes that the fidelity or precision of representations will diminish with increasing set size. Both this debate and the closely related discussion about the nature of WM representations has not been settled so far, and evidence for either view has been reported.

The nature of WM representations has originally been investigated by means of behavioral studies using the change detection paradigm. In their seminal work, Luck and Vogel (1997; see also Vogel et al., 2001) investigated WM capacity for objects and features. For example, they compared performance in the change detection task under a condition in which an observer had to memorize four simple uni-colored objects compared to four bi-colored objects, thus eight features. They observed that additional features can be maintained at no performance cost. Based on a series of experiments, they came to the conclusion that WM contains objects rather than features and that the WM capacity limit is defined in terms of the number of objects to be memorized. They suggested that the underlying mechanism of the object-based limit could be neural synchronization (Singer and Gray, 1995). Accordingly, multiple features can be maintained in WM provided that they can be bound together to form integrated objects.

This view of object-based limits in WM has been challenged, as several studies failed to replicate these findings (e.g., Delvenne and Bruyer, 2004; Parra et al., 2009; Wheeler and Treisman, 2002). Also, if the number of objects determines the upper limit of WM, the definition of what constitutes an object becomes critical. Some studies point to a close relation between the complexity of the presented items and WM capacity. For example, Alvarez and Cavanagh (2004) measured the "visual information load" of different object classes by their respective visual search rate. They found that WM capacity varied substantially across objects, that is, the greater the information load, the fewer items of that class could be held in memory. In a similar vein, using a change detection task, Eng et al. (2005) observed a decrease in WM capacity for more complex stimuli. This effect was attenuated by the use of longer presentation times. The authors concluded that perceptual complexity affects WM capacity but does not solely determine it. Nevertheless, these findings suggest that the complexity of representations strongly influences WM performance (but see Awh et al., 2007).

At the neurophysiological level, classic studies on the CDA have provided support for the fixed slot model, as the level of CDA amplitudes reaches an asymptote at about four items (Anderson et al., 2011; McCollough et al., 2007; Vogel and Machizawa, 2004). However, the influence of top-down control on different WM performance markers in change detection tasks raises doubts about the fixed slot model (see above). In addition, recent studies observing effects of object complexity on CDA amplitudes (Gao et al., 2009; Luria et al., 2009) challenge this view and suggest that binding processes may critically contribute to WM performance. In line with lower behavioral performance for more complex than for simple objects (Alvarez and Cavanagh, 2004; Eng et al., 2005), the CDA reached an asymptote at a load of only two items for complex items in these studies. Contrary to the assumptions of a purely object-based model of WM, these results suggest WM performance may also depend on the amount of resources needed for the representation of individual objects. Complex objects may consume more "storage capacity" (Gao et al., 2009) because they are made up of several features that have to be bound together to build a coherent representation (Treisman and Zhang, 2006; Wheeler and Treisman, 2002). To critically examine this view, Luria and Vogel (2011) investigated differences in CDA amplitudes for single objects (e.g., a colored square) and conjunctions of features (e.g., a bi-colored square). The authors observed large conjunction costs behaviorally that were accompanied by higher CDA amplitudes for the conjunction condition relative to the single feature condition during the initial part of the retention interval (450-600 ms poststimulus). The authors argue that the dissipation of this difference for later parts of the retention interval $(750-1000 \mathrm{~ms})$ speaks for the maintenance of fully integrated objects in WM once the relevant binding operations have been completed. Unfortunately, the authors did not include task conditions with more than two conjunction objects so that load-dependent modulations of the CDA above the previously observed limit for complex objects were not investigated. In any case, the results obtained by Gao et al. (2009), Luria et al. (2009) as well as Luria and Vogel (2011) may document the contribution of binding processes to WM performance.

Regardless of whether features are bound completely prior to the maintenance process proper such that only integrated objects are maintained, or whether features are loosely integrated and 
separately maintained in WM, the discussion suggests that the integration of features into compound representations through binding mechanisms is a key function of WM, and that these compound representations correspond to what is subjectively experienced as a perceived or remembered object. In addition to binding processes related to feature binding within objects, binding processes between objects (e.g., in terms of relational information) have also been shown to influence WM performance in change detection tasks (Jiang et al., 2004, 2000).

How do our results contribute to this discussion? First, we observed that visual WM capacity, as measured by the $k$-score, varies within individuals as a function of presentation time. This observation suggests that visual WM capacity limits are not fixed, but depend on the more or less complete execution of a series of processing steps (Sander et al., 2011a,b). Second, the relations of CDA amplitudes to load and presentation time differed between children, younger adults, and older adults, supporting the theoretical proposition that both binding and control processes might influence this component (Sander et al., 2011b). Third, we provided support for the prior assumption that inhibition processes related to alpha oscillations critically support visual WM performance (Sander et al., 2012). Thus, the empirical evidence from our lab suggests that multiple processes jointly limit visual WM performance.

These observations call for the development of an intermediate view that contains elements of both the fixed slot and the flexible resource accounts. According to this view, a limited number of slots may determine the maximum number of representations held in memory, whereas available resources determine the representational resolution of individual items (Barton et al., 2009; for a recent review see Fukuda et al., 2010a; Zhang and Luck, 2008). Computational models have suggested that theta-phase-locked gamma oscillations provide a temporal coding scheme for WM maintenance (Jensen and Lisman, 1996; Lisman and Idiart, 1995). According to these models, WM capacity is predicted by the ratio of theta to gamma cycles. The upper limit of the possible numbers of items defined by this ratio conditions the potential for successful binding of within-objects features. This suggestion is closely related to the "weak object hypothesis" (Olson and Jiang, 2002), which assumes that WM may be limited by the number of features, but that binding of information into integrated objects may alleviate this limitation. Future research needs to clarify whether number of objects and resolution are two fully orthogonal factors that determine WM performance (e.g., Fukuda et al., 2010b) or whether they are correlated and can be traded against each other.

\section{Questions for future research}

In this article, we suggested a two-component framework of visual-spatial WM to integrate neural and behavioral evidence on age-graded differences and changes in the mechanisms supporting WM performance from childhood to old age. Our framework is not meant to lead to an entirely new theory of visual WM. However, our framework provides a general heuristic for deriving age-comparative research questions that are informed by recent advances in the cognitive neuroscience of working memory, and that may in turn contribute to further advances in the field. In the following, we illustrate the heuristic utility of the framework with a selection of research questions that await further study.

The first question concerns the scope of the proposed framework. So far, the available studies investigating children and older adults within the same WM paradigm all used a visual changedetection paradigm. Thus, the framework has to be tested in other domains of WM, such as auditory and, in particular, verbal WM (Baddeley and Logie, 1999). It is well known that WM processing varies, inevitably, by modality and domain. For instance, the processing of visual stimuli is more likely to activate occipital brain regions, whereas the processing of auditory is more likely to activate temporal regions. At the same time, available empirical evidence and neural theories suggest that some of the basic mechanisms of neural information processing supporting WM generalize across modalities and domains. In particular, evidence from different modalities and domains strongly support the general proposition that incoming information is coded in neural firing rates that are synchronized to represent, transmit, and maintain coherent representations of that information. Binding mechanisms of this kind have been observed in both visual and auditory modalities (e.g. Bertrand and Tallon-Baudry, 2000). Analogous observations seem to hold in relation to top-down control mechanisms of selection and maintenance in memory. For example, with respect to the contribution of alpha oscillations to inhibitory processes in WM, recent reviews stress similarities in signature and function across domains (Weisz et al., 2011). Thus, at least some of the mechanisms involved in WM may generalize across modalities and domains. Future studies need to investigate the extent to which these mechanisms act as domain-general pacemakers of age-graded changes in WM.

Another important question for future research concerns the differentiation and specification of the two components, and of the interactions between them. Cognitive theories have identified rehearsal and refreshing mechanisms as key processes of WM performance (Baddeley and Logie, 1999). In line with others (e.g. Awh and Jonides, 2001; Repovs and Baddeley, 2006) we would argue that rehearsal in visual-spatial WM is an attention-based mechanism serving the maintenance of information. One way to rehearse information in WM is to shift attention over spatial locations. Another way is to direct attention to a memory item (Zimmer, 2008), also referred to as "refreshing" (Raye et al., 2002). Neuroimaging studies have related the initiation of refreshing processes to anterior PFC, and the refreshing process itself to increased activity in dorsolateral PFC (Raye et al., 2007). Modulatory effects of refreshing have been observed in posterior (e.g., stimulus-specific) regions (Johnson and Johnson, 2009; Johnson et al., 2007). Studying the mechanisms of refreshing in an age-comparative setting will directly contribute to a better understanding of this aspect of topdown control. Such studies would shed light on the spontaneous use of rehearsal/refreshing mechanisms, and on the efficiency of these mechanisms in different age groups (for relevant behavioral evidence, see Schneider et al., 2009). The efficiency of top-down control may depend on the quality of the representations, pointing to interactions between the two components (see Mitchell et al., 2010, for a study on refreshing with older adults). Likewise, further conceptual and empirical refinement of the binding component may inform age comparisons, especially in relation to the exploration of age differences at different "levels of binding" (Craik, 2006), such as intra-item binding, inter-item binding, and temporal ordering (for behavioral aging studies of binding in visual WM, see Brockmole et al., 2008; Parra et al., 2009).

Similarly, the role of the parietal cortex in the context of lifespan research and the two-component framework of visual memory awaits clarification. The parietal cortices are likely to critically contribute to the interaction between frontal and posterior parts of the brain, and thus for the two components suggested in our framework. In particular, the IPS is often considered as an attentional modulator of distant neural networks (Majerus et al., 2007) and seems to be involved in WM processes in different modalities and domains (Cowan et al., 2011; Majerus et al., 2010). Recent evidence suggests that the parietal cortex links the operation of a supramodal attention system to modality-specific processes, pointing to a hybrid or relay role for this area (Banerjee et al., 2011). Future age-comparative studies need to elucidate the function of the 
parietal lobe in the interaction between binding and top-down control component. In children, white-matter microstructural properties of the superior longitudinal fasciculus (SLF), which connects parietal and lateral prefrontal cortices, have been found to relate verbal WM performance (Ostby et al., 2011) and spatial WM performance (Vestergaard et al., 2011). Similarly, the cortical thickness of the parietal lobe and of lateral PFC has been related to WM performance (Ostby et al., 2011), again in children. Thus, the protracted maturational time course of the parietal region seems to support the claim that the interaction between top-down control and posterior brain regions functions less efficiently in children up to early adolescence than in younger adults. However, we note that the contributions of structural changes in parietal regions and associated fiber tracts to functional and behavioral changes in WM remain to be explored.

In addition to delineating age-related differences and changes in the structure and function of individual regions, developmental alterations in the dynamic interplay among the various nodes of the WM network need to be examined in greater detail. Measures of functional connectivity may offer a useful tool for elucidating the relevance of age-graded changes in the interaction of the two components for WM performance. Initial studies of this kind point to profound developmental differences in the configuration and recruitment of brain networks in childhood (e.g., Hwang et al., 2010; Jolles et al., 2011) and adulthood (e.g., Andrews-Hanna et al., 2007; Damoiseaux et al., 2008). Developmental changes in childhood seem to reflect a decrease in short-range connections and an increase in large-scale connections (e.g., Fair et al., 2009, 2007). With respect to changes from childhood to late adolescence and early adulthood, the two-component model proposed in this article leads to the prediction that more posterior binding mechanisms are increasingly brought under control by frontal top-down mechanisms as children grow older.

With respect to changes from early adulthood to late adulthood and advanced old age, predictions are less straightforwards, as they need to accommodate the large heterogeneity of WM functioning in old age (Lindenberger et al., in press; Nyberg et al., 2012). Generally, normal aging seems to result in a decrease of longrange connections between frontal and posterior brain regions (e.g., Andrews-Hanna et al., 2007; Damoiseaux et al., 2008), and to increased connectivity between hitherto less connected brain areas (e.g. Cook et al., 2007). Similar to other recent theorires of WM (Cappell et al., 2010), the two-component framework of working memory posits that the configuration of functional interactions between frontal and posterior depends on task difficulty and individual performance level (e.g., processing ressources; cf. Kinsbourne and Hicks, 1978). In addition to more local changes, normal aging may compromise the ability to make use of longrange connections for implementing task-relevant interactions between feature binding and top-down control. The onset and degrees of such deleterious system-general changes may differ widely across individuals (e.g., Nyberg et al., 2012; cf. Garrett et al., 2012), and their influence on the functional dynamics of the WM network remains to be explored.

A related promising future research line focuses on the investigation of age-related changes in oscillatory mechanisms of information processing. The available evidence from studies with younger adults has provided convincing evidence for the crucial role of temporal synchronization in higher cognition (e.g., Axmacher et al., 2006; Buzsaki and Draguhn, 2004; Canolty and Knight, 2010; Jensen and Mazaheri, 2010; Klimesch et al., 2007; Sauseng et al., 2010), and has underscored the need to articulate age-graded changes in large-scale and local network properties (cf. McIntosh et al., 2010). What remains unclear is how functional changes in the various frequency bands relate to the early development and later decline of different cognitive functions. In particular, the interplay between faster and slower frequencies in the coordination of top-down and bottom-up influences (Canolty and Knight, 2010; Palva and Palva, 2007; von Stein and Sarnthein, 2000) remains to be addressed in age-comparative studies. Evidence based on samples of younger adults suggests that the ratio of theta-gamma coupling is closely related to the observed capacity limit in WM (Axmacher et al., 2010; Sauseng et al., 2009). So far, it is not known whether lower WM performance in children and older adults is due to changes in oscillatory activity in either theta, or gamma frequency, the precision of their coupling, or both. This question needs to be addressed with appropriate statistical methods in future studies (for a review of available synchronization measures, see Sauseng and Klimesch, 2008).

\section{Conclusion}

The goal of this review was to advance the understanding of lifespan changes in WM performance by taking differential effects of maturation and senescence on different brain regions and their interactions into consideration. We reported behavioral and EEG evidence from our own lab that aimed to track the ontogeny of top-down control and binding processes in WM across the lifespan.

In this article, the review of the literature substantiates the general proposition that children and older adults differ in the efficiency, relative contributions, and temporal dynamics of topdown control and binding to WM, despite behavioral similarities between the two groups. This line of reasoning exemplifies the lifespan-psychological postulate that aging is not a reversal of child development (Craik and Bialystok, 2006), and that the cortical functional circuitries underlying cognitive performance differ between children, younger adults, and older adults, reflecting lifespan changes in the relative contributions and interactions among mechanisms of maturation, learning, and senescence (Lindenberger et al., 2007; Werkle-Bergner et al., 2006). Only few integrated accounts of lifespan changes in cognition exist (e.g., Baltes et al., 2006, 1999; Craik and Bialystok, 2006; Lindenberger, 2001; McIntosh et al., 2010; Salthouse, 1996; Shing and Lindenberger, 2011; Shing et al., 2010, 2008). Accordingly, the behavioral neuroscience and cognitive psychology of child development and aging rarely make contact with each other. Integration of theories from both ends of the lifespan offers the opportunity to provide new insights for the respective areas. More importantly, one may argue that such integration also advances our understanding of cognition in general. According to this view, a comprehensive account of brain and behavior requires an understanding of age-graded brain changes, behavioral changes, and changes in brain-behavior relations (e.g., Elman et al., 1996; Molenaar, 1986). This perspective has informed the present review, which has aimed to strengthen the links between general theories of cognition, behavioral neuroscience, and lifespan research.

\section{Acknowledgments}

This research was conducted within the project 'Cognitive and Neural Dynamics of Memory across the Lifespan (ConMem)' of the Max Planck Institute for Human Development, Center for Lifespan Psychology. The Max Planck Society and the German Research Foundation (DFG, HE 3347/3-1) financially supported the research. This article was written in the context of the doctoral dissertation of MCS, who was also a member of the Berlin School of Mind and Brain, Berlin, Germany. UL is supported by the Gottfried Wilhelm Leibniz prize of the Deutsche Forschungsgemeinschaft.

We thank Julia Delius for editorial assistance, and Yee Lee Shing, Yana Fandakova, Roman Freunberger, and Thomas Grandy for valuable discussions. 


\section{References}

Alvarez, G.A., Cavanagh, P., 2004. The capacity of visual short-term memory is set both by visual information load and by number of objects. Psychological Science $15,106-111$.

Anderson, D.E., Vogel, E.K., Awh, E., 2011. Precision in visual working memory reaches a stable plateau when individual item limits are exceeded. Journal of Neuroscience 31, 1128-1138.

Andrews-Hanna, J.R., Snyder, A.Z., Vincent, J.L., Lustig, C., Head, D., Raichle, M.E., Buckner, R.L., 2007. Disruption of large-scale brain systems in advanced aging. Neuron 56, 924-935.

Astle, D.E., Scerif, G., 2011. Interactions between attention and visual short-term memory (VSTM): what can be learnt from individual and developmental differences? Neuropsychologia 49, 1435-1445.

Awh, E., Barton, B., Vogel, E.K., 2007. Visual working memory represents a fixed number of items regardless of complexity. Psychological Science 18, 622-628.

Awh, E., Jonides, J., 2001. Overlapping mechanisms of attention and spatial working memory. Trends in Cognitive Sciences 5, 119-126.

Axmacher, N., Henseler, M.M., Jensen, O., Weinreich, I., Elger, C.E., Fell, J., 2010. Cross-frequency coupling supports multi-item working memory in the human hippocampus. Proceedings of National Academy of Sciences of the United States of America 107, 3228-3233.

Axmacher, N., Mormann, F., Fernandez, G., Elger, C.E., Fell, J., 2006. Memory formation by neuronal synchronization. Brain Research Reviews 52, 170-182.

Babiloni, C., Babiloni, F., Carducci, F., Cappa, S.F., Cincotti, F., Del Percio, C., Miniussi, C., Vito Moretti, D., Rossi, S., Sosta, K., Rossini, P.M., 2004. Human cortical rhythms during visual delayed choice reaction time tasks: a high-resolution EEG study on normal aging. Behavioural Brain Research 153, 261-271.

Bäckman, L., Nyberg, L., Lindenberger, U., Li, S.C., Farde, L., 2006. The correlative triad among aging, dopamine, and cognition: current status and future prospects. Neuroscience and Biobehavioral Reviews 30, 791-807.

Baddeley, A., 2003. Working memory: looking back and looking forward. Nature Reviews Neuroscience 4,829-839.

Baddeley, A., Logie, R.H., 1999. Working memory: the multiple-component model. In: Miyake, A., Shah, P. (Eds.), Models of Working Memory: Mechanisms of Active Maintenance and Executive Control. Cambridge University Press, New York, pp. 28-61.

Bahramisharif, A., van Gerven, M., Heskes, T., Jensen, O., 2010. Covert attention allows for continuous control of brain-computer interfaces. European Journal of Neuroscience 31, 1501-1508.

Baier, B., Karnath, H.O., Dieterich, M., Birklein, F., Heinze, C., Muller, N.G., 2010. Keeping memory clear and stable - the contribution of human basal ganglia and prefrontal cortex to working memory. Journal of Neuroscience 30, 9788-9792.

Baltes, P.B., Lindenberger, U., 1997. Emergence of a powerful connection between sensory and cognitive functions across the adult life span: a new window to the study of cognitive aging? Psychology and Aging 12, 12-21.

Baltes, P.B., Lindenberger, U., Staudinger, U.M., 2006. Life span theory in developmental psychology. In: Damon, W., Lerner, R.M. (Eds.), Handbook of Child Psychology. Theoretical Models of Human Development, vol. 1. Wiley, New York, pp. 569-664.

Baltes, P.B., Staudinger, U.M., Lindenberger, U., 1999. Lifespan psychology: theory and application to intellectual functioning. Annual Review of Psychology 50, 471-507.

Banerjee, S., Snyder, A.C., Molholm, S., Foxe, J.J., 2011. Oscillatory alpha-band mechanisms and the deployment of spatial attention to anticipated auditory and visual target locations: supramodal or sensory-specific control mechanisms? Journal of Neuroscience 31, 9923-9932.

Bar, M., 2003. A cortical mechanism for triggering top-down facilitation in visual object recognition. Journal of Cognitive Neuroscience 15, 600-609.

Barrouillet, P., Camos, V., 2007. The time-based resource-sharing model of working meory. In: Osaka, N., Logie, R.H., D’Esposito, M. (Eds.), The Cognitive Neuroscience of Working Memory. Oxford University Press, Oxford, UK, pp. 59-80.

Barton, B., Ester, E.F., Awh, E., 2009. Discrete resource allocation in visual working memory. Journal of Experimental Psychology: Human Perception and Performance 35, 1359-1367.

Basar-Eroglu, C., Brand, A., Hildebrandt, H., Kedzior, K., Mathes, B., Schmiedt, C., 2007. Working memory related gamma oscillations in schizophrenia patients. International Journal of Psychophysiology 64, 39-45.

Bays, P.M., Catalao, R.F., Husain, M., 2009. The precision of visual working memory is set by allocation of a shared resource. Journal of Vision 9 (7), 1-11.

Bays, P.M., Husain, M., 2008. Dynamic shifts of limited working memory resources in human vision. Science 321, 851-854.

Bays, P.M., Wu, E.Y., Husain, M., 2011. Storage and binding of object features in visual working memory. Neuropsychologia 49, 1622-1631.

Bergfield, K.L., Hanson, K.D., Chen, K., Teipel, S.J., Hampel, H., Rapoport, S.I., Moeller, J.R., Alexander, G.E., 2010. Age-related networks of regional covariance in MRI gray matter: reproducible multivariate patterns in healthy aging. NeuroImage 49, 1750-1759.

Berry, A.S., Zanto, T.P., Rutman, A.M., Clapp, W.C., Gazzaley, A., 2009. Practice-related improvement in working memory is modulated by changes in processing external interference. Journal of Neurophysiology 102, 1779-1789.

Bertrand, O., Tallon-Baudry, C., 2000. Oscillatory gamma activity in humans: a possible role for object representation. International Journal of Psychophysiology 38, 211-223.

Borella, E., Carretti, B., De Beni, R., 2008. Working memory and inhibition across the adult life-span. Acta Psychologica 128, 33-44.
Brahmbhatt, S.B., White, D.A., Barch, D.M., 2010. Developmental differences in sustained and transient activity underlying working memory. Brain Research 1354, $140-151$.

Brockmole, J.R., Parra, M., Della Sala, S., Logie, R.H., 2008. Do binding deficits account for age-related decline in visual working memory? Psychonomic Bulletin and Review 15, 543-547.

Bressler, S.L., Kelso, J.A., 2001. Cortical coordination dynamics and cognition. Trends in Cognitive Sciences 5, 26-36.

Brookes, M.J., Wood, J.R., Stevenson, C.M., Zumer, J.M., White, T.P., Liddle, P.F., Morris, P.G., 2011. Changes in brain network activity during working memory tasks: a magnetoencephalography study. NeuroImage 55, 1804-1815.

Bundesen, C., 1990. A theory of visual attention. Psychological Review 97, 523-547.

Bundesen, C., Habekost, T., Kyllingsbaek, S., 2005. A neural theory of visual attention: bridging cognition and neurophysiology. Psychological Review 112, 291-328.

Bunge, S.A., Dudukovic, N.M., Thomason, M.E., Vaidya, C.J., Gabrieli, J.D., 2002. Immature frontal lobe contributions to cognitive control in children: evidence from fMRI. Neuron 33, 301-311.

Bunge, S.A., Wright, S.B., 2007. Neurodevelopmental changes in working memory and cognitive control. Current Opinion in Neurobiology 17, 243-250.

Buzsaki, G., Draguhn, A., 2004. Neuronal oscillations in cortical networks. Science 304, 1926-1929.

Cabeza, R., Anderson, N.D., Locantore, J.K., McIntosh, A.R., 2002. Aging gracefully: compensatory brain activity in high-performing older adults. Neurolmage 17, 1394-1402.

Cabeza, R., Daselaar, S.M., Dolcos, F., Prince, S.E., Budde, M., Nyberg, L., 2004. Taskindependent and task-specific age effects on brain activity during working memory, visual attention and episodic retrieval. Cerebral Cortex 14, 364-375.

Cabeza, R., Nyberg, L., Park, D.C., 2005. Cognitive neuroscience of aging: linking cognitive and cerebral aging. Oxford University Press, New York.

Canolty, R.T., Edwards, E., Dalal, S.S., Soltani, M., Nagarajan, S.S., Kirsch, H.E., Berger, M.S., Barbaro, N.M., Knight, R.T., 2006. High gamma power is phase-locked to theta oscillations in human neocortex. Science 313, 1626-1628.

Canolty, R.T., Knight, R.T., 2010. The functional role of cross-frequency coupling. Trends in Cognitive Sciences 14, 506-515.

Cantero, J.L., Atienza, M., Cruz-Vadell, A., Suarez-Gonzalez, A., Gil-Neciga, E., 2009. Increased synchronization and decreased neural complexity underlie thalamocortical oscillatory dynamics in mild cognitive impairment. Neurolmage 46, 938-948.

Capotosto, P., Babiloni, C., Romani, G.L., Corbetta, M., 2009. Frontoparietal cortex controls spatial attention through modulation of anticipatory alpha rhythms. Journal of Neuroscience 29, 5863-5872.

Cappell, K.A., Gmeindl, L., Reuter-Lorenz, P.A., 2010. Age differences in prefontal recruitment during verbal working memory maintenance depend on memory load. Cortex 46, 462-473.

Carp, J., Gmeindl, L., Reuter-Lorenz, P.A., 2010. Age differences in the neural representation of working memory revealed by multi-voxel pattern analysis. Frontiers in Human Neuroscience 4, 217.

Carp, J., Park, J., Polk, T.A., Park, D.C., 2011. Age differences in neural distinctiveness revealed by multi-voxel pattern analysis. NeuroImage $56,736-743$.

Casey, B.J., Cohen, J.D., Jezzard, P., Turner, R., Noll, D.C., Trainor, R.J., Giedd, J., Kaysen, D., Hertz-Pannier, L., Rapoport, J.L., 1995. Activation of prefrontal cortex in children during a nonspatial working memory task with functional MRI. Neurolmage 2, 221-229.

Chee, M.W., Goh, J.O., Venkatraman, V., Tan, J.C., Gutchess, A., Sutton, B., Hebrank, A., Leshikar, E., Park, D., 2006. Age-related changes in object processing and contextual binding revealed using fMR adaptation. Journal of Cognitive Neuroscience 18, 495-507.

Ciesielski, K.T., Ahlfors, S.P., Bedrick, E.J., Kerwin, A.A., Hamalainen, M.S., 2010. Topdown control of MEG alpha-band activity in children performing categorical n-back task. Neuropsychologia 48, 3573-3579.

Ciesielski, K.T., Lesnik, P.G., Savoy, R.L., Grant, E.P., Ahlfors, S.P., 2006. Developmental neural networks in children performing a categorical n-back zask. NeuroImage 33, 980-990.

Clapp, W.C., Rubens, M.T., Gazzaley, A., 2010. Mechanisms of working memory disruption by external interference. Cerebral Cortex 20, 859-872.

Conklin, H.M., Luciana, M., Hooper, C.J., Yarger, R.S., 2007. Working memory performance in typically developing children and adolescents: behavioral evidence of protracted frontal lobe development. Devlopmental Neuropsycholgy 31, 103-128.

Cook, I.A., Bookheimer, S.Y., Mickes, L., Leuchter, A.F., Kumar, A., 2007. Aging and brain activation with working memory tasks: an fMRI study of connectivity. International Journal of Geriatric Psychiatry 22, 332-342.

Corbetta, M., Patel, G., Shulman, G.L., 2008. The reorienting system of the human brain: From environment to theory of mind. Neuron 58, 306-324.

Cowan, N., 2001. The magical number 4 in short-term memory: a reconsideration of mental storage capacity. Behavioral and Brain Sciences 24, 87-114 (Discussion 114-185).

Cowan, N., Elliott, E.M., Scott Saults, J., Morey, C.C., Mattox, S., Hismjatullina, A., Conway, A.R., 2005. On the capacity of attention: its estimation and its role in working memory and cognitive aptitudes. Cognitive Psychology 51, 42-100.

Cowan, N., Li, D., Moffitt, A., Becker, T.M., Martin, E.A., Saults, J.S., Christ, S.E., 2011. A neural region of abstract working memory. Journal of Cognitive Neuroscience 23, 2852-2863.

Cowan, N., Morey, C.C., AuBuchon, A.M., Zwilling, C.E., Gilchrist, A.L., 2010. Sevenyear-olds allocate attention like adults unless working memory is overloaded. Developmental Science 13, 120-133. 
Cowan, N., Naveh-Benjamin, M., Kilb, A., Saults, J.S., 2006. Life-span development of visual working memory: when is feature binding difficult? Developmental Psychology 42, 1089-1102.

Craik, F.I., 2006. Remembering items and their contexts: effects of ageing and divided attention. In: Zimmer, H.D., Mecklinger, A., Lindenberger, U. (Eds.), Handbook of Binding and Memory: Perspectives from Cognitive Neuroscience. Oxford University Press, Oxford, pp. 571-594.

Craik, F.I., Bialystok, E., 2006. Cognition through the lifespan: mechanisms of change. Trends in Cognitive Sciences 10, 131-138.

Crone, E.A., Wendelken, C., Donohue, S., van Leijenhorst, L., Bunge, S.A., 2006. Neurocognitive development of the ability to manipulate information in working memory. Proceedings of National Academy of Sciences of the United States of America 103, 9315-9320.

Culham, J.C., Cavanagh, P., Kanwisher, N.G., 2001. Attention response functions: characterizing brain areas using fMRI activation during parametric variations of attentional load. Neuron 32, 737-745.

Cummins, T.D., Finnigan, S., 2007. Theta power is reduced in healthy cognitive aging. International Journal of Psychophysiology 66, 10-17.

Curtis, C.E., 2006. Prefrontal and parietal contributions to spatial working memory. Neuroscience 139, 173-180.

Curtis, C.E., D’Esposito, M., 2003. Persistent activity in the prefrontal cortex during working memory. Trends in Cognitive Sciences 7, 415-423.

Cusack, R., Lehmann, M., Veldsman, M., Mitchell, D.J., 2009. Encoding strategy and not visual working memory capacity correlates with intelligence. Psychonomic Bulletin and Review 16, 641-647.

Cusack, R., Mitchell, D.J., Duncan, J., 2010. Discrete object representation, attention switching, and task difficulty in the parietal lobe. Journal of Cognitive Neuroscience 22, 32-47.

D'Esposito, M., 2007. From cognitive to neural models of working memory. Philosophical Transactions of the Royal Society of London B: Biological Sciences 362, 761-772.

D'Esposito, M., Postle, B.R., Ballard, D., Lease, J., 1999. Maintenance versus manipulation of information held in working memory: an event-related fMRI study. Brain and Cognition 41, 66-86.

Damoiseaux, J.S., Beckmann, C.F., Sanz Arigita, E.J., Barkhof, F., Scheltens, Ph., Stam, C.J., Smith, S.M., Rombouts, S.A.R.B., 2008. Reduced resting-state brain activity in the "default network" in normal aging. Cerebral Cortex 18, 1856-1864.

Daselaar, S.M., Fleck, M.S., Dobbins, I.G., Madden, D.J., Cabeza, R., 2006. Effects of healthy aging on hippocampal and rhinal memory functions: an event-related fMRI study. Cerebral Cortex 16, 1771-1782.

Davis, S.W., Dennis, N.A., Daselaar, S.M., Fleck, M.S., Cabeza, R., 2008. Que PASA? The posterior-anterior shift in aging. Cerebral Cortex 18, 1201-1209.

de Fockert, J.W., Ramchurn, A., van Velzen, J., Bergstrom, Z., Bunce, D., 2009. Behavioral and ERP evidence of greater distractor processing in old age. Brain Research 1282, 67-73.

de Frias, C.M., Lovden, M., Lindenberger, U., Nilsson, L.-G., 2007. Revisiting the dedifferentiation hypothesis with longitudinal multi-cohort data. Intelligence 35, 381-392.

Deiber, M.P., Rodriguez, C., Jaques, D., Missonnier, P., Emch, J., Millet, P., Gold, G., Giannakopoulos, P., Ibanez, V., 2010. Aging effects on selective attentionrelated electroencephalographic patterns during face encoding. Neuroscience $171,173-186$.

Delvenne, J.-F., Bruyer, R., 2004. Does visual short-term memory store bound features? Visual Cognition 11, 1-27.

Demiralp, T., Bayraktaroglu, Z., Lenz, D., Junge, S., Busch, N.A., Maess, B., Ergen, M., Herrmann, C.S., 2007. Gamma amplitudes are coupled to theta phase in human EEG during visual perception. International Journal of Psychophysiology 64, 24-30.

Dempster, F.N., 1992. The rise and fall of the inhibitory mechanism: toward a unified theory of cognitive development and aging. Developmental Review 12, 45-75.

Desimone, R., Duncan, J., 1995. Neural mechanisms of selective visual attention. Annual Review of Neuroscience 18, 193-222.

Diamond, A., 2002. Normal development of prefrontal cortex from birth to young adulthood: cognitive functions, anatomy, and biochemistry. In: Stuss, D.T., Knight, R.T. (Eds.), Principles of Frontal Lobe Function. Oxford University Press, London, UK, pp. 466-503.

Doesburg, S.M., Green, J.J., McDonald, J.J., Ward, L.M., 2009. From local inhibition to long-range integration: a functional dissociation of alpha-band synchronization across cortical scales in visuospatial attention. Brain Research 1303, 97-110.

Doesburg, S.M., Herdman, A.T., Ribary, U., Cheung, T., Moiseev, A., Weinberg, H. Liotti, M., Weeks, D., Grunau, R.E., 2010. Long-range synchronization and local desynchronization of alpha oscillations during visual short-term memory retention in children. Experimental Brain Research 201, 719-727.

Drew, T., Vogel, E.K., 2008. Neural measures of individual differences in selecting and tracking multiple moving objects. Journal of Neuroscience 28, 4183-4191.

Dustman, R.E., Shearer, D.E., Emmerson, R.Y., 1993. EEG and event-related potentials in normal aging. Progress in Neurobiology 41, 369-401.

Dustman, R.E., Shearer, D.E., Emmerson, R.Y., 1999. Life-span changes in EEG spectral amplitude, amplitude variability and mean frequency. Clinical Neurophysiology 110, 1399-1409.

Edin, F., Klingberg, T., Johansson, P., McNab, F., Tegner, J., Compte, A., 2009. Mechanism for top-down control of working memory capacity. Proceedings of National Academy of Sciences of the United States of America 106, 6802-6807.

Edin, F., Macoveanu, J., Olesen, P., Tegner, J., Klingberg, T., 2007. Stronger synaptic connectivity as a mechanism behind development of working memory-related brain activity during childhood. Journal of Cognitive Neuroscience 19, 750-760.
Eimer, M., Kiss, M., 2010. An electrophysiological measure of access to representations in visual working memory. Psychophysiology 47, 197-200.

Elman, J.L., Bates, E.A., Johnson, M.H., Karmiloff-Smith, A., Parisi, D., Plunkett, K. 1996. Rethinking Innateness: a Connectionist Perspective on Development. MIT Press, Cambridge, MA.

Emrich, S.M., Al-Aidroos, N., Pratt, J., Ferber, S., 2009. Visual search elicits the electrophysiological marker of visual working memory. PLoS One 4, e8042.

Eng, H.Y., Chen, D., Jiang, Y., 2005. Visual working memory for simple and complex visual stimuli. Psychonomic Bulletin and Review 12, 1127-1133.

Engel, A.K., Fries, P., Konig, P., Brecht, M., Singer, W., 1999. Temporal binding, binocular rivalry, and consciousness. Consciousness and Cognition 8, 128-151.

Engel, A.K., Fries, P., Singer, W., 2001. Dynamic predictions: oscillations and synchrony in top-down processing. Nature Reviews Neuroscience 2, 704-716.

Engle, R.W., 2002. Working memory capacity as executive attention. Current Directions in Psychological Science 11, 19-23.

Ester, E.F., Serences, J.T., Awh, E., 2009. Spatially global representations in human primary visual cortex during working memory maintenance. Journal of Neuroscience 29, 15258-15265.

Fair, D.A., Cohen, A.L., Power, J.D., Dosenbach, N.U., Church, J.A., Miezin, F.M., Schlaggar, B.L., Petersen, S.E., 2009. Functional brain networks develop from a local to distributed organization. PLoS Computational Biology 5, e1000381.

Fair, D.A., Dosenbach, N.U., Church, J.A., Cohen, A.L., Brahmbhatt, S., Miezin, F.M., Barch, D.M., Raichle, M.E., Petersen, S.E., Schlaggar, B.L., 2007. Development of distinct control networks through segregation and integration. Proceedings of National Academy of Sciences of the United States of America 104, 13507-13512.

Fell, J., Axmacher, N., 2011. The role of phase synchronization in memory processes. Nature Reviews Neuroscience 12, 105-118.

Finn, A.S., Sheridan, M.A., Kam, C.L., Hinshaw, S., D’Esposito, M., 2010. Longitudinal evidence for functional specialization of the neural circuit supporting working memory in the human brain. Journal of Neuroscience 30, 11062-11067.

Fougnie, D., Asplund, C.L., Marois, R., 2010. What are the units of storage in visual working memory? Journal of Vision 10, 27.

Freunberger, R., Fellinger, R., Sauseng, P., Gruber, W., Klimesch, W., 2009. Dissociation between phase-locked and nonphase-locked alpha oscillations in a working memory task. Human Brain Mapping 30, 3417-3425.

Freunberger, R., Werkle-Bergner, M., Griesmayr, B., Lindenberger, U., Klimesch, W., 2011. Brain oscillatory correlates of working memory constraints. Brain Research 1375, 93-102.

Fries, P., 2005. A mechanism for cognitive dynamics: neuronal communication through neuronal coherence. Trends in Cognitive Sciences 9, 474-480.

Fries, P., Scheeringa, R., Oostenveld, R., 2008. Finding gamma. Neuron 58, 303-305.

Fukuda, K., Awh, E., Vogel, E.K., 2010a. Discrete capacity limits in visual working memory. Current Opinion in Neurobiology 20, 177-182.

Fukuda, K., Vogel, E., Mayr, U., Awh, E., 2010b. Quantity, not quality: the relationship between fluid intelligence and working memory capacity. Psychonomic Bulletin and Review 17, 673-679.

Fukuda, K., Vogel, E.K., 2009. Human variation in overriding attentional capture. Journal of Neuroscience 29, 8726-8733.

Fuster, J.M., 2002. Frontal lobe and cognitive development. Journal of Neurocytology 31, 373-385.

Gao, Z., Li, J., Liang, J., Chen, H., Yin, J., Shen, M., 2009. Storing fine detailed information in visual working memory - evidence from event-related potentials. Journal of Vision 9, 17.

Garrett, D.D., Kovacevic, N., McIntosh, A.R., Grady, C.L., 2010. Blood oxygen leveldependent signal variability is more than just noise. Journal of Neuroscience 30 , 4914-4921.

Garrett, D.D., Kovacevic, N., McIntosh, A.R., Grady, C.L., 2012. The modulation of BOLD variability between cognitive states varies by age and processing speed. Cerebral Cortex (publisehd online March 14).

Gathercole, S.E., 1999. Cognitive approaches to the development of short-term memory. Trends in Cognitive Sciences 3, 410-419.

Gathercole, S.E., Pickering, S.J., Ambridge, B., Wearing, H., 2004. The structure of working memory from 4 to 15 years of age. Developmental Psychology 40, 177-190.

Gazzaley, A., 2011. Influence of early attentional modulation on working memory. Neuropsychologia 49, 1410-1424.

Gazzaley, A., Clapp, W., Kelley, J., McEvoy, K., Knight, R.T., D’Esposito, M., 2008 Age-related top-down suppression deficit in the early stages of cortical visual memory processing. Proceedings of National Academy of Sciences of the United States of America 105, 13122-13126.

Gazzaley, A., Cooney, J.W., McEvoy, K., Knight, R.T., D’Esposito, M., 2005a. Top-down enhancement and suppression of the magnitude and speed of neural activity. Journal of Cognitive Neuroscience 17, 507-517.

Gazzaley, A., Cooney, J.W., Rissman, J., D’Esposito, M., 2005b. Top-down suppression deficit underlies working memory impairment in normal aging. Nature Neuroscience 8, 1298-1300.

Gazzaley, A., D’Esposito, M., 2005. Bold functional MRI and cognitive aging. In: Cabeza, R., Nyberg, L., Park, D.C. (Eds.), Cognitive neuroscience of aging: linking cognitive and cerebral aging. Oxford University Press, Oxford.

Gazzaley, A., Rissman, J., Cooney, J., Rutman, A., Seibert, T., Clapp, W., D’Esposito, M., 2007. Functional interactions between prefrontal and visual association cortex contribute to top-down modulation of visual processing. Cerebral Cortex 17 (Suppl. 1), i125-i135.

Geier, C.F., Garver, K., Terwilliger, R., Luna, B., 2009. Development of working memory maintenance. Journal of Neurophysiology 101, 84-99. 
Gevins, A., Smith, M.E., McEvoy, L., Yu, D., 1997. High-resolution EEG mapping of cortical activation related to working memory: effects of task difficulty, type of processing, and practice. Cerebral Cortex 7, 374-385.

Ghetti, S., DeMaster, D.M., Yonelinas, A.P., Bunge, S.A., 2010. Developmental differences in medial temporal lobe function during memory encoding. Journal of Neuroscience 30, 9548-9556.

Giedd, J.N., Blumenthal, J., Jeffries, N.O., Castellanos, F.X., Liu, H., Zijdenbos, A., Paus, T., Evans, A.C., Rapoport, J.L., 1999. Brain development during childhood and adolescence: a longitudinal MRI study. Nature Neuroscience 2, 861-863.

Giorgio, A., Santelli, L., Tomassini, V., Bosnell, R., Smith, S., De Stefano, N., JohansenBerg, H., 2010. Age-related changes in grey and white matter structure throughout adulthood. NeuroImage 51, 943-951.

Gogtay, N., Giedd, J.N., Lusk, L., Hayashi, K.M., Greenstein, D., Vaituzis, A.C., Nugent 3rd, T.F., Herman, D.H., Clasen, L.S., Toga, A.W., Rapoport, J.L., Thompson, P.M., 2004. Dynamic mapping of human cortical development during childhood through early adulthood. Proceedings of National Academy of Sciences of the United States of America 101, 8174-8179.

Gold, J.M., Wilk, C.M., McMahon, R.P., Buchanan, R.W., Luck, S.J., 2003. Working memory for visual features and conjunctions in schizophrenia. Journal of Abnormal Psychology 112, 61-71.

Grady, C.L., McIntosh, A.R., Bookstein, F., Horwitz, B., Rapoport, S.I., Haxby, J.V., 1998 Age-related changes in regional cerebral blood flow during working memory for faces. NeuroImage 8, 409-425.

Greenwood, P.M., 2000. The frontal aging hypothesis evaluated. Journal of the International Neuropsychological Society 6, 705-726.

Greenwood, P.M., 2007. Functional plasticity in cognitive aging: review and hypothesis. Neuropsychology 21, 657-673.

Griffin, I.C., Nobre, A.C., 2003. Orienting attention to locations in internal representations. Journal of Cognitive Neuroscience 15, 1176-1194.

Grimault, S., Robitaille, N., Grova, C., Lina, J.M., Dubarry, A.S., Jolicoeur, P., 2009. Oscillatory activity in parietal and dorsolateral prefrontal cortex during retention in visual short-term memory: additive effects of spatial attention and memory load. Human Brain Mapping 30, 3378-3392.

Gruber, T., Trujillo-Barreto, N.J., Giabbiconi, C.M., Valdes-Sosa, P.A., Muller, M.M., 2006. Brain electrical tomography (BET) analysis of induced gamma band responses during a simple object recognition task. NeuroImage 29, 888-900.

Gruber, T., Tsivilis, D., Montaldi, D., Muller, M.M., 2004. Induced gamma band responses: an early marker of memory encoding and retrieval. Neuroreport 15 , 1837-1841.

Habekost, T., Starrfelt, R., 2009. Visual attention capacity: a review of TVA-based patient studies. Scandinavian Journal of Psychology 50, 23-32.

Haegens, S., Osipova, D., Oostenveld, R., Jensen, O., 2010. Somatosensory working memory performance in humans depends on both engagement and disengagement of regions in a distributed network. Human Brain Mapping 31, 26-35.

Händel, B.F., Haarmeier, T., Jensen, O., 2011. Alpha oscillations correlate with the successful inhibition of unattended stimuli. Journal of Cognitive Neuroscience 23, 2494-2502.

Haenschel, C., Bittner, R.A., Waltz, J., Haertling, F., Wibral, M., Wolf, S., Linden, D.E.J., Rodriguez, E., 2009. Cortical oscillatory activity is critical for working memory as revealed by deficits in early-onset schizophrenia. Journal of Neuroscience 29, 9481-9489.

Hanslmayr, S., Aslan, A., Staudigl, T., Klimesch, W., Herrmann, C.S., Bauml, K.H., 2007. Prestimulus oscillations predict visual perception performance between and within subjects. NeuroImage 37, 1465-1473.

Hanslmayr, S., Klimesch, W., Sauseng, P., Gruber, W., Doppelmayr, M., Freunberger, R., Pecherstorfer, T., 2005. Visual discrimination performance is related to decreased alpha amplitude but increased phase locking. Neuroscience Letters 375, 64-68.

Harrison, A., Jolicoeur, P., Marois, R., 2010. "What" and "where" in the intraparietal sulcus: an FMRI study of object identity and location in visual short-term memory. Cerebral Cortex 20, 2478-2485.

Hasher, L., Lustig, C., Zacks, R., 2007. Inhibitory mechanisms and the control of attention. In: Conway, A.R.A. (Ed.), Variation in Working Memory. Oxford University Press, New York, pp. 227-249.

Hasher, L., Zacks, R.T., 1988. Working memory, comprehension, and aging: a review and a new view. In: Bower, G.H. (Ed.), The Psychology of Learning and Motivation: Advances in Research and Theory. Academic Press, San Diego, CA, USA, pp. $193-225$

Herrmann, C.S., Frund, I., Lenz, D., 2010. Human gamma-band activity: a review on cognitive and behavioral correlates and network models. Neuroscience and Biobehavioral Reviews 34, 981-992.

Herrmann, C.S., Mecklinger, A., Pfeifer, E., 1999. Gamma responses and ERPs in a visual classification task. Clinical Neurophysiology 110, 636-642.

Hogan, M.J., Swanwick, G.R., Kaiser, J., Rowan, M., Lawlor, B., 2003. Memory-related EEG power and coherence reductions in mild Alzheimer's disease. International Journal of Psychophysiology 49, 147-163.

Hommel, B., Colzato, L., 2004. Visual attention and the temporal dynamics of feature integration. Visual Cognition 11, 483-521.

Huang, L., 2010. Visual working memory is better characterized as a distributed resource rather than discrete slots. Journal of Vision 11, 1-8.

Huttenlocher, P.R., 1979. Synaptic density in human frontal cortex - developmental changes and effects of aging. Brain Research 163, 195-205.

Huttenlocher, P.R., 1990. Morphometric study of human cerebral cortex development. Neuropsychologia 28, 517-527.

Hwang, K., Velanova, K., Luna, B., 2010. Strengthening of top-down frontal cognitive control networks underlying the development of inhibitory control: a functional magnetic resonance imaging effective connectivity study. Journal of Neuroscience 30, 15535-15545.

Ikkai, A., McCollough, A.W., Vogel, E.K., 2010. Contralateral delay activity provides a neural measure of the number of representations in visual working memory. Journal of Neurophysiology 103, 1963-1968.

Jacobs, J., Kahana, M.J., 2009. Neural representations of individual stimuli in humans revealed by gamma-band electrocorticographic activity. Journal of Neuroscience 29, 10203-10214.

Jensen, O., 2005. Reading the hippocampal code by theta phase-locking. Trends in Cognitive Sciences 9, 551-553.

Jensen, O., Colgin, L.L., 2007. Cross-frequency coupling between neuronal oscillations. Trends in Cognitive Sciences 11, 267-269.

Jensen, O., Gelfand, J., Kounios, J., Lisman, J.E., 2002. Oscillations in the alpha band $(9-12 \mathrm{~Hz})$ increase with memory load during retention in a short-term memory task. Cerebral Cortex 12, 877-882.

Jensen, O., Kaiser, J., Lachaux, J.P., 2007. Human gamma-frequency oscillations associated with attention and memory. Trends in Neurosciences 30,317-324.

Jensen, O., Lisman, J.E., 1996. Novel lists of $7 \pm 2$ known items can be reliably stored in an oscillatory short-term memory network: Interaction with long-term memory. Learning and Memory 3, 257-263.

Jensen, O., Mazaheri, A., 2010. Shaping functional architecture by oscillatory alpha activity: gating by inhibition. Frontiers in Human Neuroscience 4, 186.

Jensen, O., Tesche, C.D., 2002. Frontal theta activity in humans increases with memory load in a working memory task. European Journal of Neuroscience 15 1395-1399.

Jernigan, T.L., Archibald, S.L., Fennema-Notestine, C., Gamst, A.C., Stout, J.C., Bonner, J., Hesselink, J.R., 2001. Effects of age on tissues and regions of the cerebrum and cerebellum. Neurobiology of Aging 22, 581-594.

Jiang, Y., Chun, M.M., Olson, I.R., 2004. Perceptual grouping in change detection. Perception and Psychophysics 66, 446-453.

Jiang, Y., Olson, I.R., Chun, M.M., 2000. Organization of visual short-term memory. Journal of Experimental Psychology Learning, Memory, and Cognition 26, 683-702.

Johansen-Berg, H., 2010. Behavioural relevance of variation in white matter microstructure. Current Opinion in Neurology 23, 351-358.

Johnson, M.R., Johnson, M.K., 2009. Top-down enhancement and suppression of activity in category selective extrastriate cortex from an act of reflective attention. Journal of Cognitive Neuroscience 21, 2320-2327.

Johnson, M.R., Mitchell, K.J., Raye, C.L., D’Esposito, M., Johnson, M.K., 2007. A brief thought can modulate activity in extrastriate visual areas: top-down effects of just seen visual stimuli. Neurolmage 37, 290-299.

Johnson, M.K., Mitchell, K.J., Raye, C.L., Greene, E.J., 2004. An age-related deficit in prefrontal cortical function associated with refreshing information. Psychological Science 15, 127-132.

Jokisch, D., Jensen, O., 2007. Modulation of gamma and alpha activity during a working memory task engaging the dorsal or ventral stream. Journal of Neuroscience $27,3244-3251$

Jolles, D.D., van Buchem, M.A., Crone, E.A., Rombouts, S.A.R.B., 2011. A comprehensive study of whole-brain functional connectivity in children and young adults. Cerebral Cortex 21, 385-391.

Jolicoeur, P., Brisson, B., Robitaille, N., 2008. Dissociation of the N2pc and sustained posterior contralateral negativity in a choice response task. Brain Research 1215 160-172.

Jonides, J., Marshuetz, C., Smith, E.E., Reuter-Lorenz, P.A., Koeppe, R.A., Hartley, A. 2000. Age differences in behavior and PET activation reveal differences in interference resolution in verbal working memory. Journal of Cognitive Neuroscience $12,188-196$.

Jost, K., Bryck, R.L., Vogel, E.K., Mayr, U., 2011. Are old adults just like low working memory young adults? Filtering efficiency and age differences in visual working memory. Cerebral Cortex 21, 1147-1154.

Jovicich, J., Peters, R.J., Koch, C., Braun, J., Chang, L., Ernst, T., 2001. Brain areas specific for attentional load in a motion-tracking task. Journal of Cognitive Neuroscience $13,1048-1058$

Jutras, M.J., Buffalo, E.A., 2010. Synchronous neural activity and memory formation Current Opinion in Neurobiology 20, 150-155.

Kane, M.J., Bleckley, M.K., Conway, A.R., Engle, R.W., 2001. A controlled-attention view of working-memory capacity. Journal of Experimental Psychology: General $130,169-183$

Kelly, S.P., Lalor, E.C., Reilly, R.B., Foxe, J.J., 2006. Increases in alpha oscillatory power reflect an active retinotopic mechanism for distracter suppression during sustained visuospatial attention. Journal of Neurophysiology 95, 3844-3851.

Kinsbourne, M., Hicks, R.E., 1978. Functional cerebral space: a model for overflow, transfer and interference effects in human performance: a tutorial review. In: Requin, J. (Ed.), Attention and Performance VII. Lawrence Erlbaum Associates, Hillsdale, New Jersey, pp. 345-362.

Kiss, M., Driver, J., Eimer, M., 2009. Reward priority of visual target singletons modulates event-related potential signatures of attentional selection. Psychological Science 20, 245-251.

Klimesch, W., 1999. EEG alpha and theta oscillations reflect cognitive and memory performance: a review and analysis. Brain Research Reviews 29 169-195.

Klimesch, W., Doppelmayr, M., Russegger, H., Pachinger, T., 1996. Theta band power in the human scalp EEG and the encoding of new information. Neuroreport 7 , 1235-1240.

Klimesch, W., Sauseng, P., Hanslmayr, S., 2007. EEG alpha oscillations: the inhibitiontiming hypothesis. Brain Research Reviews 53, 63-88. 
Klingberg, T., 2006. Development of a superior frontal-intraparietal network for visuo-spatial working memory. Neuropsychologia 44, 2171-2177.

Klingberg, T., Forssberg, H., Westerberg, H., 2002. Increased brain activity in frontal and parietal cortex underlies the development of visuospatial working memory capacity during childhood. Journal of Cognitive Neuroscience 14, 1-10.

Klingberg, T., Vaidya, C.J., Gabrieli, J.D., Moseley, M.E., Hedehus, M., 1999. Myelination and organization of the frontal white matter in children: a diffusion tensor MRI study. Neuroreport 10, 2817-2821.

Kopell, N., Ermentrout, G.B., Whittington, M.A., Traub, R.D., 2000. Gamma rhythms and beta rhythms have different synchronization properties. Proceedings of National Academy of Sciences of the United States of America 97, 1867-1872.

Kuo, B.C., Yeh, Y.-Y., Chen, A.J.-W., D’Esposito, M., 2011. Functional connectivity during top-down modulation of visual short-term memory representations. Neuropsychologia 49, 1589-1596.

Kuo, B.C., Rao, A., Lepsien, J., Nobre, A.C., 2009. Searching for targets within the spatial layout of visual short-term memory. Journal of Neuroscience 29, 8032-8038.

Kwon, H., Reiss, A.L., Menon, V., 2002. Neural basis of protracted developmental changes in visuo-spatial working memory. Proceedings of National Academy of Sciences of the United States of America 99, 13336-13341.

Landau, A.N., Esterman, M., Robertson, L.C., Bentin, S., Prinzmetal, W., 2007. Different effects of voluntary and involuntary attention on EEG activity in the gamma band. Journal of Neuroscience 27, 11986-11990.

Lee, A.C., Rudebeck, S.R., 2010. Investigating the interaction between spatial perception and working memory in the human medial temporal lobe. Journal of Cognitive Neuroscience 22, 2823-2835.

Lepsien, J., Griffin, I.C., Devlin, J.T., Nobre, A.C., 2005. Directing spatial attention in mental representations: Interactions between attentional orienting and working-memory load. NeuroImage 26, 733-743.

Lepsien, J., Nobre, A.C., 2006. Cognitive control of attention in the human brain: Insights from orienting attention to mental representations. Brain Research $1105,20-31$.

Lepsien, J., Nobre, A.C., 2007. Attentional modulation of object representations in working memory. Cerebral Cortex 17, 2072-2083.

Li, S.-C., von Oertzen, T., Lindenberger, U., 2006. A neurocomputational model of stochastic resonance and aging. Neurocomputing 69, 1553-1560.

Li, S.C., Lindenberger, U., Sikstrom, S., 2001. Aging cognition: from neuromodulation to representation. Trends in Cognitive Sciences 5, 479-486.

Linden, D.E., 2007. The working memory networks of the human brain. Neuroscientist 13, 257-267.

Linden, D.E., Bittner, R.A., Muckli, L., Waltz, J.A., Kriegeskorte, N., Goebel, R., Singer, W., Munk, M.H., 2003. Cortical capacity constraints for visual working memory: dissociation of fMRI load effects in a fronto-parietal network. Neurolmage 20, 1518-1530.

Lindenberger, U., 2001. Lifespan theories of cognitive development. In: Smelser, N.J., Baltes, P.B. (Eds.), International Encyclopedia of the Social and Behavioral Sciences. Elsevier, Amsterdam, pp. 8848-8854.

Lindenberger, U., Burzynska, A.Z., Nagel, I.E. Heterogeneity in frontal-lobe aging. In: Stuss, D.T., Knight, R.T.(Eds.), Principles of Frontal Lobe Functions, 2nd ed. Oxford University Press, New York, in press.

Lindenberger, U., Li, S.C., Lövden, M., Schmiedek, F., 2007. The Center for Lifespan Psychology at the Max Planck Institute for Human Development: overview of conceptual agenda and illustration of research activities. International Journal of Psychology 42.

Linke, A.C., Vicente-Grabovetsky, A., Mitchell, D.J., Cusack, R., 2011. Encoding strategy accounts for individual differences in change detection measures of VSTM. Neuropsychologia 49, 1476-1486.

Lisman, J.E., Idiart, M.A., 1995. Storage of $7 \pm 2$ short-term memories in oscillatory subcycles. Science 267, 1512-1515.

Luciana, M., Conklin, H.M., Hooper, C.J., Yarger, R.S., 2005. The development of nonverbal working memory and executive control processes in adolescents. Child. Dev. 76, 697-712.

Luciana, M., Nelson, C.A., 1998. The functional emergence of prefrontally-guided working memory systems in four- to eight-year-old children. Neuropsychologia 36, 273-293.

Luck, S.J., Vogel, E.K., 1997. The capacity of visual working memory for features and conjunctions. Nature 390, 279-281.

Luna, B., 2009. Developmental changes in cognitive control through adolescence. Advances in Child Development and Behavior 37, 233-278.

Luna, B., Garver, K.E., Urban, T.A., Lazar, N.A., Sweeney, J.A., 2004. Maturation of cognitive processes from late childhood to adulthood. Child Development 75, 1357-1372.

Luria, R., Sessa, P., Gotler, A., Jolicoeur, P., Dell'Acqua, R., 2009. Visual short-term memory capacity for simple and complex objects. Journal of Cognitive Neuroscience 22, 496-512.

Luria, R., Vogel, E.K., 2011. Shape and color conjunction stimuli are represented as bound objects in visual working memory. Neuropsychologia 49, 1632-1639.

MacDonald, S.W., Nyberg, L., Backman, L., 2006. Intra-individual variability in behavior: links to brain structure, neurotransmission and neuronal activity. Trends in Neurosciences 29, 474-480.

Madden, D.J., Bennett, I.J., Song, A.W., 2009. Cerebral white matter integrity and cognitive aging: contributions from diffusion tensor imaging. Neuropsychology Review 19, 415-435.

Madden, D.J., Spaniol, J., Whiting, W.L., Bucur, B., Provenzale, J.M., Cabeza, R., White, L.E., Huettel, S.A., 2007. Adult age differences in the functional neuroanatomy of visual attention: a combined fMRI and DTI study. Neurobiology of Aging 28, 459-476.
Madden, D.J., Turkington, T.G., Provenzale, J.M., Denny, L.L., Langley, L.K., Hawk, T.C. Coleman, R.E., 2002. Aging and attentional guidance during visual search: functional neuroanatomy by positron emission tomography. Psychology and Aging 17, 24-43.

Madden, D.J., Turkington, T.G., Provenzale, J.M., Hawk, T.C., Hoffman, J.M., Coleman, R.E., 1997. Selective and divided visual attention: age-related changes in regional cerebral blood flow measured by H2(15)O PET. Human Brain Mapping 5, 389-409.

Majerus, S., Bastin, C., Poncelet, M., Van der Linden, M., Salmon, E., Collette, F. Maquet, P., 2007. Short-term memory and the left intraparietal sulcus: focus of attention? Further evidence from a face short-term memory paradigm. Neurolmage $35,353-367$.

Majerus, S., D’Argembeau, A., Martinez Perez, T., Belayachi, S., Van der Linden, M. Collette, F., Salmon, E., Seurinck, R., Fias, W., Maquet, P., 2010. The commonality of neural networks for verbal and visual short-term memory. Journal of Cognitive Neuroscience 22, 2570-2593.

Marois, R., Ivanoff, J., 2005. Capacity limits of information processing in the brain. Trends in Cognitive Sciences 9, 296-305.

Mattay, V.S., Fera, F., Tessitore, A., Hariri, A.R., Berman, K.F., Das, S., Meyer Lindenberg, A., Goldberg, T.E., Callicott, J.H., Weinberger, D.R., 2006. Neurophysiological correlates of age-related changes in working memory capacity. Neuroscience Letters 392, 32-37.

Mazaheri, A., Jensen, O., 2008. Asymmetric amplitude modulations of brain oscillations generate slow evoked responses. Journal of Neuroscience 28, 7781-7787.

McCollough, A.W., Machizawa, M.G., Vogel, E.K., 2007. Electrophysiological measures of maintaining representations in visual working memory. Cortex 43 77-94.

McEvoy, L.K., Pellouchoud, E., Smith, M.E., Gevins, A., 2001. Neurophysiological sig nals of working memory in normal aging. Brain Research Cognitive Brain Reserch $11,363-376$.

McIntosh, A.R., Kovacevic, N., Lippe, S., Garrett, D., Grady, C., Jirsa, V., 2010. The development of a noisy brain. Archives Italiennes de Biologie 148, 323-337.

McNab, F., Klingberg, T., 2008. Prefrontal cortex and basal ganglia control access to working memory. Nature Neuroscience $11,103-107$.

Melloni, L., Schwiedrzik, C.M., Rodriguez, E., Singer, W., 2009. (Micro)Saccades, corollary activity and cortical oscillations. Trends in Cognitive Sciences 13, 239-245.

Michels, L., Moazami-Goudarzi, M., Jeanmonod, D., Sarnthein, J., 2008. EEG alpha distinguishes between cuneal and precuneal activation in working memory. NeuroImage 40, 1296-1310.

Miller, E.K., Cohen, J.D., 2001. An integrative theory of prefrontal cortex function. Annual Review of Neuroscience 24, 167-202.

Minamoto, T., Osaka, M., Engle, R.W., Osaka, N., 2012. Incidental encoding of goal irrelevant information is associated with insufficient engagement of the dorsal frontal cortex and the inferior parietal cortex. Brain Research 1429, 82-97.

Mitchell, D.J., Cusack, R., 2008. Flexible, capacity-limited activity of posterior parietal cortex in perceptual as well as visual short-term memory tasks. Cerebral Cortex 18, 1788-1798.

Mitchell, D.J., Cusack, R., 2011. The temporal evolution of electromagnetic markers sensitive to the capacity limits of visual short-term memory. Frontiers in Human Neuroscience 5,18

Mitchell, K.J., Johnson, M.R., Higgins, J.A., Johnson, M.K., 2010. Age differences in brain activity during perceptual versus reflective attention. Neuroreport 21, 293-297.

Molenaar, P., 1986. On the impossibility of acquiring more powerful structures: a neglected alternative. Human Development 29, 245-251.

Morcom, A.M., Friston, K.J., 2012. Decoding episodic memory in ageing: a Bayesian analysis of activity patterns predicting memory. NeuroImage 59, 1772-1782.

Müller, V., Gruber, W., Klimesch, W., Lindenberger, U., 2009. Lifespan differences in cortical dynamics of auditory perception. Developmental Science 12, 839-853.

Murre, J.M.J., Wolters, G., Raffone, A., 2006. Binding in working memory and longterm memory: towards an integrated model. In: Zimmer, H.D., Mecklinger, A. Lindenberger, U. (Eds.), Handbook of Binding and Memory: Perspectives from Cognitive Neuroscience. University Press, Oxford, pp. 221-250.

Nagel, I.E., Preuschhof, C., Li, S.C., Nyberg, L., Backman, L., Lindenberger, U., Heekeren, H.R., 2009. Performance level modulates adult age differences in brain activation during spatial working memory. Proceedings of National Academy of Sciences of the United States of America 106, 22552-22557.

Nagel, I.E., Preuschhof, C., Li, S.C., Nyberg, L., Backman, L., Lindenberger, U., Heekeren, H.R., 2011. Load modulation of BOLD response and connectivity predicts working memory performance in younger and older adults. Journal of Cognitive Neuroscience 23, 2030-2045.

Nagy, Z., Westerberg, H., Klingberg, T., 2004. Maturation of white matter is associated with the development of cognitive functions during childhood. Journal of Cognitive Neuroscience 16, 1227-1233.

Nelson, C.A., Luciana, M., 2008. Handbook of Developmental Cognitive Neuroscience. MIT Press, Cambridge.

Nelson, C.A., Monk, C.S., Lin, J., Carver, L.J., Thomas, K.M., Truwit, C.L., 2000. Functional neuroanatomy of spatial working memory in children. Developmental Psychology 36, 109-116.

Niedermeyer, E., 1997. Alpha rhythms as physiological and abnormal phenomena. International Journal of Psychophysiology 26, 31-49.

Nobre, A.C., 2001. The attentive homunculus: now you see it, now you don't. Neuroscience and Biobehavioral Reviews 25, 477-496.

Nobre, A.C., Griffin, I.C., Rao, A., 2007. Spatial attention can bias search in visua short-term memory. Frontiers in Human Neuroscience 1, 4.

Nyberg, L., Lövden, M., Riklund, K., Lindenberger, U., Bäckman, L., 2012. Memory aging and brain maintenance. Trends in Cognitive Sciences 16, 292-305. 
Ostby, Y., Tamnes, C.K., Fjell, A.M., Walhovd, K.B., 2011. Morphometry and connectivity of the fronto-parietal verbal working memory network in development. Neuropsychologia 49, 3854-3862.

O’Sullivan, M., Jones, D.K., Summers, P.E., Morris, R.G., Williams, S.C., Markus, H.S., 2001. Evidence for cortical disconnection as a mechanism of age-related cognitive decline. Neurology 57, 632-638.

Olesen, P.J., Macoveanu, J., Tegner, J., Klingberg, T., 2007. Brain activity related to working memory and distraction in children and adults. Cerebral Cortex 17, 1047-1054.

Olesen, P.J., Nagy, Z., Westerberg, H., Klingberg, T., 2003. Combined analysis of DTI and fMRI data reveals a joint maturation of white and grey matter in a frontoparietal network. Brain Research Cognitive Brain Reserch 18, 48-57.

Olson, I.R., Jiang, Y., 2002. Is visual short-term memory object based? Rejection of the strong-object hypothesis. Perception and Psychophysics 64, 1055-1067.

Olson, I.R., Moore, K.S., Stark, M., Chatterjee, A., 2006a. Visual working memory is impaired when the medial temporal lobe is damaged. Journal of Cognitive Neuroscience 18, 1087-1097.

Olson, I.R., Page, K., Moore, K.S., Chatterjee, A., Verfaellie, M., 2006b. Working memory for conjunctions relies on the medial temporal lobe. Journal of Neuroscience $26,4596-4601$.

Palva, J.M., Monto, S., Kulashekhar, S., Palva, S., 2010. Neuronal synchrony reveals working memory networks and predicts individual memory capacity. Proceedings of National Academy of Sciences of the United States of America 107, 7580-7585.

Palva, J.M., Palva, S., Kaila, K., 2005. Phase synchrony among neuronal oscillations in the human cortex. Journal of Neuroscience 25, 3962-3972.

Palva, S., Palva, J.M., 2007. New vistas for alpha-frequency band oscillations. Trends in Neurosciences 30, 150-158.

Park, D.C., Payer, D., 2006. Working memory across the adult lifespan. In: Bialystok, E., Craik, F.I.M. (Eds.), Lifespan Cognition: Mechanisms of Change. Oxford University Press, New York, US, pp. 128-142.

Park, D.C., Polk, T.A., Park, R., Minear, M., Savage, A., Smith, M.R., 2004. Aging reduces neural specialization in ventral visual cortex. Proceedings of National Academy of Sciences of the United States of America 101, 13091-13095.

Park, D.C., Reuter-Lorenz, P., 2009. The adaptive brain: aging and neurocognitive scaffolding. Annual Review of Psychology 60, 173-196.

Park, J., Carp, J., Hebrank, A., Park, D.C., Polk, T.A., 2010. Neural specificity predicts fluid processing ability in older adults. Journal of Neuroscience 30, 9253-9259.

Parra, M.A., Abrahams, S., Logie, R.H., Sala, S.D., 2009. Age and binding withindimension features in visual short-term memory. Neuroscience Letters 449, $1-5$.

Pashler, H., 1988. Familiarity and visual change detection. Perception and Psychophysics $44,369-378$.

Payer, D., Marshuetz, C., Sutton, B., Hebrank, A., Welsh, R.C., Park, D.C., 2006. Decreased neural specialization in old adults on a working memory task. Neuroreport $17,487-491$.

Payne, L., Kounios, J., 2009. Coherent oscillatory networks supporting short-term memory retention. Brain Research 1247, 126-132.

Peiffer, A.M., Hugenschmidt, C.E., Maldjian, J.A., Casanova, R., Srikanth, R., Hayasaka, S., Burdette, J.H., Kraft, R.A., Laurienti, P.J., 2009. Aging and the interaction of sensory cortical function and structure. Human Brain Mapping 30, 228-240.

Piekema, C., Rijpkema, M., Fernandez, G., Kessels, R.P., 2010. Dissociating the neural correlates of intra-item and inter-item working-memory binding. PLoS One 5, e10214.

Polich, J., 1997a. EEG and ERP assessment of normal aging. Electroencephalography and Clinical Neurophysiology 104, 244-256.

Polich, J., 1997b. On the relationship between EEG and P300: individual differences, aging, and ultradian rhythms. International Journal of Psychophysiology 26, 299-317.

Postle, B.R., 2006. Working memory as an emergent property of the mind and brain. Neuroscience 139, 23-38.

Prinz, P.N., Dustman, R.E., Emmerson, R., 1990. Electrophysiology and aging. In: Birren, J.E., Schaie, K.W. (Eds.), Handbook of the Psychology of Aging. Academic Press, San Diego, pp. 135-149.

Raghavachari, S., Kahana, M.J., Rizzuto, D.S., Caplan, J.B., Kirschen, M.P., Bourgeois, B., Madsen, J.R., Lisman, J.E., 2001. Gating of human theta oscillations by a working memory task. Journal of Neuroscience 21,3175-3183.

Ranganath, C., 2006. Working memory for visual objects: complementary roles of inferior temporal, medial temporal, and prefrontal cortex. Neuroscience 139, 277-289.

Ranganath, C., Cohen, M.X., Brozinsky, C.J., 2005. Working memory maintenance contributes to long-term memory formation: neural and behavioral evidence. Journal of Cognitive Neuroscience 17, 994-1010.

Ranganath, C., D’Esposito, M., 2001. Medial temporal lobe activity associated with active maintenance of novel information. Neuron 31, 865-873.

Raye, C.L., Johnson, M.K., Mitchell, K.J., Greene, E.J., Johnson, M.R., 2007. Refreshing: a minimal executive function. Cortex 43, 135-145.

Raye, C.L., Johnson, M.K., Mitchell, K.J., Reeder, J.A., Greene, E.J., 2002. Neuorimaging a single thought: dorsolateral PFC activity associated with refreshing justactivated information. NeuroImage 15, 447-453.

Raz, N., Lindenberger, U., Rodrigue, K.M., Kennedy, K.M., Head, D., Williamson, A., Dahle, C., Gerstorf, D., Acker, J.D., 2005. Regional brain changes in aging healthy adults: general trends, individual differences and modifiers. Cerebral Cortex 15, 1676-1689.

Raz, N., Rodrigue, K.M., 2006. Differential aging of the brain: patterns, cognitive correlates and modifiers. Neuroscience and Biobehavioral Reviews 30, 730-748.
Repovs, G., Baddeley, A., 2006. The multi-component model of WM: explorations in experimental cognitive psychology. Neuroscience 139, 5-21.

Resnick, S.M., Goldszal, A.F., Davatzikos, C., Golski, S., Kraut, M.A., Metter, E.J., Bryan, R.N., Zonderman, A.B., 2000. One-year age changes in MRI brain volumes in older adults. Cerebral Cortex 10, 464-472.

Reuter-Lorenz, P.A., Cappell, K.A., 2008. Neurocognitive aging and the compensation hypothesis. Current Directions in Psychological Science 17, 177-182.

Reuter-Lorenz, P.A., Jonides, J., Smith, E.E., Hartley, A., Miller, A., Marshuetz, C., Koeppe, R.A., 2000. Age differences in the frontal lateralization of verbal and spatial working memory revealed by PET. Journal of Cognitive Neuroscience 12, 174-187.

Reuter-Lorenz, P.A., Park, D.C., 2010. Human neuroscience and the aging mind: a new look at old problems. Journal of Gerontology B: Psychological Scinces and Social Sciences 65, 405-415.

Riggs, K.J., McTaggart, J., Simpson, A., Freeman, R.P., 2006. Changes in the capacity of visual working memory in 5- to 10-year-olds. Journal of Experimental Child Psychology 95, 18-26.

Rihs, T.A., Michel, C.M., Thut, G., 2007. Mechanisms of selective inhibition in visual spatial attention are indexed by alpha-band EEG synchronization. European Journal of Neuroscience 25, 603-610.

Rihs, T.A., Michel, C.M., Thut, G., 2009. A bias for posterior alpha-band power suppression versus enhancement during shifting versus maintenance of spatial attention. NeuroImage 44, 190-199.

Rissman, J., Gazzaley, A., D’Esposito, M., 2008. Dynamic adjustments in prefrontal, hippocampal, and inferior temporal interactions with increasing visual working memory load. Cerebral Cortex 18, 1618-1629.

Rissman, J., Gazzaley, A., D’Esposito, M., 2009. The effect of non-visual working memory load on top-down modulation of visual processing. Neuropsychologia 47, 1637-1646.

Robitaille, N., Grimault, S., Jolicoeur, P., 2009. Bilateral parietal and contralateral responses during maintenance of unilaterally encoded objects in visual shortterm memory: evidence from magnetoencephalography. Psychophysiology 46, 1090-1099.

Robitaille, N., Marois, R., Todd, J., Grimault, S., Cheyne, D., Jolicoeur, P., 2010. Distinguishing between lateralized and nonlateralized brain activity associated with visual short-term memory: FMRI, MEG, and EEG evidence from the same observers. NeuroImage 53, 1334-1345.

Rodrigue, K.M., Kennedy, K.M., 2011. The cognitive consequences of structural changes to the aging brain. In: Schaie, K.W., Willis, S.L. (Eds.), Handbook of the Psychology of Aging. , seventh ed. Academic Press Elsevier, pp. 73-91.

Romanski, L.M., 2004. Domain specificity in the primate prefrontal cortex. Cognitive, Affective and Behavioral Neuroscience 4, 421-429.

Romei, V., Brodbeck, V., Michel, C., Amedi, A., Pascual-Leone, A., Thut, G., 2008. Spontaneous fluctuations in posterior alpha-band EEG activity reflect variability in excitability of human visual areas. Cerebral Cortex 18, 2010-2018.

Romei, V., Gross, J., Thut, G., 2010. On the role of prestimulus alpha rhythms over occipito-parietal areas in visual input regulation: correlation or causation? Journal of Neuroscience 30, 8692-8697.

Rouder, J.N., Morey, R.D., Cowan, N., Zwilling, C.E., Morey, C.C., Pratte, M.S., 2008. An assessment of fixed-capacity models of visual working memory. Proceedings of National Academy of Sciences of the United States of America 105, 5975-5979.

Ruff, C.C., Kristjansson, A., Driver, J., 2007. Readout from iconic memory and selective spatial attention involve similar neural processes. Psychological Science 18, 901-909.

Rutman, A.M., Clapp, W.C., Chadick, J.Z., Gazzaley, A., 2010. Early top-down control of visual processing predicts working memory performance. Journal of Cognitive Neuroscience 22, 1224-1234.

Rypma, B., D'Esposito, M., 2000. Isolating the neural mechanisms of age-related changes in human working memory. Nature Neuroscience 3, 509-515.

Salat, D.H., Buckner, R.L., Snyder, A.Z., Greve, D.N., Desikan, R.S., Busa, E., Morris, J.C., Dale, A.M., Fischl, B., 2004. Thinning of the cerebral cortex in aging. Cerebral Cortex 14, 721-730.

Salthouse, T.A., 1996. The processing-speed theory of adult age differences in cognition. Psychological Review 103, 403-428.

Sander, M.C., Werkle-Bergner, M., Lindenberger, U., 2012. Amplitude modulations and inter-trial phase stability of alpha-oscillations differentially reflect working memory constraints across the lifespan. Neurolmage 59, 646-654.

Sander, M.C., Werkle-Bergner, M., Lindenberger, U., 2011a. Binding and strategic selection in working memory: a lifespan dissociation. Psychology and Aging 26 , 612-624.

Sander, M.C., Werkle-Bergner, M., Lindenberger, U., 2011b. Contralateral delay activity reveals life-span age differences in top-down modulation of working memory contents. Cerebral Cortex 21, 2809-2819.

Sarnthein, J., Petsche, H., Rappelsberger, P., Shaw, G.L., von Stein, A., 1998. Synchronization between prefrontal and posterior association cortex during human working memory. Proceedings of National Academy of Sciences of the United States of America 95, 7092-7096.

Sauseng, P., Griesmayr, B., Freunberger, R., Klimesch, W., 2010. Control mechanisms in working memory: a possible function of EEG theta oscillations. Neuroscience and Biobehavioral Reviews 34, 1015-1022.

Sauseng, P., Hoppe, J., Klimesch, W., Gerloff, C., Hummel, F.C., 2007. Dissociation of sustained attention from central executive functions: local activity and interregional connectivity in the theta range. European Journal of Neuroscience 25 587-593. 
Sauseng, P., Klimesch, W., 2008. What does phase information of oscillatory brain activity tell us about cognitive processes? Neuroscience and Biobehavioral Reviews 32, 1001-1013.

Sauseng, P., Klimesch, W., Doppelmayr, M., Hanslmayr, S., Schabus, M., Gruber, W.R., 2004. Theta coupling in the human electroencephalogram during a working memory task. Neuroscience Letters 354, 123-126.

Sauseng, P., Klimesch, W., Gruber, W.R., Birbaumer, N., 2008. Cross-frequency phase synchronization: a brain mechanism of memory matching and attention. Neurolmage $40,308-317$.

Sauseng, P., Klimesch, W., Heise, K.F., Gruber, W.R., Holz, E., Karim, A.A., Glennon, M., Gerloff, C., Birbaumer, N., Hummel, F.C., 2009. Brain oscillatory substrates of visual short-term memory capacity. Current Biology 19, 1846-1852.

Sauseng, P., Klimesch, W., Schabus, M., Doppelmayr, M., 2005a. Fronto-parietal EEG coherence in theta and upper alpha reflect central executive functions of working memory. International Journal of Psychophysiology 57, 97-103.

Sauseng, P., Klimesch, W., Stadler, W., Schabus, M., Doppelmayr, M., Hanslmayr, S., Gruber, W.R., Birbaumer, N., 2005b. A shift of visual spatial attention is selectively associated with human EEG alpha activity. European Journal of Neuroscience 22, 2917-2926.

Schack, B., Vath, N., Petsche, H., Geissler, H.G., Moller, E., 2002. Phase-coupling of theta-gamma EEG rhythms during short-term memory processing. International Journal of Psychophysiology 44, 143-163.

Scherf, K.S., Sweeney, J.A., Luna, B., 2006. Brain basis of developmental change in visuospatial working memory. Journal of Cognitive Neuroscience 18, 1045-1058.

Schmithorst, V.J., Wilke, M., Dardzinski, B.J., Holland, S.K., 2002. Correlation of white matter diffusivity and anisotropy with age during childhood and adolescence: a cross-sectional diffusion-tensor MR imaging study. Radiology 222, 212-218.

Schneider-Garces, N.J., Gordon, B.A., Brumback-Peltz, C.R., Shin, E., Lee, Y., Sutton, B.P., Maclin, E.L., Gratton, G., Fabiani, M., 2010. Span, CRUNCH, and beyond: working memory capacity and the aging brain. Journal of Cognitive Neuroscience 22, 655-669.

Schneider, W., Knopf, M., Sodian, B., 2009. Verbal memory development from early childhood to early adulthood. In: Schneider, W., Bullock, M. (Eds.), Human Development from Early Childhood to Early Adulthood: Findings from a 20-Year Longitudinal Study. Psychology Press, New York, pp. 63-90.

Schneider, W., Schumann-Hengsteler, R., Sodian, B., 2005. Young Children's Cognitive Development: Interrelationships among Executive Functioning, Working Memory, Verbal Ability, and Theory of Mind. Lawrence Erlbaum Associates Publishers, Mahwah, NJ.

Schweinsburg, A.D., Nagel, B.J., Tapert, S.F., 2005. fMRI reveals alteration of spatial working memory networks across adolescence. Journal of the International Neuropsychological Society 11, 631-644.

Sederberg, P.B., Kahana, M.J., Howard, M.W., Donner, E.J., Madsen, J.R., 2003. Theta and gamma oscillations during encoding predict subsequent recall. Journal of Neuroscience 23, 10809-10814.

Serences, J.T., Ester, E.F., Vogel, E.K., Awh, E., 2009. Stimulus-specific delay activity in human primary visual cortex. Psychological Science 20, 207-214.

Sheremata, S.L., Bettencourt, K.C., Somers, D.C., 2010. Hemispheric asymmetry in visuotopic posterior parietal cortex emerges with visual short-term memory load. Journal of Neuroscience 30, 12581-12588.

Shibuya, H., Bundesen, C., 1988. Visual selection from multielement displays: measuring and modeling effects of exposure duration. Journal of Experimental Psychology: Human Perception and Performance 14, 591-600.

Shing, Y.L., Lindenberger, U., 2011. The development of episodic memory: lifespan lessons. Child Development Perspectives 5, 148-155.

Shing, Y.L., Werkle-Bergner, M., Brehmer, Y., Müller, V., Li, S.C., Lindenberger, U., 2010. Episodic memory across the lifespan: the contributions of associative and strategic components. Neuroscience and Biobehavioral Reviews 34, 1080-1091.

Shing, Y.L., Werkle-Bergner, M., Li, S.C., Lindenberger, U., 2008. Associative and strategic components of episodic memory: a life-span dissociation. Journal of Experimental Psychology: General 137, 495-513.

Singer, W., Gray, C.M., 1995. Visual feature integration and the temporal correlation hypothesis. Annual Review of Neuroscience 18, 555-586.

Snook, L., Paulson, L.A., Roy, D., Phillips, L., Beaulieu, C., 2005. Diffusion tensor imaging of neurodevelopment in children and young adults. Neurolmage 26, 1164-1173.

Solbakk, A.K., Fuhrmann Alpert, G., Furst, A.J., Hale, L.A., Oga, T., Chetty, S., Pickard, N., Knight, R.T., 2008. Altered prefrontal function with aging: Insights into ageassociated performance decline. Brain Research 1232, 30-47.

Sowell, E.R., Peterson, B.S., Thompson, P.M., Welcome, S.E., Henkenius, A.L., Toga, A.W., 2003. Mapping cortical change across the human life span. Nature Neuroscience 6, 309-315.

Sowell, E.R., Thompson, P.M., Holmes, C.J., Jernigan, T.L., Toga, A.W., 1999. In vivo evidence for post-adolescent brain maturation in frontal and striatal regions. Nature Neuroscience 2, 859-861.

Sowell, E.R., Thompson, P.M., Toga, A.W., 2004. Mapping changes in the human cortex throughout the span of life. Neuroscientist 10, 372-392.

Sperling, G., 1960. The information available in brief visual presentations. Psychological Monographs: General and Applied 74, 1-30.

Stoermer, V.S., Li, S.C., Heekeren, H.R., Lindenberger, U. Normative shifts of cortical mechanisms of encoding contribute to adult age differences in visual-spatial working memory, submitted for publication.

Stoermer, V.S., Passow, S., Biesenack, J., Li, S.C., 2011. Dopaminergic and cholinergic modulations of visual-spatial attention and working memory: insights from molecular genetic research and implications for adult cognitive development. Developmental Psychology.

Stuss, D.T., Craik, F.I., Sayer, L., Franchi, D., Alexander, M.P., 1996. Comparison of older people and patients with frontal lesions: evidence from world list learning. Psychology and Aging 11, 387-395.

Tallon-Baudry, C., Bertrand, O., 1999. Oscillatory gamma activity in humans and its role in object representation. Trends in Cognitive Sciences 3, 151-162.

Tallon-Baudry, C., Bertrand, O., Delpuech, C., Permier, J., 1997. Oscillatory gammaband $(30-70 \mathrm{~Hz})$ activity induced by a visual search task in humans. Journal of Neuroscience 17, 722-734.

Tallon-Baudry, C., Bertrand, O., Peronnet, F., Pernier, J., 1998. Induced gamma-band activity during the delay of a visual short-term memory task in humans. Journal of Neuroscience 18, 4244-4254.

Tallon-Baudry, C., Kreiter, A., Bertrand, O., 1999. Sustained and transient oscillatory responses in the gamma and beta bands in a visual short-term memory task in humans. Visual Neuroscience 16, 449-459.

Thomas, K.M., King, S.W., Franzen, P.L., Welsh, T.F., Berkowitz, A.L., Noll, D.C., Birmaher, V., Casey, B.J., 1999. A developmental functional MRI study of spatia working memory. Neurolmage 10, 327-338.

Thomason, M.E., Race, E., Burrows, B., Whitfield-Gabrieli, S., Glover, G.H., Gabrieli, J.D., 2009. Development of spatial and verbal working memory capacity in the human brain. Journal of Cognitive Neuroscience 21, 316-332.

Thut, G., Nietzel, A., Brandt, S.A., Pascual-Leone, A., 2006. Alpha-band electroencephalographic activity over occipital cortex indexes visuospatial attention bias and predicts visual target detection. Journal of Neuroscience 26 9494-9502.

Todd, J.J., Han, S.W., Harrison, S., Marois, R., 2011. The neural correlates of visua working memory encoding: a time-resolved fMRI study. Neuropsychologia 49, 1527-1536.

Todd, J.J., Marois, R., 2004. Capacity limit of visual short-term memory in human posterior parietal cortex. Nature 428, 751-754.

Todd, J.J., Marois, R., 2005. Posterior parietal cortex activity predicts individual differences in visual short-term memory capacity. Cognitive, Affective and Behaviora Neuroscience 5, 144-155.

Treisman, A., 1996. The binding problem. Current Opinion in Neurobiology 6 $171-178$.

Treisman, A., Zhang, W., 2006. Location and binding in visual working memory. Memory and Cognition 34, 1704-1719.

Treisman, A.M., Gelade, G., 1980. A feature-integration theory of attention. Cognitive Psychology 12, 97-136.

Tsujimoto, S., Yamamoto, T., Kawaguchi, H., Koizumi, H., Sawaguchi, T., 2004 Prefrontal cortical activation associated with working memory in adults and preschool children: an event-related optical topography study. Cerebral Cortex $14,703-712$.

Tuladhar, A.M., ter Huurne, N., Schoffelen, J.M., Maris, E., Oostenveld, R., Jensen, O. 2007. Parieto-occipital sources account for the increase in alpha activity with working memory load. Human Brain Mapping 28, 785-792.

Uhlhaas, P.J., Pipa, G., Lima, B., Melloni, L., Neuenschwander, S., Nikolic, D., Singer, W., 2009a. Neural synchrony in cortical networks: history, concept and current status. Frontier in Integrative Neuroscience 3, 17.

Uhlhaas, P.J., Roux, F., Rodriguez, E., Rotarska-Jagiela, A., Singer, W., 2010. Neural synchrony and the development of cortical networks. Trends in Cognitive Sciences $14,72-80$.

Uhlhaas, P.J., Roux, F., Singer, W., Haenschel, C., Sireteanu, R., Rodriguez, E., 2009b. The development of neural synchrony reflects late maturation and restructuring of functional networks in humans. Proceedings of National Academy of Sciences of the United States of America 106, 9866-9871.

Vestergaard, M., Madsen, K.S., Baaré, W.F.C., Skimminge, A., Ejersbo, L.R., Ramsoy, T.Z., Gerlach, C., Akeson, P., Paulson, O.B., Jernigan, T.L., 2011. White matter microstructure in superior longitudinal fasciculus associated with spatial working memory performance in children. Journal of Cognitive Neuroscience 9 2135-2146.

van Dijk, H., van der Werf, J., Mazaheri, A., Medendorp, W.P., Jensen, O., 2010. Modulations in oscillatory activity with amplitude asymmetry can produce cognitively relevant event-related responses. Proceedings of National Academy of Sciences of the United States of America 107, 900-905.

van Gerven, M., Jensen, O., 2009. Attention modulations of posterior alpha as a control signal for two-dimensional brain-computer interfaces. Journal of Neuroscience Methods 179, 78-84.

Varela, F., Lachaux, J.P., Rodriguez, E., Martinerie, J., 2001. The brainweb: phase synchronization and large-scale integration. Nature Reviews Neuroscience 2, 229-239.

Vogel, E.K., Machizawa, M.G., 2004. Neural activity predicts individual differences in visual working memory capacity. Nature 428, 748-751.

Vogel, E.K., McCollough, A.W., Machizawa, M.G., 2005. Neural measures reveal individual differences in controlling access to working memory. Nature 438 , 500-503.

Vogel, E.K., Woodman, G.F., Luck, S.J., 2001. Storage of features, conjunctions and objects in visual working memory. Journal of Experimental Psychology: Human Perception and Performance 27, 92-114.

Von der Malsburg, C., 1981. The correlation theory of brain function. Internal Report 81-2. Max Planck Institute for Biophysical Chemistry, Göttingen.

von Stein, A., Sarnthein, J., 2000. Different frequencies for different scales of cortical integration: from local gamma to long range alpha/theta synchronization. International Journal of Psychophysiology 38, 301-313. 
Voytek, B., Knight, R.T., 2010. Prefrontal cortex and basal ganglia contributions to visual working memory. Proceedings of National Academy of Sciences of the United States of America 107, 18167-18172.

Watanabe, M., 2002. Integration across multiple cognitive and motivational domains in monkey prefrontal cortex. In: Stuss, D.T., Knight, R.T. (Eds.), Principles of frontal lobe functioning. Oxford University Press, New York, pp. 326-337.

Weisz, N., Hartman, T., Müller, N., Lorenz, I., Obleser, J., 2011. Alpha rhythms in audition: cognitive and clinical perspectives. Frontiers in Psychology 2, 73.

Welford, A.T., 1981. Signal, noise, performance and age. Human Factors 23, 97-109.

Wen, W., Sachdev, P., 2004. The topography of white matter hyperintensities on brain MRI in healthy 60- to 64-year-old individuals. NeuroImage 22, 144-154.

Werkle-Bergner, M., Freunberger, R., Sander, M.C., Lindenberger, U., Klimesch, W., 2012. Inter-individual performance differences in younger and older adults differentially relate to amplitude modulations and phase stability of oscillations controlling working memory contents. NeuroImage 60, 71-82.

Werkle-Bergner, M., Müller, V., Li, S.C., Lindenberger, U., 2006. Cortical EEG correlates of successful memory encoding: implications for lifespan comparisons. Neuroscience and Biobehavioral Reviews 30, 839-854.

Werkle-Bergner, M., Shing, Y.L., Müller, V., Li, S.C., Lindenberger, U., 2009. EEG gamma-band synchronization in visual coding from childhood to old age: evidence from evoked power and inter-trial phase locking. Clinical Neurophysiology 120, 1291-1302.

West, R., 1999. Visual distraction, working memory, and aging. Memory and Cognition 27, 1064-1072.

West, R.L., 1996. An application of prefrontal cortex function theory to cognitive aging. Psychological Bulletin 120, 272-292.

Wheeler, M.E., Treisman, A.M., 2002. Binding in short-term visual memory. Journal of Experimental Psychology: General 131, 48-64.

Wilken, P., Ma, W.J., 2004. A detection theory account of change detection. Journal of Vision 4, 1120-1135.

Woodman, G.F., Vogel, E.K., 2008. Selective storage and maintenance of an object's features in visual working memory. Psychonomic Bulletin and Review 15, 223-229.

Worden, M.S., Foxe, J.J., Wang, N., Simpson, G.V., 2000. Anticipatory biasing of visuospatial attention indexed by retinotopically specific alpha-band electroencephalography increases over occipital cortex. Journal of Neuroscience 20, RC63.

$\mathrm{Xu}, \mathrm{Y}$., 2007. The role of the superior intraparietal sulcus in supporting visual short-term memory for multifeature objects. Journal of Neuroscience 27, 11676-11686

$\mathrm{Xu}, \mathrm{Y} ., 2009$. Distinctive neural mechanisms supporting visual object individuation and identification. Journal of Cognitive Neuroscience 21, 511-518.
Xu, Y., Chun, M.M., 2006. Dissociable neural mechanisms supporting visual shortterm memory for objects. Nature 440, 91-95.

$\mathrm{Xu}$, Y., Chun, M.M., 2009. Selecting and perceiving multiple visual objects. Trends in Cognitive Sciences 13, 167-174.

Yakolev, P.I., Lecours, A.R., 1967. The myelogenetic cycles of regional maturation of the brain. In: Minkowski, A. (Ed.), Regional Development of the Brain in Early Life. Blackwell Scientific, Oxford, pp. 3-70.

Yordanova, J., Kolev, V., 1997. Alpha response system in children: changes with age. International Journal of Psychophysiology 26, 411-430.

Yuval-Greenberg, S., Tomer, O., Keren, A.S., Nelken, I., Deouell, L.Y., 2008. Transient induced gamma-band response in EEG as a manifestation of miniature saccades. Neuron 58, 429-441.

Zanto, T.P., Gazzaley, A., 2009. Neural suppression of irrelevant information underlies optimal working memory performance. Journal of Neuroscience 29, 3059-3066.

Zanto, T.P., Hennigan, K., Ostberg, M., Clapp, W.C., Gazzaley, A., 2010a. Predictive knowledge of stimulus relevance does not influence top-down suppression of irrelevant information in older adults. Cortex 46, 564-574.

Zanto, T.P., Rubens, M.T., Bollinger, J., Gazzaley, A., 2010b. Top-down modulation of visual feature processing: the role of the inferior frontal junction. Neurolmage 53, 736-745.

Zanto, T.P., Toy, B., Gazzaley, A., 2010c. Delays in neural processing during working memory encoding in normal aging. Neuropsychologia 48, 13-25.

Zanto, T.P., Rubens, M.T., Thangavel, A., Gazzaley, A., 2011. Causal role of the prefrontal cortex in top-down modulation of visual processing and working memory. Nature Neuroscience 14, 656-661.

Zhang, W., Luck, S.J., 2008. Discrete fixed-resolution representations in visual working memory. Nature 453, 233-235.

Zimmer, H.D., 2008. Visual and spatial working memory: from boxes to networks. Neuroscience and Biobehavioral Reviews 32, 1373-1395.

Zimmer, H.D., Mecklinger, A., Lindenberger, U., 2006a. Binding in Human Memory: a Neurocognitive Perspective. Oxford University Press, Oxford, United Kingdom.

Zimmer, H.D., Mecklinger, A., Lindenberger, U., 2006b. Levels of binding: types, mechanisms, and functions of binding in remembering. In: Zimmer, H.D., Mecklinger, A., Lindenberger, U. (Eds.), Handbook of Binding and Memory. University Press, Oxford.

Zimmerman, M.E., Brickman, A.M., Paul, R.H., Grieve, S.M., Tate, D.F., Gunstad, J., Cohen, R.A., Aloia, M.S., Williams, L.M., Clark, C.R., Whitford, T.J., Gordon, E., 2006. The relationship between frontal gray matter volume and cognition varies across the healthy adult lifespan. American Journal of Geriatric Psychiatry 14, 823-833. 